UNIVERSIDADE DE SÃO PAULO
HOSPITAL DE REABILITAÇÃO DE ANOMALIAS CRANIOFACIAS

TIAGO TURRI DE CASTRO RIBEIRO

Comparação das alterações craniofaciais após a cirurgia ortognática bimaxilar em indivíduos classe III com fissura de lábio e palato unilateral e com fissura isolada de palato

BAURU

2020 



\section{Comparação das alterações craniofaciais após a cirurgia ortognática bimaxilar em indivíduos classe III com fissura de lábio e palato unilateral e com fissura isolada de palato}

Tese apresentada ao Hospital de Reabilitação de Anomalias Craniofaciais da Universidade de São para obtenção do título de Doutor em Ciências da Reabilitação, na área de concentração Fissuras Orofaciais e Anomalias Relacionadas.

Orientador: Prof. Dr. Renato Yassutaka Faria Yaedú Versão Corrigida

BAURU 
TURRI DE CASTRO RIBEIRO, Tiago

Comparação das alterações craniofaciais após a cirurgia ortognática bimaxilar em indivíduos classe III com fissura de lábio e palato unilateral e com fissura isolada de palato / Tiago Turri de Castro Ribeiro -- Bauru, 2020.

140 p. : 37il. ; $31 \mathrm{~cm}$.

Tese (doutorado) -- Hospital de Reabilitação de Anomalias Craniofaciais, Universidade de São Paulo, 2020.

Orientador: Prof. Dr. Renato Yassutaka Faria Yaedú

Autorizo, exclusivamente para fins acadêmicos e científicos, a reprodução total ou parcial desta dissertação/tese, por processos fotocopiadores e outros meios eletrônicos.

Assinatura:

Data: $21 / 07 / 2020$

Comitê de Ética do HRAC-USP

Protocolo ํㅜ: 4.057.576 
ERRATA 

FOLHA DE APROVAÇÃO 



\section{DEDICATÓRIA}

Dedico essa Tese aos meus pacientes do Centrinho!

Quisera eu ter uma pequena fração da coragem e força de vontade que vocês têm em estarem atuando nessa vida em que se propuseram a viver, na liberdade da escolha espiritual.

Minha eterna admiração e gratidão por todos que já tive a grande honra de tratar e aos seus pais, parceiros de jornada.

Muito obrigado por me aceitarem como auxiliador...

Que essa Tese possa contribuir um pouco com a técnica reabilitadora! 



\section{AGRADECIMENTOS}

Agradeço a minha esposa Adriana pelo apoio sempre presente, pelo auxílio com as crianças nos meus momentos de ausência, pelos conselhos sempre sábios em relação a estruturação e foco e pelo amor em dividir comigo essa jornada mesmo com todas minhas limitações.

Agradeço a minha filha Júlia, que apesar de ainda ter 12 anos agiu com muita maturidade nesses quase 4 anos, sabendo esperar minha volta, sabendo postergar nossas realizações de pai e filha e sabendo me ajudar em tudo que precisei, sua casinha na árvore agora sai! Com muito merecimento!!!!

Agradeço ao meu filho Enrico, que com 5 anos também agiu como um verdadeiro mocinho, soube esperar o papai nas longas estadas no escritório e me dar muita alegria nos momentos de desânimo...

Amo vocês três e sei o quanto se sacrificaram por mim nesse processo... Muito obrigado!!!!!

Obrigado aos meus pais por me darem os recursos materiais que me permitiram chegar até aqui. Tenho muita gratidão pelo sacrifício que fizeram por mim nos momentos em que estive sob responsabilidade de vocês. 



\section{AGRADECIMENTOS}

Ao meu Orientador, que aqui me refiro com "O" maiúsculo, meus sinceros agradecimentos! Como ex aluno da FOB-USP fico muito feliz de saber da qualidade e capacidade desse professor que tive o prazer de conhecer nos tempos de faculdade e agora ser orientado de maneira magistral. Renato, muito obrigado pela paciência, dedicação e generosidade que me conduziu.

Aos meus amigos do setor de ortodontia que tenho a grande alegria de dividir boa parte do meu tempo, aos meus mestres, Arlete, Sílvia, Terumi, Araci, Rita, Aiello, aos meus "veteranos" Adriano e Rogério, a minha contemporânea Renata e a "caçulinha" Gleise.... É uma grande honra trabalhar com vocês!

Às auxiliares que são um grande exemplo de eficiência e profissionalismo, Denise, Solange, Sônia, Suzana, Leila, Celina, Suzana e Rosângela. Muito obrigado por sempre estarem comigo!

A todos os funcionários do HRAC-USP que tenho contato direto ou indireto. Essa instituição PÚBLICA é o maior exemplo de que nosso país pode ser muito mais do que é. Tenho muito orgulho de trabalhar aqui com vocês! 

"Para ser grande, sê inteiro: nada Teu exagera ou exclui. Sê todo em cada coisa. Põe o quanto é no mínimo que fazes. Assim em cada lago a lua toda brilha, porque alta vive!" 



\section{RESUMO}

O objetivo deste estudo foi avaliar radiograficamente as características e alterações craniofaciais de indivíduos com fissura de lábio e palato unilateral submetidos a cirurgia ortognática para correção da classe III e comparar os achados com um grupo controle de indivíduos com fissura isolada de palato também submetidos a cirurgia ortognática para correção da classe III. A amostra do estudo foi de telerradiografias em norma lateral de 45 indivíduos selecionados retrospectivamente e aleatoriamente, divididos em 2 grupos: (1) grupo experimental: 30 indivíduos adultos com fissura de lábio e palato unilateral submetidos a cirurgia ortognática bimaxilar para correção da classe III e (2) grupo controle: 15 indivíduos adultos com fissura isolada de palato submetidos a cirurgia ortognática bimaxilar para correção da classe III. Mensurações craniofaciais e de espessura de tecido mole foram realizadas nas telerradiografias em norma lateral, pré operatórias e de controle de 6 meses pós cirurgia. Os dados obtidos através da análise cefalométrica com o programa Dolphin Imaging, foram comparados estatisticamente utilizando o teste ANOVA e o coeficiente de correlação de Pearson. Os indivíduos do grupo experimental apresentaram maior incremento vertical da maxila, menor projeção sagital do ponto subnasal, relação mais pobre entre os lábios, maior protrusão, espessura e eversão do lábio inferior, além de maior espessura de tecido mole na região do mento em relação aos do grupo controle, em T1 e em T2. Mesmo com o efeito corretivo para a oclusão e para a relação de tecidos duros, a cirurgia ortognática bimaxilar não possibilitou os mesmos resultados com relação aos tecidos moles, que exibiram uma conformação menos harmônica no grupo experimental.

Descritores: Má oclusão Classe III, Cirurgia Ortognática, Fissura de lábio e palato. 



\begin{abstract}
Comparison of craniofacial changes after bimaxillary orthognathic surgery in class III individuals with unilateral cleft lip and palate and isolated cleft palate
\end{abstract}

The aim of this study was to radiographically assess the characteristics and craniofacial changes of patients with unilateral cleft lip and palate undergoing orthognathic surgery for class III correction and to compare the findings with a control group of patients with isolated cleft palate also undergoing orthognathic surgery for Class III correction. The study sample was lateral $x$-ray radiographs of 45 patients selected retrospectively and randomly, divided into 2 groups: (1) experimental group: 30 adult patients with unilateral cleft lip and palate undergoing bimaxillary orthognathic surgery for correction of class III and (2) control group: 15 adult patients with isolated cleft palate undergoing bimaxillary orthognathic surgery for class III correction. Craniofacial and soft tissue thickness measurements were performed on lateral norm radiographs, preoperatively and 6 months after surgery. The data obtained through cephalometric analysis were compared statistically using the ANOVA test and Pearson's correlation coefficient. The individuals in the experimental group showed a greater vertical increase in the maxilla, less sagittal projection of the subnasal point, a poorer relationship between the lips, greater protrusion, thickness and eversion of the lower lip, in addition to greater thickness of soft tissue in the chin region compared to the control group, at T1 and T2. Even with the corrective effect for occlusion and for the relationship of hard tissues, bimaxillary orthognathic surgery did not allow the same results on soft tissues, which showed a less harmonic conformation in the experimental group.

Keywords: Malocclusion, Angle Class III; Orthognathic Surgery, Cleft lip and palate. 



\section{LISTA DE ILUSTRAÇÕES}

\section{FIGURAS}

Figura 1 Pontos cefalométricos e mensurações lineares e angulares de tecido duro: S, sela; N, Nasio; LHR, linha horizontal de referência (obtida $7^{\circ}$ a partir da linha S-N); LVR, linha vertical de referência (perpendicular a LHR, passando por S); Po, pório; Or, orbitário; Co, condílio; Ar, articular e A, subespinhal.

Figura 2 Pontos cefalométricos e mensurações lineares e angulares de tecido duro: S, sela; N, Nasio; Po, pório; Or, orbitário; Co, condílio; Ar, articular, A, subespinhal; B, supra mentoniano; Go, gônio; Me, mentoniano; Gn, gnátio e Pog, pogônio

Figura 3 Pontos cefalométricos e mensurações lineares e angulares de tecido duro: S, sela; N, Nasio; A, subespinhal; Go, gônio; Me, mentoniano e $\mathrm{Gn}$, gnátio.

Figura 4 Pontos cefalométricos e mensurações lineares de tecido duro: S, sela; N, Nasio; LHR, linha horizontal de referência (obtida $7^{\circ}$ a partir da linha S-N); LVR, linha vertical de referência (perpendicular a LHR, passando por S); A, subespinhal; lis, incisal do incisivo superior; lii, incisal do incisivo inferior; $B$, supra mentoniano e Pog, pogônio

Figura 5 Pontos cefalométricos e mensurações lineares e angulares de tecido duro: S, sela; N, Nasio; Es, estômio superior ; lis, incisal do incisivo superior; lii, incisal do incisivo inferior; Go, gônio; Gn, gnátio

Figura 6 Pontos cefalométricos e mensurações lineares e angulares de tecido mole: S, sela; N, Nasio; LHR, linha horizontal de referência (obtida $7^{\circ}$ a partir da linha S-N); LVR, linha vertical de referência (perpendicular a LHR, passando por S); N' násio tecido mole; G' glabela tecido mole; Pn, ponta nasal; Sn, subnasal; A,'subespinhal tecido mole; B', supra mentoniano tecido mole; Pog', pogônio tecido mole e Me', mentoniano tecido mole.

Figura 7 Pontos cefalométricos e mensurações lineares e angulares de tecido mole: S, sela; N, Násio; N' násio tecido mole; G' glabela tecido mole; Pn, ponta nasal; Sn, subnasal; A,'subespinhal tecido mole e B', supra mentoniano tecido mole.

Figura 8 Pontos cefalométricos e mensurações lineares de tecido mole: S, sela; N, Násio; Sn, subnasal; A,'subespinhal tecido mole; Ls, lábio superior; Es, estômio superior; Ei, estômio inferior; Li, lábio inferior; B', supra mentoniano tecido mole; B e Pog', pogônio tecido mole. 

Figura 9 Pontos cefalométricos e mensurações lineares e angulares de tecido mole: S, sela; N, Nasio; Col, columela; Sn, subnasal; A,'subespinhal tecido mole; Ls, lábio superior; Es, estômio superior; Ei, estômio inferior; Li, lábio inferior; B', supra mentoniano tecido mole e Pog', pogônio tecido mole.

Figura 10 Pontos cefalométricos e mensurações lineares e angulares de tecido mole: S, sela; N, Nasio; Sn, subnasal; Ls, lábio superior; VIs, vestibular do lábio superior; Vli, vestibular do lábio inferior; Li, lábio inferior; B, supra mentoniano; B', supra mentoniano tecido mole; Pog, pogônio e Pog', pogônio tecido mole.

Figura 11 Pontos cefalométricos e mensurações lineares de tecido mole: S, sela; N, Nasio; Pn, ponta nasal; A' subespinhal tecido mole; Ls, lábio superior; Li, lábio inferior; B', supra mentoniano tecido mole e Pog', pogônio tecido mole.

Figura 12 Sobreposição dos traçados médios dos grupos controle (preto) e experimental (vermelho) em T1

Figura 13 Sobreposição dos traçados médios dos grupos controle (preto) e experimental (vermelho) em T2

Figura 14 Sobreposição dos traçados médios do grupo experimental em T1 (preto) e T2 (vermelho).

Figura 15 Sobreposição dos traçados médios do grupo controle em T1 (preto) e T2 (vermelho).

Figura 16 Traçado médio do grupo experimental em T1

Figura 17 Traçado médio do grupo experimental em T2

Figura 18 Traçado médio do grupo controle em T1

Figura 19 Traçado médio do grupo controle em T2

\section{GRÁFICOS}

Gráfico 1 Correlação da posição sagital da maxila com o ponto subnasal no grupo experimental.

Gráfico 2 Correlação da posição sagital da maxila com o ponto subnasal no grupo controle.

Gráfico 3 Correlação da posição sagital do incisivo superior com o lábio superior no grupo experimental.

Gráfico 4 Correlação da posição sagital do incisivo superior com o lábio superior no grupo controle.

Gráfico 5 Correlação da relação intermaxilar óssea angular e da relação intermaxilar sagital de tecido mole no grupo experimental. 

Gráfico 6 Correlação da relação intermaxilar óssea angular e da relação intermaxilar sagital de tecido mole no grupo controle.

Gráfico 7 Correlação da relação intermaxilar óssea angular com a relação sagital entre os lábios no grupo experimental

Gráfico 8 Correlação da relação intermaxilar óssea angular com a relação sagital entre os lábios no grupo controle.

Gráfico 9 Correlação da relação intermaxilar óssea linear com a relação intermaxilar sagital de tecido mole no grupo experimental...............

Gráfico 10 Correlação da relação intermaxilar óssea linear com a relação intermaxilar sagital de tecido mole no grupo controle.

Gráfico 11 Correlação da relação intermaxilar óssea linear com a relação sagital entre os lábios no grupo experimental..................................

Gráfico 12 Correlação da relação intermaxilar óssea linear com a relação sagital entre os lábios no grupo controle.........................

Gráfico 13 Correlação entre a relação sagital mandibular e a protrusão do lábio inferior no grupo experimental.

Gráfico 14 Correlação entre a relação sagital mandibular e a protrusão do lábio inferior no grupo controle.

Gráfico 15 Correlação entre a relação sagital mandibular e a espessura do lábio inferior no grupo experimental.

Gráfico 16 Correlação entre a relação sagital mandibular e a espessura do lábio inferior no grupo controle.

Gráfico 17 Correlação entre a relação sagital mandibular e a inclinação do lábio inferior no grupo experimental.

Gráfico 18 Correlação entre a relação sagital mandibular e a inclinação do lábio inferior no grupo controle. 



\section{LISTA DE TABELAS}

Tabela 1- Dados descritivos dos indivíduos do estudo............................. 56

Tabela 2- Definições das medidas de tecido duro da figura 1................ 57

Tabela 3- Definições das medidas de tecido duro da figura 2................ 58

Tabela 4- Definições das medidas de tecido duro da figura 3................ 59

Tabela 5- Definições das medidas de tecido duro da figura 4................ 60

Tabela 6- Definições das medidas de tecido duro da figura 5.................. 61

Tabela 7- Definições das medidas de tecido duro da figura 6................. 62

Tabela 8- Definições das medidas de tecido duro da figura $7 \ldots \ldots \ldots \ldots \ldots \ldots . . . . \quad 63$

Tabela 9- Definições das medidas de tecido duro da figura 8................. 64

Tabela 10- Definições das medidas de tecido duro da figura 9 .................. $\quad 65$

Tabela 11- Definições das medidas de tecido duro da figura 10............... 66

Tabela 12- Definições das medidas de tecido duro da figura 11................ 67

Tabela 13- Erro do método da análise cefalométrica(Apêndice)................ 121

Tabela 14- Tecido duro. Comparação inicial e final nos grupos experimental e controle....................................................... 72

Tabela 15- Tecido mole. Comparação inicial e final nos grupos experimental e controle......................................................... 77

Tabela 16- Tecido duro grupo experimental T1xT2 ................................ 124

Tabela 17- Tecido mole grupo experimental T1xT2 ................................ 125

Tabela 18- Tecido duro grupo controle T1xT2 ....................................... 126

Tabela 19- Tecido mole grupo controle T1xT2 ……………………...... 127

Tabela 20- Diferença entre as alterações de tecido duro entre os grupos experimental e controle........................................................ 85

Tabela 21- Diferença entre as alterações de tecido mole entre os grupos experimental e controle. 



\section{LISTA DE ABREVIATURA E SIGLAS}

\begin{tabular}{|c|c|}
\hline $\mathbf{S}$ & Sela \\
\hline $\mathbf{N}$ & Násio \\
\hline LHR & Linha horizontal de referência \\
\hline LVR & Linha vertical de referência \\
\hline Po & Pório \\
\hline Or & Orbitário \\
\hline Co & Condílio \\
\hline Ar & Articular \\
\hline $\mathbf{A}$ & Subespinhal \\
\hline B & Supra mentoniano \\
\hline Go & Gônio \\
\hline Me & Mentoniano \\
\hline Gn & Gnátio \\
\hline Pog & Pogônio \\
\hline lis & Incisal do incisivo superior \\
\hline lii & lii Incisal do incisivo inferior \\
\hline Es & Estômio superior \\
\hline Ei & Estômio Inferior \\
\hline $\mathbf{N}^{\prime}$ & Násio tecido mole \\
\hline G' & Glabela tecido mole \\
\hline Pn & Ponta nasal \\
\hline Sn & Subnasal \\
\hline$A^{\prime}$ & Subespinhal tecido mole \\
\hline $\mathbf{B}^{\prime}$ & Supramentoniano tecido mole \\
\hline Pog' & Pogônio tecido mole \\
\hline Me' & Mentoniano tecido mole \\
\hline Col & Columela \\
\hline Ls & Lábio superior \\
\hline Li & Lábio inferior \\
\hline Vls & Vestibular do lábio superior \\
\hline
\end{tabular}





$\begin{array}{ll}\text { Vii } & \text { Vestibular do lábio inferior } \\ \text { T1 } & \text { Pré operatório imediato } \\ \text { T2 } & \text { Pós operatório de no mínimo } 6 \text { meses pós cirúrgico } \\ \text { Mm } & \text { MilímetroS } \\ \text { HRAC-USP } & \begin{array}{l}\text { Hospital de Reabilitação de Anomalias Craniofaciais- } \\ \text { Universidade de São Paulo }\end{array} \\ \text { Dp } & \text { Desvio padrão } \\ \text { Icc } & \text { Coeficiente de correlação intraclasse } \\ \text { TD } & \text { Tecido duro } \\ \text { TM } & \text { Tecido mole }\end{array}$





\section{SUMÁRIO}

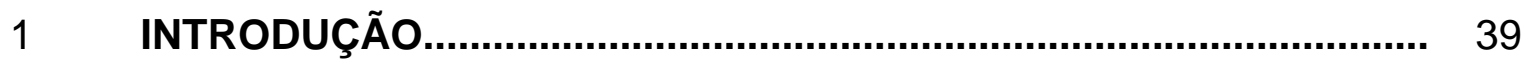

2 REVISÃO DE LITERATURA....................................................... 45

$3 \quad$ PROPOSIÇÃO.......................................................................... 51

4 MATERIAL E MÉTODOS.......................................................... 55

$4.1 \quad$ Considerações éticas..................................................................... 55

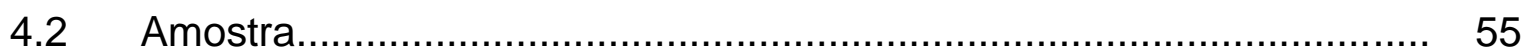

4.2.1 Critérios de inclusão............................................................... 56

4.3 Grandezas cefalométrica............................................................... 56

4.4 Forma de análise dos resultados.................................................. 67

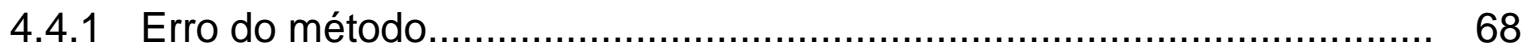

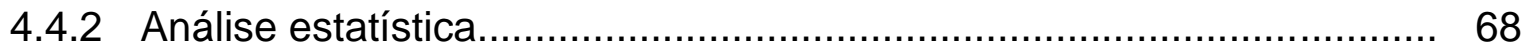

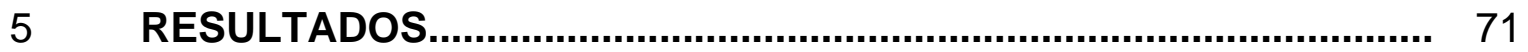

5.1 Diferenças de tecido duro e mole entre os grupos em T1 e em T2...... 71

5.2 Alterações do tecido duro e mole do grupo experimental T1xT2........... 79

5.3 Alterações do tecido duro e mole do grupo controle T1xT2................. 81

5.4 Comparação entre as alterações de tecido duro e mole ocorridas nos grupos experimental e controle....................................................... 84

5.5 Correlação de Pearson.................................................................... 89

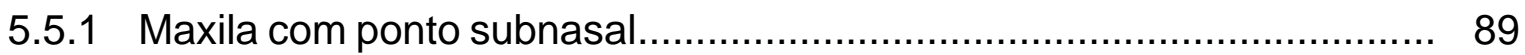

5.5.2 Incisivo superior com lábio superior................................................ 90

5.5.3 Relação intermaxilar óssea angular com a relação intermaxilar sagital

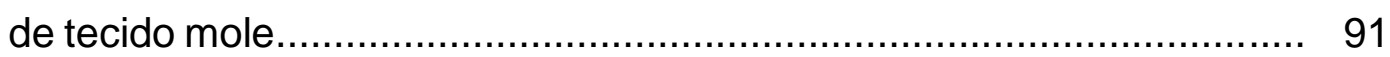

5.5.4 Relação intermaxilar óssea angular com a relação intermaxilar sagital entre os lábios 

5.5.5 Relação intermaxilar óssea linear com a relação intermaxilar sagital de tecido mole..................................................................... 93

5.5.6 Relação intermaxilar óssea com a relação sagital entre os lábios........ 94

5.5.7 Posição sagital mandibular e protrusão, espessura e inclinação do

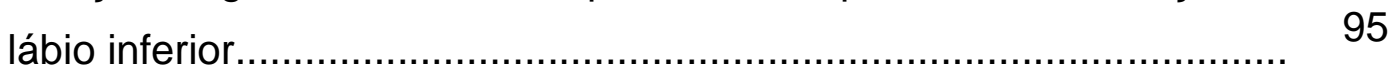

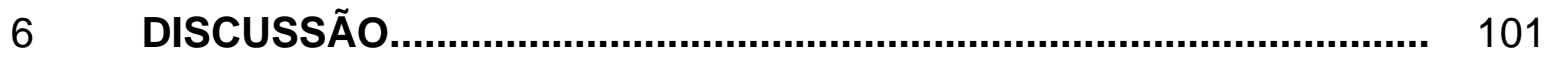

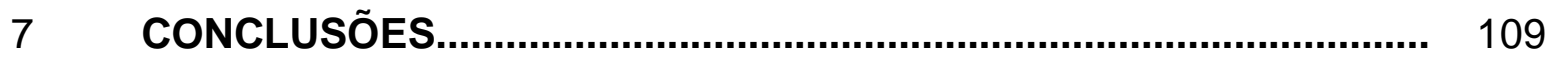

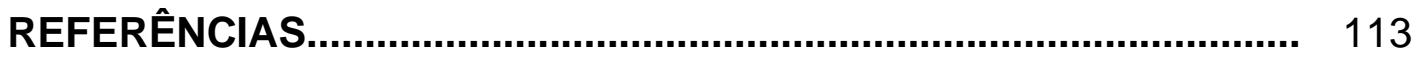

APÊNCICE

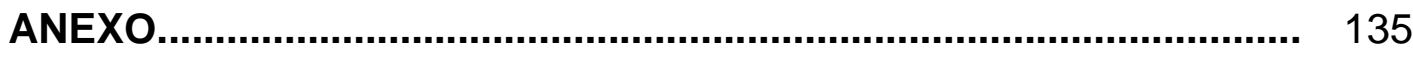





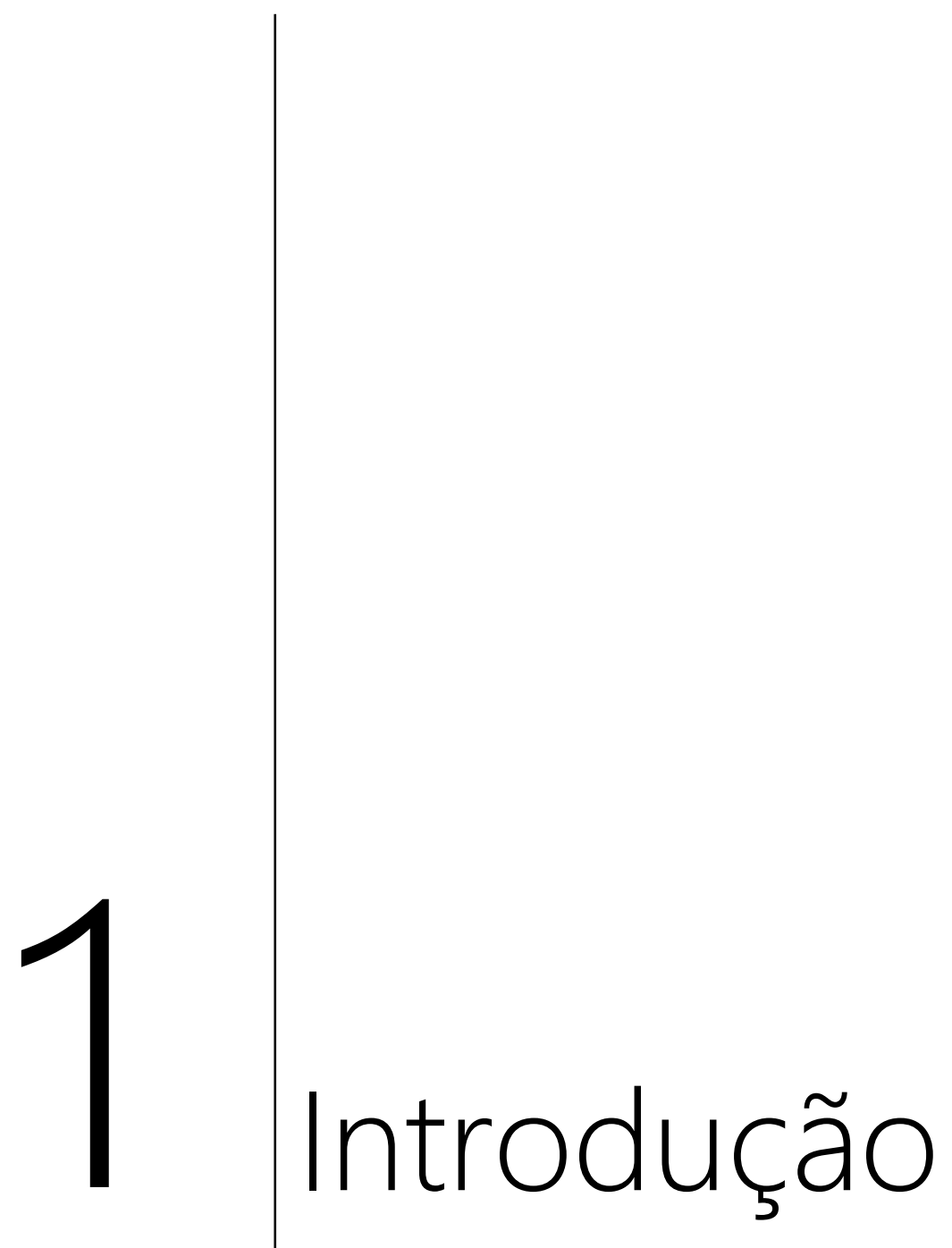





\section{INTRODUÇÃO}

O conhecimento da morfologia craniofacial e de suas nuances é de suma importância para o diagnóstico ortodôntico. Para o manejo adequado do processo reabilitador, o ortodontista deve conhecer os parâmetros de normalidade para a face e para a oclusão, alvos do processo reabilitador ortodôntico ou ortodôntico/cirúrgico(CAPELOZZA FILHO, 2004).

Indivíduos com fissura labiopalatina apresentam variações morfológicas e funcionais em relação aos indivíduos sem fissura, variações típicas de uma face marcada pelo defeito congênito e pelas sequelas impostas pelo processo reabilitador longo e invasivo. (FREITAS et al., 2012)

Sabe-se que o crescimento craniofacial de indivíduos com fissura de lábio e palato é diferente do crescimento craniofacial de indivíduos sem fissura, a maxila e mandíbula são menores e mais retruídas e o padrão de crescimento é mais vertical.( (DOĞAN; ÖNÇAĞ; AKIN, 2006)e (MOREIRA et al., 2014).

A face também apresenta particularidades impostas pela fissura em si e pelas cicatrizes criadas pelo processo reabilitador, o lábio superior é mais curto e assimétrico (PARK; $\mathrm{KOH} ; \mathrm{CHOI}, 2015$ ), o nariz é assimétrico e o lábio inferior é menor, mais protruído e curvado(TOYGAR; AKÇAM; ARMAN, 2004).

Indivíduos com fissura isolada de palato submetidos a palatoplastia apresentam um leve comprometimento no comportamento sagital da maxila, com uma menor projeção zigomática na face, porém, sem comprometimento do padrão facial (DA SILVA FILHO; ROSA; LAURIS, 2007). O crescimento craniofacial desses indivíduos em relação aos indivíduos sem fissura também mostra uma alteração, com a maxila sendo menor, mais retruída e inclinada no sentido horário e a mandíbula sendo mais retruída. A altura facial superior e total também se mostram menores(PARIKAKIS; LARSON; KARSTEN, 2020); (BECKER et al., 2001)

Na comparação direta entre os indivíduos com fissura de lábio e palato unilateral e os indivíduos com fissura isolada de palato um estudo descreve que ambos possuem relação esquelética de Classe III e inclinação lingual de incisivos, sendo que os indivíduos com fissura de lábio e palato unilateral têm uma predominância do tipo 
facial dolicofacial e os indivíduos com fissura isolada de palato tem uma predominância do tipo facial mesofacial. (LÓPEZ-GIMÉNEZ et al., 2018)

Devido ao crescimento maxilar mais pobre e as particularidades associadas ao lábio e ao palato com fissura posterior, o prognóstico de tratamento dos indivíduos com fissura de lábio e palato é mais reservado em relação aos indivíduos com fissura isolada de palato(SCHULTES; GAGGL; KÄRCHER, 2000)

Cerca de 20 a $66 \%$ dos indivíduos com fissura de lábio e palato tem indicação para reabilitação com cirurgia ortognática(HATHAWAY et al., 2011). Essa indicação ocorre em cerca de $13 \%$ dos indivíduos com fissura isolada de palato (DASKALOGIANNAKIS; MEHTA, 2009). Ambos apresentam frequência maior se comparada com a população de indivíduos sem fissura labiopalatina que é de $2 \%$ a 4\%(PROFFIT; TURVEY; PHILLIPS, 1996; PROFFIT, 2007).

Com o avanço do planejamento e da técnica cirúrgica, sabe-se que a cirurgia ortognática bimaxilar, quando bem indicada, apresenta resultados melhores em termos de estabilidade e estética do contorno facial em relação a cirurgia de avanço de maxila ou recuo de mandíbula isoladas. (WOLFORD; CHEMELLO; HILLIARD, 1994; CHEMELLO; WOLFORD; BUSCHANG, 1994; HIRANO; SUZUKI, 2001; BAUMANN; SINKO, 2003). Modificações técnicas para a realização da osteotomia maxilar de indivíduos com fissura de palato com ou sem envolvimento de lábio também têm sido propostas na literatura.(SUSARLA et al., 2020)

Porém, não há na literatura estudos que realizaram comparação entre indivíduos com fissura de lábio e palato e fissura isolada de palato submetidos a cirurgia ortognática bimaxilar.

Os parâmetros e referências usados para correção ortodôntico-cirúrgica dos indivíduos com fissura lábiopalatina são os mesmos dos usados nos indivíduos sem fissura, os resultados, porém, são diferentes principalmente do ponto de vista da estética facial devido a particularidades como a presença de cicatrizes no lábio superior e assimetrias na asa nasal. A relação oclusal final também apresenta algumas diferenças entre estes indivíduos, já que a presença da fissura está associada a agenesias dentárias e alterações na forma dos arcos, nem sempre passíveis de serem corrigidas completamente no preparo ortodôntico. As limitações dos resultados obtidos através do tratamento ortodôntico-cirúrgico dos indivíduos com fissura de lábio e 
palato precisam ser melhor estudadas a fim de que parâmetros de tratamento mais objetivos e específicos possam ser obtidos.

Para verificar a influência da fissura no lábio e rebordo alveolar operados na morfologia craniofacial antes e após a cirurgia ortognática se avaliou e comparou a morfologia craniofacial de indivíduos com fissura de lábio e palato e indivíduos com fissura isolada de palato submetidos a cirurgia ortognática bimaxilar para correção da classe III esquelética. 



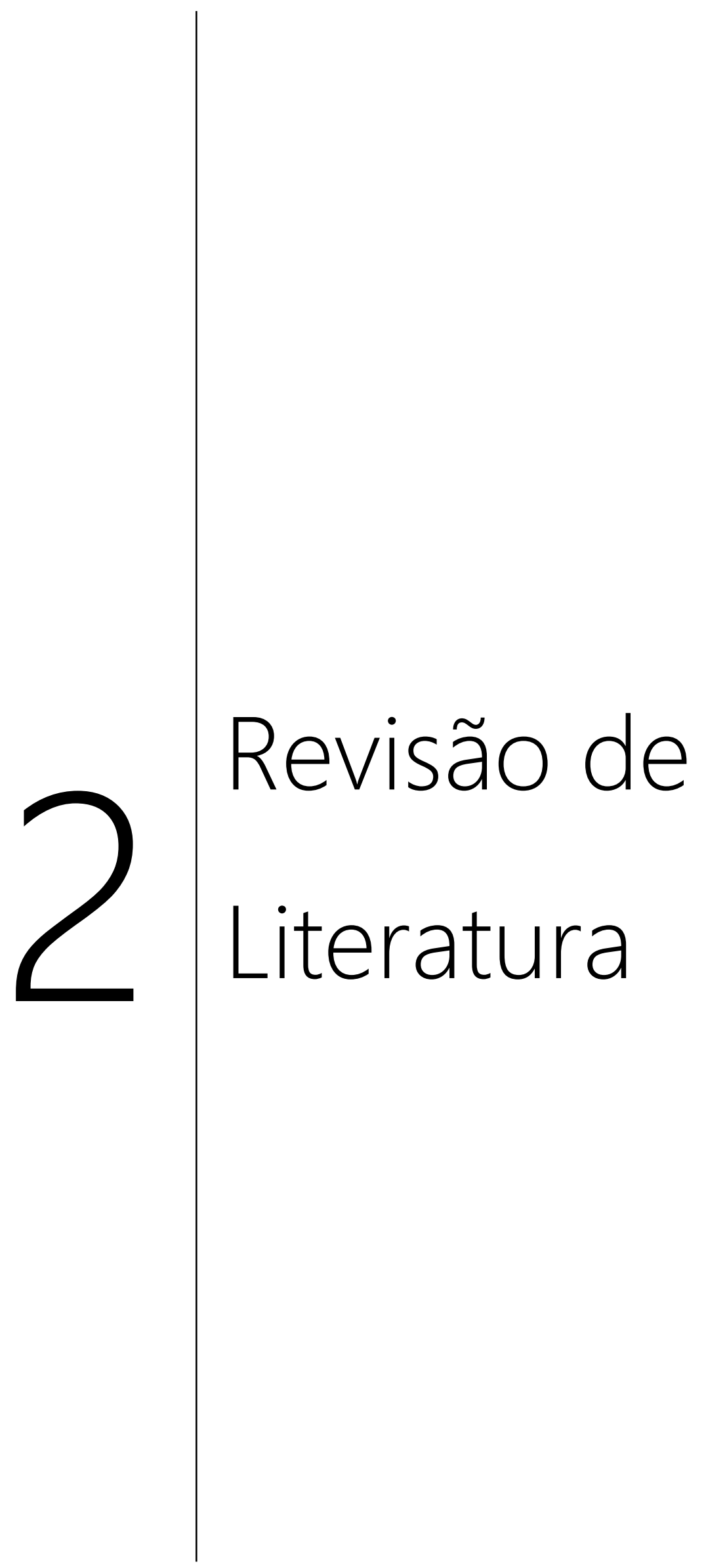





\section{REVISÃO DE LITERATURA}

Sabe-se que o indivíduo com fissura lábiopalatina apresenta uma restrição de crescimento maxilar. $\mathrm{Na}$ tentativa de elucidar a ação da queiloplastia e da palatoplastia no crescimento maxilar dos indivíduos com fissura lábiopalatina, (BICHARA et al., 2015) realizaram uma revisão sistemática e meta análise e sugeriram ser a cirurgia primária reparadora de lábio, a queiloplastia, a principal influência negativa para o crescimento maxilar.

Comparações entre as características cefalométricas de tecido duro e mole de indivíduos com e sem fissura têm sido realizadas amplamente na literatura .( SCAF G et al, 1989, DOGAN, S. et al, 2005; MOREIRA, I. et al, 2014,(LIN et al., 2016).

A morfologia da base do crânio de indivíduos classe III com fissura unilateral completa não apresenta diferenças em comparação com os indivíduos classe III sem fissura, sendo a deficiência maxilar presente nos indivíduos com fissura associada apenas com o comprimento reduzido da maxila(TINANO et al., 2015).

Indivíduos com e sem fissura, com má oclusão de classe III apresentam uma relação maxilo-mandibular similar, porém, os indivíduos com fissura apresentam maior retrusão maxilar e mandibular em relação a base do crânio e discrepâncias verticais mais severas. Além disso, os indivíduos com fissura apresentam maior retroinclinação de incisivos superiores, pequeno valor de Wits e perfil mole mais côncavo(LINTON, 1998; LIN et al., 2016).

A mandíbula dos indivíduos com fissura de lábio e palato ou fissura isolada de palato apresenta uma maior rotação no sentido horário, um ângulo goníaco mais aberto e é estruturalmente menor, se comparada a indivíduos sem fissura ou com fissura sem envolvimento de palato (GABRIEL DA SILVA FILHO; CORRÊA NORMANDO; FILHO, 1993). Indivíduos com fissura isolada de palato não operados têm o mesmo potencial de crescimento craniofacial de indivíduos sem fissura. (LU et al., 2007), (SILVA FILHO; CAVASSAN; SAMPAIO, 1989; DA SILVA FILHO; ROSA; LAURIS, 2007).

Já a maior frequência de indicação para cirurgia ortognática dos indivíduos com fissura de lábio e palato quando comparados aos que possuem fissura isolada de palato é devido a maior restrição do crescimento maxilar induzida pela queiloplastia, 
já que a palatoplastia, indicada para ambos os grupos, parece não causar uma grande restrição de crescimento maxilar.(NORMANDO; DA SILVA FILHO; CAPELOZZA FILHO, 1992)

Alguns estudos comparam a morfologia craniofacial de indivíduos com e sem fissura após a realização da cirurgia ortognática de avanço maxilar para a correção da classe III.((FREIHOFER, 1976; FREIHOFER, 1977; HUI; HÄGG; TIDEMAN, 1994; VASUDAVAN; JAYARATNE; PADWA, 2012; PARK; KOH; CHOI, 2015).

O comportamento do tecido mole na região do lábio superior e nariz dos indivíduos com fissura de lábio e palato e sem fissura frente a cirurgia ortognática de avanço de maxila para a correção da classe III é bastante variável. A relação é apresentada como similar em alguns estudos (FREIHOFER, 1976; FREIHOFER, 1977; VASUDAVAN; JAYARATNE; PADWA, 2012). Porém, (HUI; HÄGG; TIDEMAN, 1994) verificaram que nos indivíduos com fissura de lábio e palato houve uma maior correlação entre a movimentação de tecidos duros e moles do que nos indivíduos sem fissura, após o avanço maxilar. Já (DIAS, 2020), encontrou uma maior resposta do lábio superior frente ao avanço maxilar nos pacientes sem fissura de lábio e palato.

(TANAKA, 2015) em uma avaliação sobre o comportamento do tecido mole frente a diferentes magnitudes de avanço de maxila em indivíduos com fissura de lábio e palato unilateral, encontrou uma maior relação tecido mole/duro em avanços de maxila menores ou iguais a 5,0 mm. O nariz diminuiu e o lábio superior não se moveu em todas as magnitudes de avanço e as maiores repercussões de tecido mole só ocorreram em avanços maiores do que $5 \mathrm{~mm}$.

Em relação a repercussão da cirurgia ortognática na relação inter-labial, (PARK; KOH; CHOI, 2015) relataram uma relação pouco harmônica entre os lábios superior e inferior dos indivíduos com fissura após a cirurgia ortognática bimaxilar. Para isso, foi realizado uma comparação entre os indivíduos com e sem fissura classe III reabilitados com cirurgia ortognática bimaxilar, porém, com foco apenas na avaliação do lábio inferior e sua relação com o lábio superior.

Já, (YUN et al., 2015), relataram bons resultados estéticos após a cirurgia ortognática bimaxilar no tratamento de indivíduos com fissura de lábio e palato, porém, 
com uma metodologia de avaliação dos tecidos moles mais simples e sem uma comparação direta, no mesmo estudo, com indivíduos sem fissura.

(BAUMANN; SINKO, 2003) sugerem que os resultados da cirurgia ortognática bimaxilar são melhores e mais estáveis do que a cirurgia ortognática de avanço de maxila em indivíduos com fissura de lábio e palato. Para eles, a harmonização do perfil facial e a correção tridimensional do complexo maxilomandibular são mais fáceis de serem obtidos com a cirurgia bimaxilar além de que a posição esquelética horizontal da maxila fica mais estável. Já,(WONG et al., 2016), não encontraram diferenças em relação a estabilidade maxilar de indivíduos com fissura de lábio e palato submetidos a cirurgia ortognática de avanço de maxila com ou sem recuo de mandíbula.

O uso de imagens em 3 dimensões em detrimento das imagens em duas dimensões para planejamento da cirurgia ortognática e para aferição dos resultados em pesquisas tem se popularizado nos estudos mais recentes.(CHANG et al., 2017; DIAS, 2020). Porém, o uso desse recurso exige uma maior experiência do profissional e um tempo maior para o aprendizado(ALMUKHTAR et al., 2014), além de que, não há ainda um padrão cefalométrico normativo para as imagens em 3 dimensões como já há amplamente para as imagens em duas dimensões(LIN et al., 2016).

A satisfação dos indivíduos classe III com ou sem fissura labiopalatina com os resultados da cirurgia ortognática foi alvo de estudo. Os autores encontraram uma menor satisfação dos indivíduos com fissura labiopalatina em relação a estética do lábio e do nariz após a cirurgia, e sugeriram a finalização do tratamento desses indivíduos com cirurgias plásticas cosméticas de lábio e nariz(YIM; BAEK, 2019).

$\mathrm{Na}$ literatura, quando se comparam os resultados cirúrgicos entre os indivíduos com e sem fissura, o maior enfoque é dado na área do nariz e lábio superior e a cirurgia ortognática é a de avanço maxilar com a técnica Le Fort I.(FREIHOFER, 1976; FREIHOFER, 1977; HUI; HÄGG; TIDEMAN, 1994; TANAKA, 2015; PARK; KOH; CHOI, 2015; DIAS, 2020). 



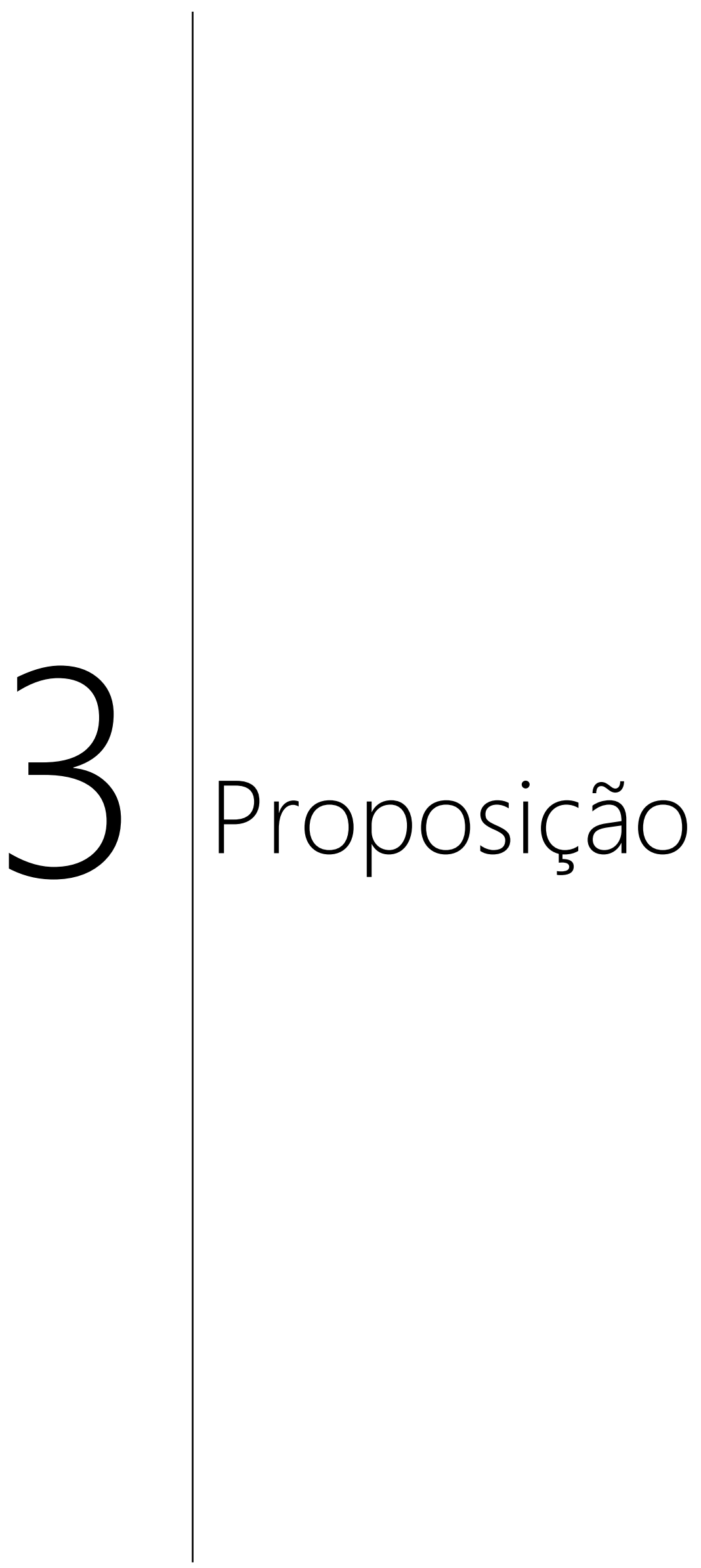





\section{PROPOSIÇÃO}

O objetivo deste estudo foi avaliar e comparar a morfologia craniofacial de indivíduos com fissura de lábio e palato unilateral e indivíduos com fissura isolada de palato submetidos a cirurgia ortognática bimaxilar para correção da classe III esquelética. 



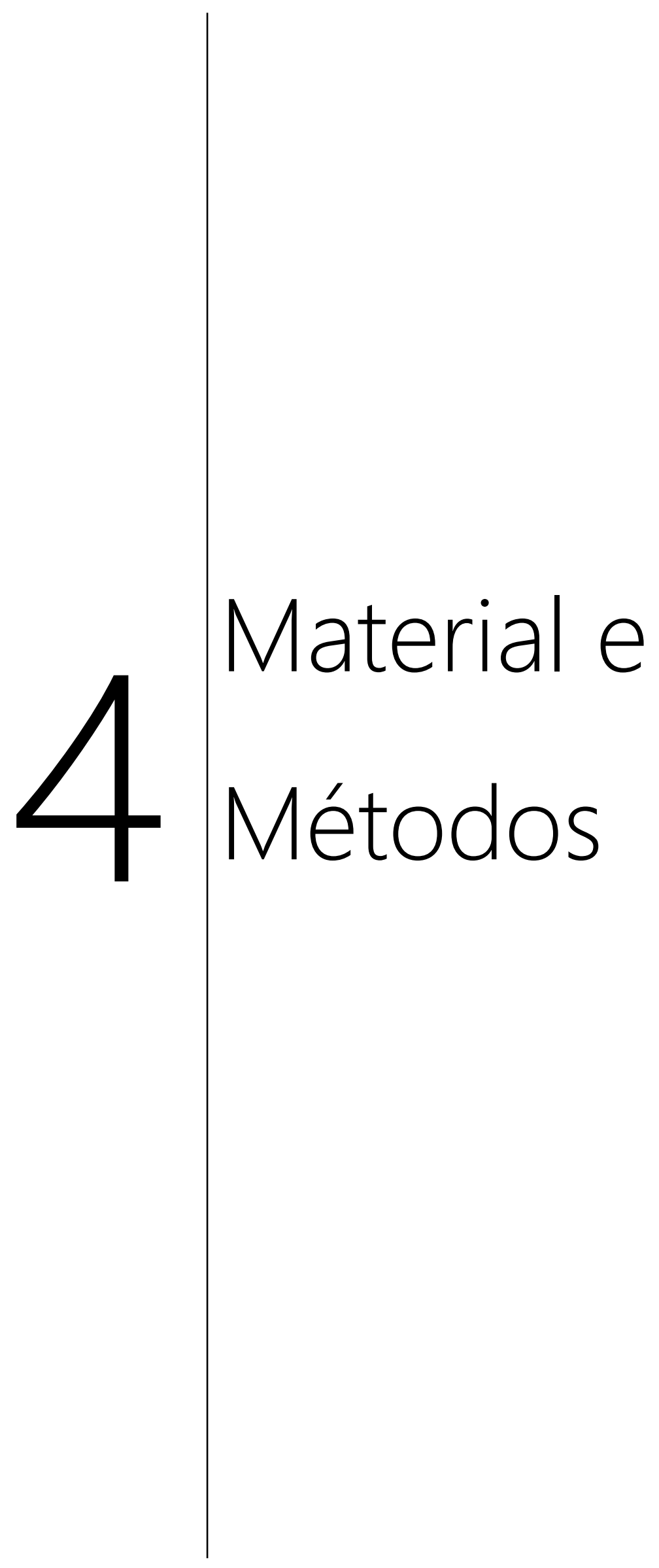





\section{MATERIAL E MÉTODOS}

\subsection{Considerações éticas}

O protocolo da pesquisa foi submetido à apreciação e foi aprovado pelo Comitê de Ética do Hospital de Reabilitação de Anomalias Craniofaciais (HRAC- USP). Número do parecer: 4.057.576 (Anexo A)

\subsection{Amostra}

Tratou-se de um estudo observacional retrospectivo com uma amostra de 90 telerradiografias em norma lateral divididas em 2 grupos: Grupo experimental, indivíduos com fissura de lábio e palato unilateral e Grupo controle: indivíduos com fissura isolada de palato; todos submetidos a cirurgia ortognática bimaxilar para correção da classe III, operados por um mesmo cirurgião com a mesma técnica cirúrgica e de planejamento cirúrgico. Foram avaliadas as telerradiografias em dois períodos: o primeiro, pré-operatório (T1) e o segundo período com mais de 6 meses de pós-operatório (T2). Desta forma o tamanho da amostra foi de 30 indivíduos para o grupo experimental (17 do sexo masculino e 13 do sexo feminino), com idades variando de 21 a 35 anos (média 26,73 anos; Dp 4,35) e 15 indivíduos no grupo controle ( 8 do sexo masculino e 7 do sexo feminino), com idades variando de 18 a 41 anos (média de 28,87 anos; Dp 6,2) Tabela 1 (página 56). As radiografias foram obtidas do arquivo do Hospital de Reabilitação de Anomalias Craniofaciais (HRACUSP).

Todos os indivíduos do grupo experimental apresentavam fissura de lábio e palato unilateral completas. Os indivíduos do grupo controle, apresentavam fissura isolada de palato, $4 \mathrm{com}$ fissura completa de palato, $5 \mathrm{com}$ envolvimento parcial do palato duro e 6 com envolvimento apenas de palato mole.

Todas as telerradiografias foram obtidas com a mesma técnica com côndilos em relação cêntrica, lábios relaxados e posição natural da cabeça. 
Tabela 1: Dados descritivos dos indivíduos do estudo.

\begin{tabular}{lccc} 
& Grupo experimental $(\mathrm{n}=30)$ & Grupo controle $(\mathrm{n}=15)$ & Valor de $\mathrm{p}$ \\
\hline Sexo M/F & $17 / 13$ & $8 / 7$ & - \\
Idade (média anos) & $26,73(\mathrm{dp} \mathrm{4,35)(21-35)}$ & $28,87(\mathrm{dp} \mathrm{6,2)}(18-41)$ & 0,209 \\
\hline
\end{tabular}

\subsubsection{Critérios de inclusão:}

1. Indivíduos não sindrômicos;

2. Cirurgias plásticas primárias realizadas em época oportuna (queiloplastia ao redor dos 3 meses e palatoplastia ao redor dos 12 meses de idade);

3. Relação de Classe III antes da cirurgia ortognática com mordida cruzada anterior e quantidade de discrepância sagital similar para os dois grupos (medida Wits $\leq-4,00 \mathrm{~mm}$ );

4. Sem histórico de retratamento:

5. Cirurgia ortognática de maxila e mandíbula, sem mentoplastia.

\subsection{Grandezas Cefalométricas}

As imagens foram geradas na forma digital e anexadas no programa Dolphin Imaging, versão 11.5 (Dolphin, Califórnia, Estados Unidos). A demarcação dos pontos foi realizada por um único operador, em uma sala com luz reduzida para melhor visualização. Os pontos de referência cefalométricos são mostrados nas Figuras de 1 a 11 e as descrições das medidas são apresentadas nas tabelas 2 a 12 (páginas 57 a 67). Para mensurações lineares sagitais e verticais utilizou-se o método proposto por (MANSOUR; BURSTONE; LEGAN, 1983), criando-se uma linha horizontal de referência (LHR) obtida a $7^{\circ}$ a partir da linha Sela-Násio e uma linha vertical de referência (LVR), perpendicular a LHR, passando pelo ponto Sela. 
Figura 1: Pontos cefalométricos e mensurações lineares e angulares de tecido duro: $\mathrm{S}$, sela; $\mathrm{N}$, Nasio; LHR, linha horizontal de referência (obtida $7^{\circ}$ a partir da linha S-N); LVR, linha vertical de referência (perpendicular a LHR, passando por S); Po, pório; Or, orbitário; Co, condílio; Ar, articular e A, subespinhal. As mensurações estão definidas na tabela 2.

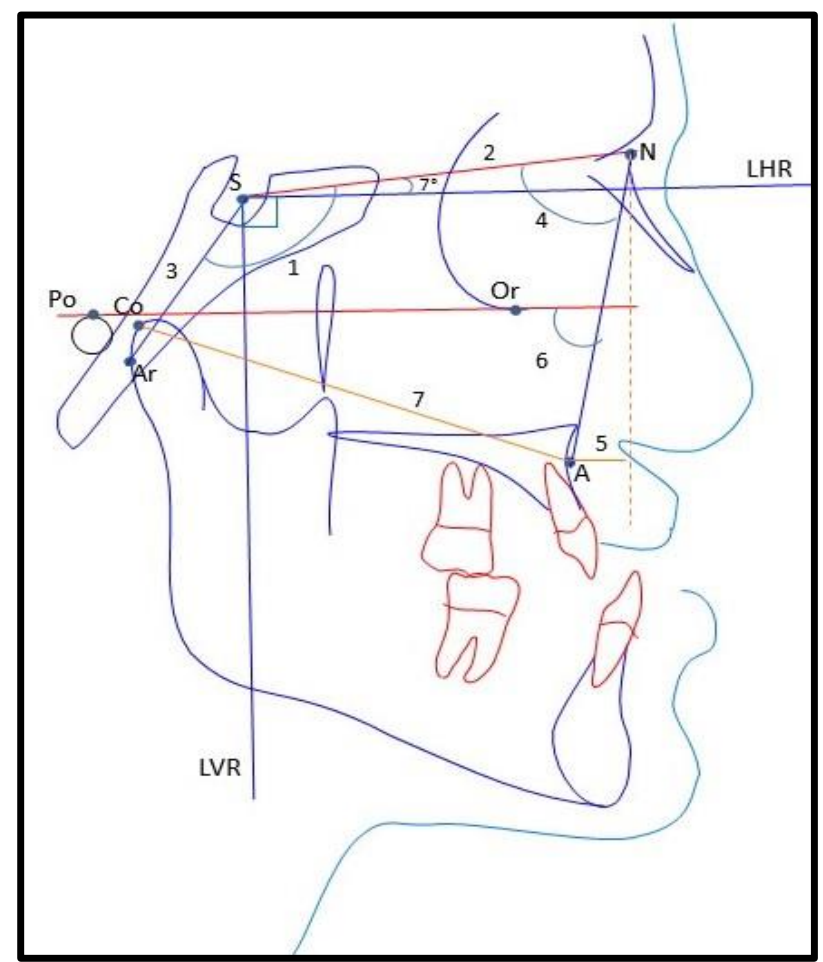

Tabela 2 - Definições das medidas de tecido duro da figura 1.

Medidas de tecido duro Definições

Base do Crânio

1- SN-Ar $\left({ }^{\circ}\right)$

2- $\mathrm{SN}(\mathrm{mm})$

3- S-Ar (mm)

Complexo Nasomaxilar

4- SNA $\left(^{\circ}\right)$

5- N-A Horizontal (// LHR) ( $\mathrm{mm})$

6- PoOr-NA $\left({ }^{\circ}\right)$

7- Co-A (mm)

$\perp$, perpendicular; // paralelo.
Ângulo da base do crânio

Comprimento da base anterior do crânio

Comprimento da base posterior do crânio

Posição anteroposterior da maxila em relação a base do crânio

Posição anteroposterior da maxila

Ângulo de profundidade maxilar

Comprimento da maxila 
Figura 2: Pontos cefalométricos e mensurações lineares e angulares de tecido duro: $\mathrm{S}$, sela; $\mathrm{N}$, Nasio; Po, pório; Or, orbitário; Co, condílio; Ar, articular, A, subespinhal; B, supra mentoniano; Go, gônio; Me, mentoniano; Gn, gnátio e Pog, pogônio. As mensurações estão definidas na tabela 3.

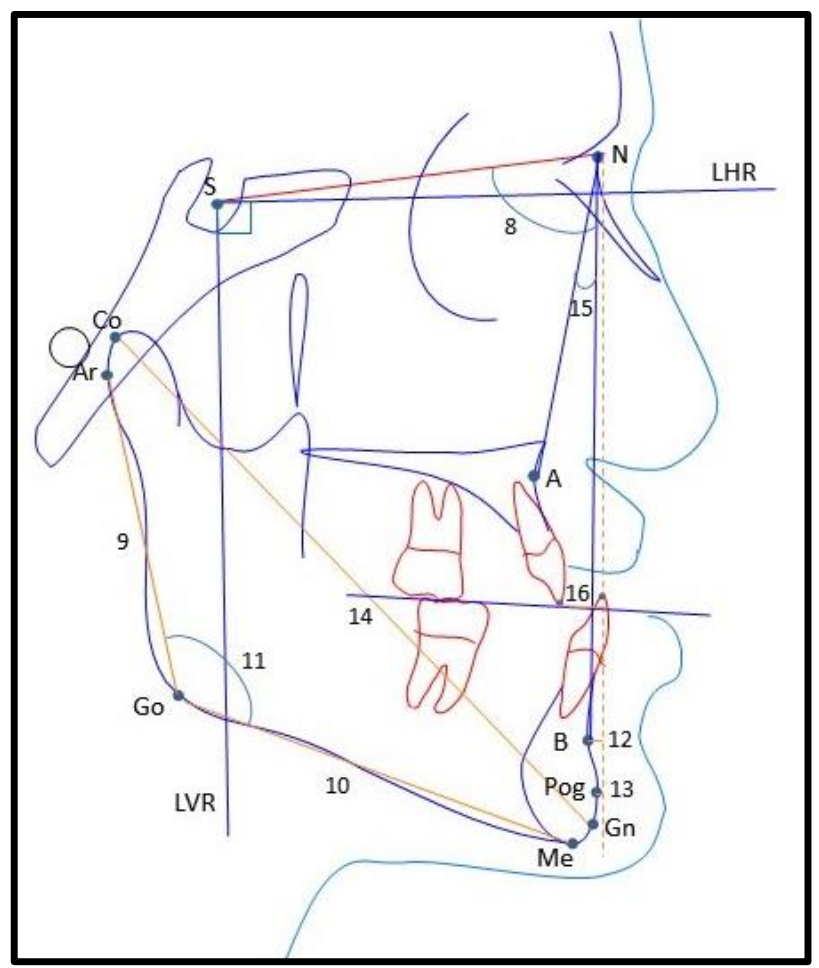

Tabela 3 - Definições das medidas de tecido duro da figura 2.

Medidas de tecido duro Definições

Morfologia e posição mandibular

8- SNB $\left(^{\circ}\right)$

Posição anteroposterior da mandíbula em relação a base do crânio

9- Ar-Go (mm)

Altura do ramo

10- Go-Me (mm)

Comprimento do corpo mandibular

11- Ar-Go-Me ( $\left.{ }^{\circ}\right)$

Ângulo goníaco

12- N-B (// LHR) (mm)

Posição anteroposterior da mandíbula

13- N-Pog (// LHR) (mm)

Posição anteroposterior do pogônio

14- Co-Gn (mm)

Comprimento da mandíbula

Relação inter-maxilar

15- ANB $\left(^{\circ}\right)$

Relação sagital intermaxilar angular

16- Wits (mm)

Realação sagital intermaxilar linear

$\perp$, perpendicular; // paralelo. 
Figura 3: Pontos cefalométricos e mensurações lineares e angulares de tecido duro: S, sela; N, Nasio; A, subespinhal; Go, gônio; Me, mentoniano e Gn, gnátio. As mensurações estão definidas na tabela 4.

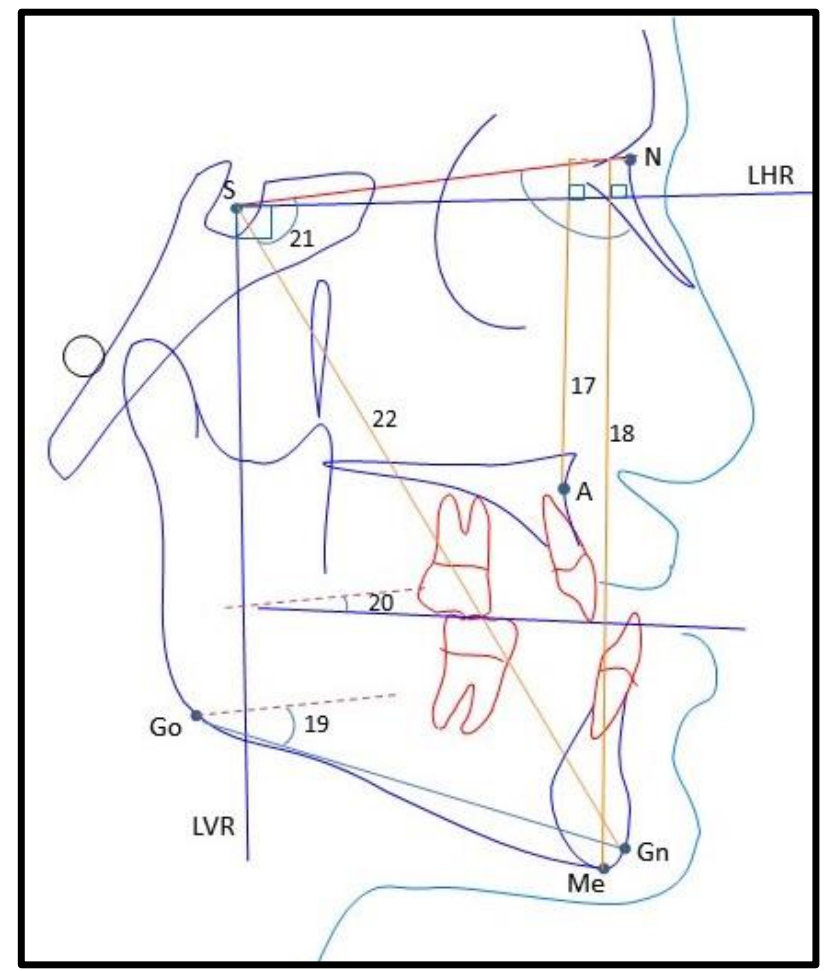

Tabela 4 - Definições das medidas de tecido duro da figura 3.

\begin{tabular}{ll} 
Medidas de tecido duro & Definições \\
\hline Dimensão vertical & \\
$17-\mathrm{N}-\mathrm{A}$ vertical $(\perp \mathrm{LHR})(\mathrm{mm})$ & Altura maxila \\
$18-\mathrm{N}-\mathrm{Me}(\perp \mathrm{LHR})(\mathrm{mm})$ & Altura facial anterior total \\
$19-\mathrm{SN}-\mathrm{GoGn}\left({ }^{\circ}\right)$ & Ângulo do plano mandibular \\
$20-\mathrm{Po}-\mathrm{SN}\left({ }^{\circ}\right)$ & Ângulo do plano oclusal \\
$21-\mathrm{SGn}-\mathrm{SN}\left({ }^{\circ}\right)$ & Eixo Y de crescimento \\
$22-\mathrm{S}-\mathrm{Gn}(\mathrm{mm})$ & Comprimento eixo $\mathrm{Y}$ \\
$\perp$, perpendicular; // paralelo. & \\
\hline
\end{tabular}


Figura 4: Pontos cefalométricos e mensurações lineares de tecido duro: S, sela; N, Nasio; LHR, linha horizontal de referência (obtida $7^{\circ}$ a partir da linha S-N); LVR, linha vertical de referência (perpendicular a LHR, passando por S); A, subespinhal; lis, incisal do incisivo superior; lii, incisal do incisivo inferior; B, supra mentoniano e Pog, pogônio. As mensurações estão definidas na tabela 5.

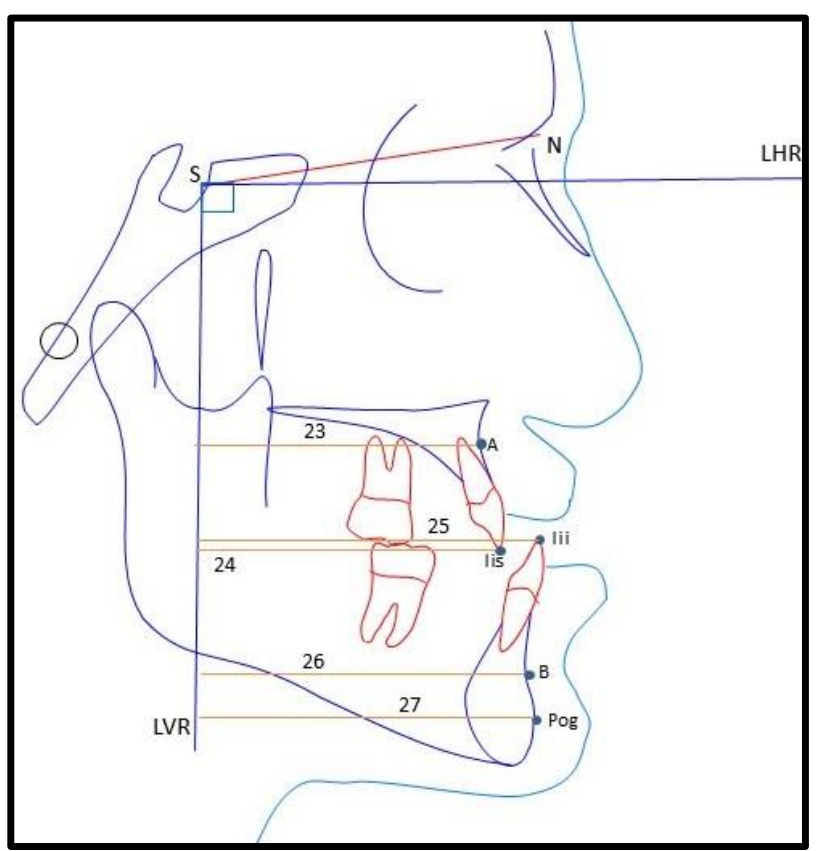

Tabela 5 - Definições das medidas de tecido duro da figura 4.

Medidas de tecido duro

Definições

LVR (linha vertical de referência) -Projeções tecido duro

\section{3- LVR-A (mm)}

24- LVR-lis (mm)

25- LVR-lii (mm)

26- LVR-B (mm)

27- LVR-Pog (mm)
Projeção sagital ponto $A$

Projeção sagital incisivo superior

Projeção sagital incisivo inferior

Projeção sagital ponto $B$

Projeção sagital ponto Pogônio

$\perp$, perpendicular; // paralelo. 
Figura 5: Pontos cefalométricos e mensurações lineares e angulares de tecido duro: S, sela; N, Nasio; Es, estômio superior ; lis, incisal do incisivo superior; lii, incisal do incisivo inferior; Go, gônio; Gn, gnátio. As mensurações estão definidas na tabela 6.

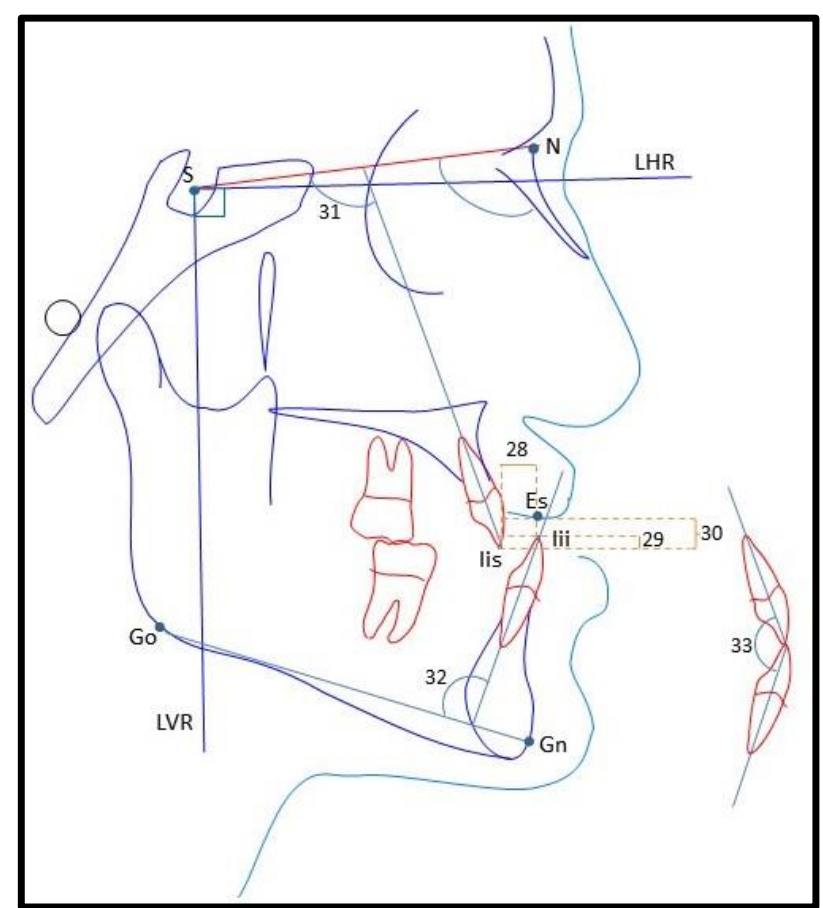

Tabela 6 - Definições das medidas de tecido duro da figura 5.

\section{Medidas de tecido duro}

\section{Definições}

Relações dentárias

28- lis-lii $(\perp$ LVR) $(\mathrm{mm})$

Trespasse Horizontal

29- lis-lii (// LVR) (mm)

Trespasse Vertical

30- Es-lis (// LVR) (mm)

Exposição incisivo superior

31- Is/SN $\left(^{\circ}\right)$

Inclinação incisivo superior

32- IMPA (li/GoGn) $\left(^{\circ}\right)$

Inclinação incisivo inferior

33- Is/li $\left(^{\circ}\right)$

Ângulo inter-incisivos

$\perp$, perpendicular; // paralelo. 
Figura 6: Pontos cefalométricos e mensurações lineares e angulares de tecido mole: S, sela; $\mathrm{N}$, Nasio; LHR, linha horizontal de referência (obtida $7^{\circ}$ a partir da linha S-N); LVR, linha vertical de referência (perpendicular a LHR, passando por S); N' násio tecido mole; G' glabela tecido mole; Pn, ponta nasal; Sn, sub-nasal; A,'subespinhal tecido mole; B', supramentoniano tecido mole; Pog', pogônio tecido mole e Me', mentoniano tecido mole. As mensurações estão definidas na tabela 7 .

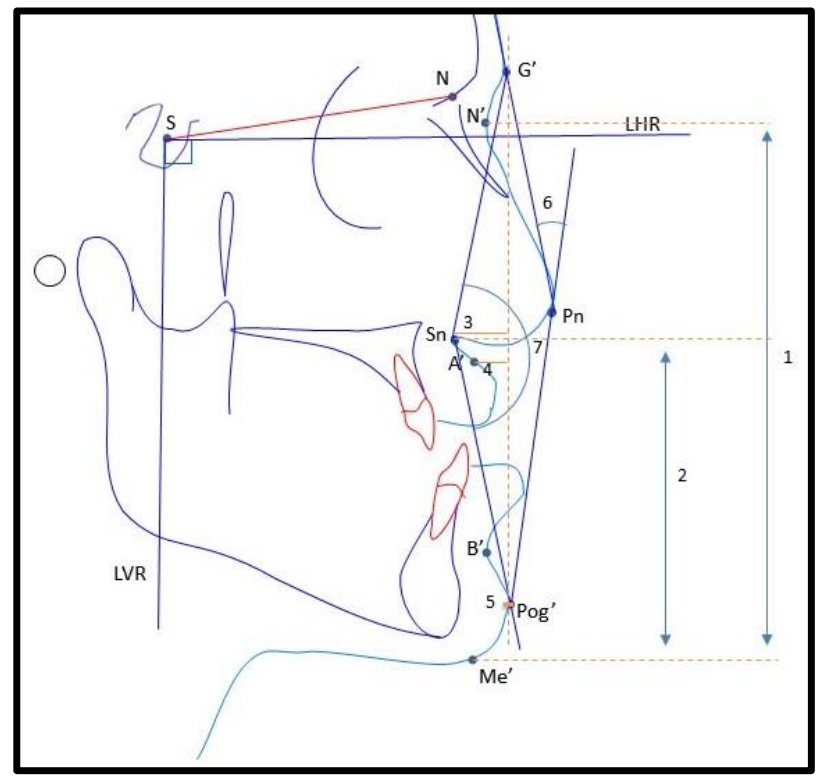

Tabela 7 - Definições das medidas de tecido mole da figura 6.

Medidas de tecido mole

Definições

Perfil facial e morfologia nasal

1- $\mathrm{Na}^{\prime}-\mathrm{Me}^{\prime}(\mathrm{mm})$

Altura facial

2- Sn-Me' (mm)

Terço inferior da face

3- G'-Sn (// LHR) (mm)

Proeminência Subnasal

4- G'-A' (// LHR) (mm)

Projeção tecido mole maxila

5- G'-Pog' (// LHR) (mm)

Projeção tecido mole mandíbula

6- G'-Pn-Pog' $\left({ }^{\circ}\right)$

Ângulo de convexidade facial total

7- G'-Sn-Pog' ( $\left.{ }^{\circ}\right)$

Ângulo de conexidade facial

$\perp$, perpendicular; // paralelo. 
Figura 7: Pontos cefalométricos e mensurações lineares e angulares de tecido mole: S, sela; N, Nasio; N' násio tecido mole; G' glabela tecido mole; Pn, ponta nasal; Sn, sub-nasal; A,'subespinhal tecido mole e B', supramentoniano tecido mole. As mensurações estão definidas na tabela 8.

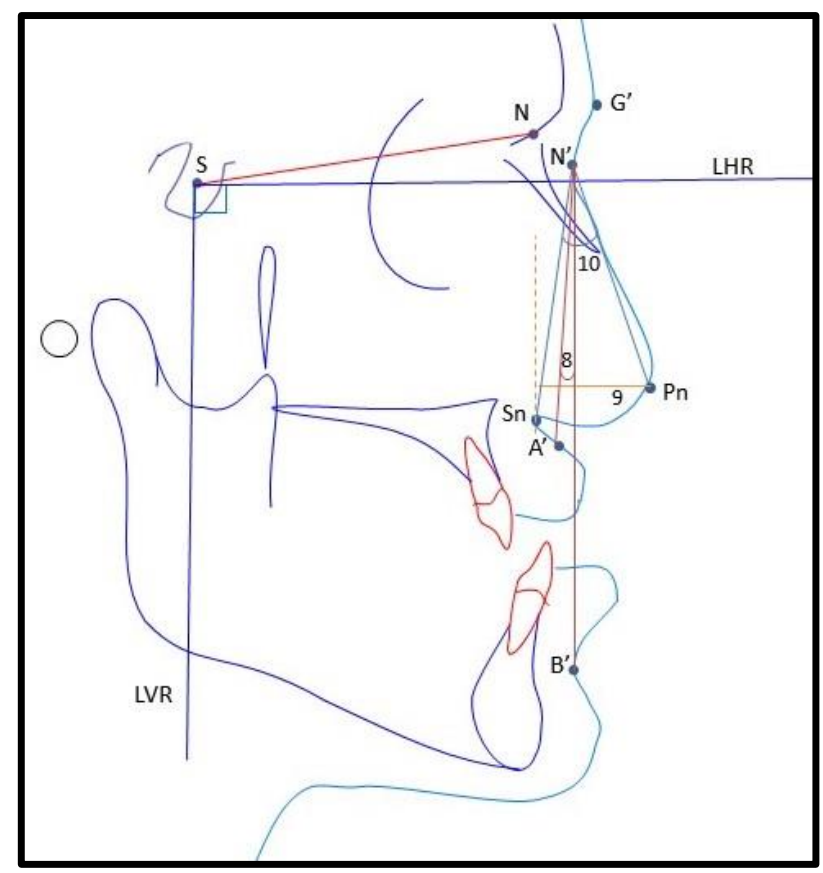

Tabela 8 - Definições das medidas de tecido mole da figura 7.

Medidas de tecido mole Definições

Perfil facial e morfologia nasal

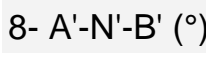

9- Sn-Pn (// LHR) (mm)

10- Pn-N'-Sn ( $\left.{ }^{\circ}\right)$
Relação sagital intermaxilar angular de tecido mole

Comprimento nasal

Ângulo nasal

$\perp$, perpendicular; // paralelo. 
Figura 8: Pontos cefalométricos e mensurações lineares de tecido mole: S, sela; N, Nasio; Sn, subnasal; A,'subespinhal tecido mole; Ls, lábio superior; Es, estômio superior; Ei, estômio inferior; Li, lábio inferior; B', supra mentoniano tecido mole; B e Pog', pogônio tecido mole. As mensurações estão definidas na tabela 9.

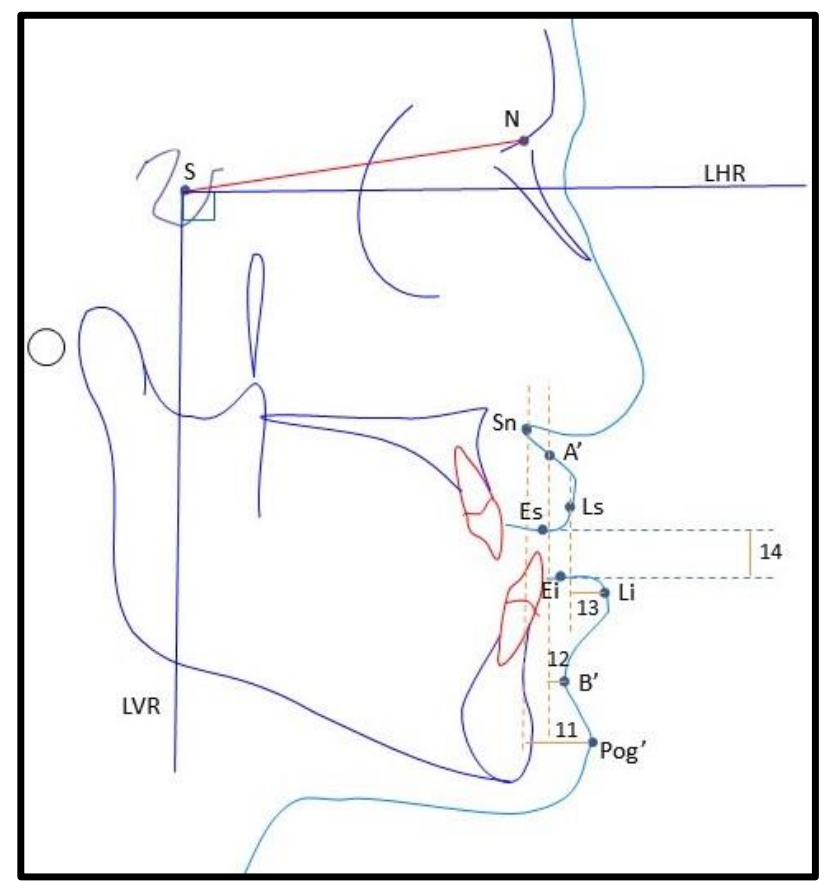

Tabela 9 - Definições das medidas de tecido mole da figura 8.

\section{Medidas de tecido mole}

Relação intermaxilar

11- Pog'-Sn (// LHR) (mm)

12- (A'-B') (// LHR) (mm)

13- Ls-Li (// LHR) (mm)

14- Es-Ei (// LVR)(mm)
Definições

Distância pogônio mole subnasal

Distância pontos A'-B'

Distância sagital lábios superior-inferior

Espaço interlabial

$\perp$, perpendicular; // paralelo. 
Figura 9: Pontos cefalométricos e mensurações lineares e angulares de tecido mole: S, sela; N, Nasio; Col, columela; Sn, sub-nasal; A,'subespinhal tecido mole; Ls, lábio superior; Es, estômio superior; Ei, estômio inferior; Li, lábio inferior; B', supra mentoniano tecido mole e Pog', pogônio tecido mole. As mensurações estão definidas na tabela 10.

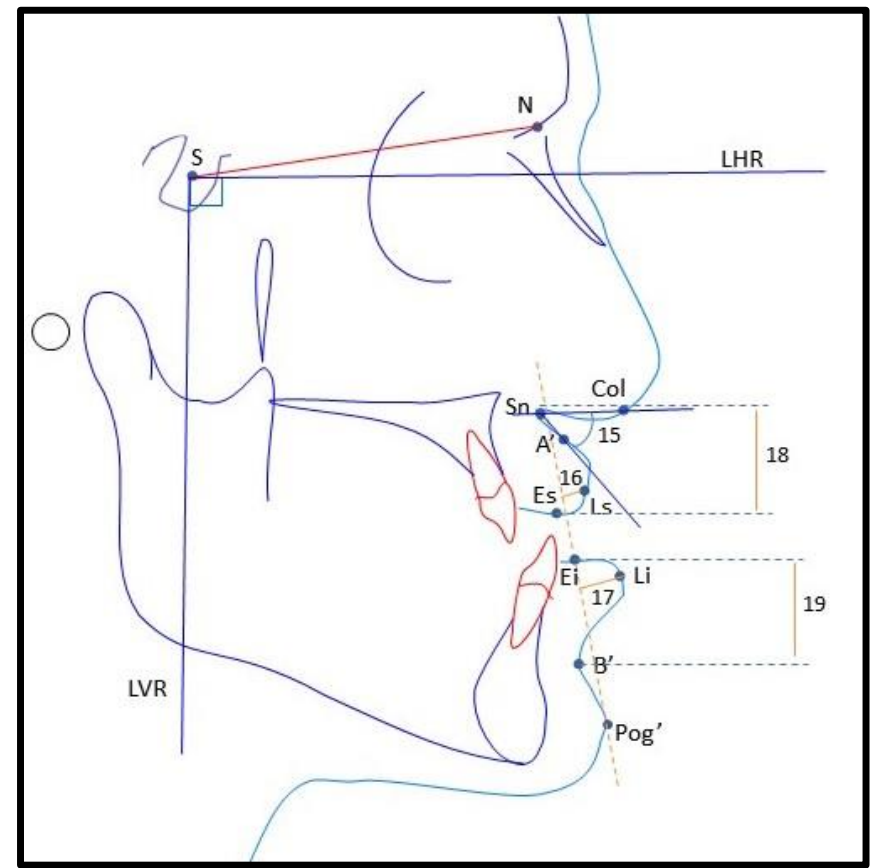

Tabela 10 - Definições das medidas de tecido mole da figura 9.

Medidas de tecido mole

Definições

Relação nasolabial e morfologia labial

15- Col-Sn-Ls $\left({ }^{\circ}\right)$

16- Ls-SnPog' (mm)

17- Li-SnPog' (mm)

18- Sn-Es $(\perp$ LHR) $(\mathrm{mm})$

19- B'-Ei ( $\perp$ LHR) $(\mathrm{mm})$
Ângulo nasolabial

Protusão do lábio superior

Protrusão do lábio inferior

Comprimento do lábio superior

Comprimento do lábio inferior

$\perp$, perpendicular; // paralelo. 
Figura 10: Pontos cefalométricos e mensurações lineares e angulares de tecido mole: S, sela; N, Nasio; Sn, subnasal; Ls, lábio superior; VIs, vestibular do lábio superior; Vli, vestibular do lábio inferior; Li, lábio inferior; B, supra mentoniano; B', supra mentoniano tecido mole; Pog, pogônio e Pog', pogônio tecido mole. As mensurações estão definidas na tabela 11.

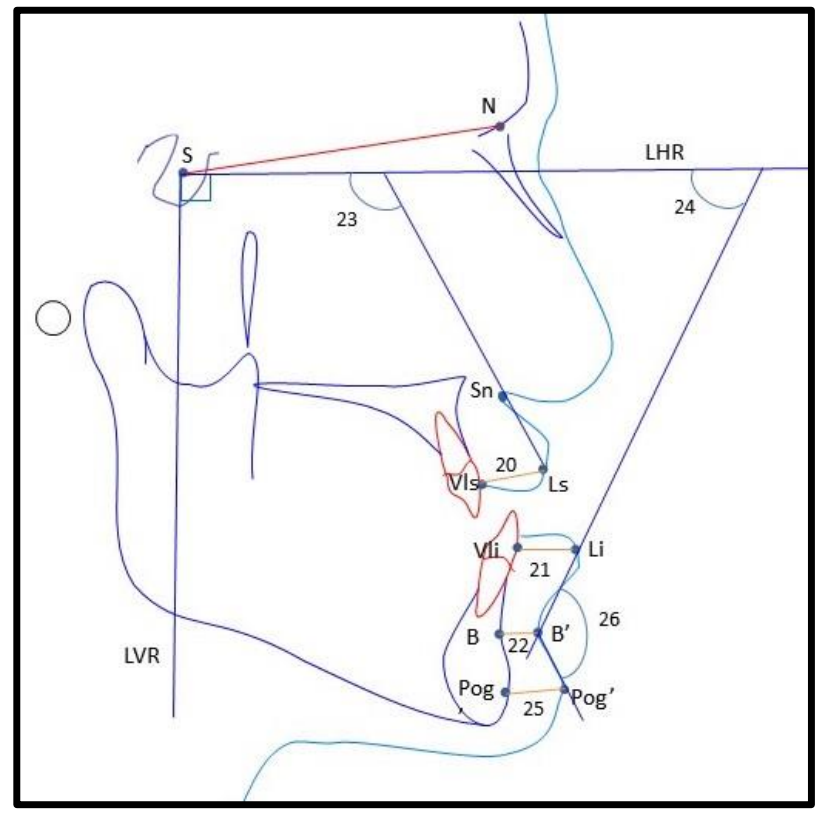

Tabela 11 - Definições das medidas de tecido mole da figura 10.

Medidas de tecido mole

Relação nasolabial e morfologia labial

20- VIs-Ls (mm)

21- Vli-li (mm)

22- B-B' (mm)

23- Ls-Sn/LHR $\left(^{\circ}\right)$

24- Li-B'/LHR $\left(^{\circ}\right)$

Morfologia do mento

25- Pog-Pog' (mm)

26- Li-B'-Pog' $\left(^{\circ}\right)$

$\perp$, perpendicular; // paralelo.

\section{Definições}

Espessura do lábio superior

Espessura do lábio inferior

Espessura da base do lábio inferior

Inclinação do lábio superior

Inclinação do lábio inferior

Espessura do mento

Ângulo mentolabial 
Figura 11: Pontos cefalométricos e mensurações lineares de tecido mole: S, sela; N, Nasio; Pn, ponta nasal; A' subespinhal tecido mole; Ls, lábio superior; Li, lábio inferior; B', supra mentoniano tecido mole e Pog', pogônio tecido mole. As mensurações estão definidas na tabela 12.

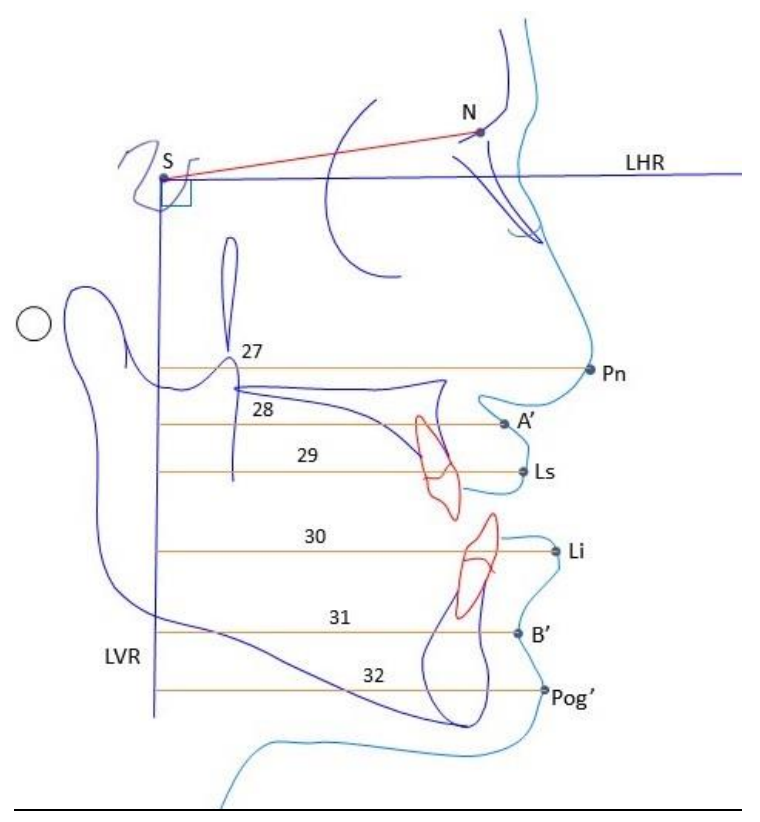

Tabela 12 - Definições das medidas de tecido mole da figura 11.

Medidas de tecido mole

LVR (linha vertical de referência) -Projeções tecido mole

27- LVR-Pn (mm)

28- LVR-A' (mm)

29- LVR-Ls (mm)

30- LVR-Li (mm)

31- LVR-B' (mm)

32- LVR-Pog' (mm)

$\perp$, perpendicular; // paralelo.

\section{Definições}

Projeção nasal sagital

Projeção sagital do ponto $A^{\prime}$

Projeção sagital do lábio superior

Projeção sagital do lábio inferior

Projeção sagital do ponto B'

Projeção sagital do mento

\subsection{Forma de análise dos resultados}




\subsubsection{Erro do método}

Para determinação do cálculo do erro do método intra-examinador, após um intervalo de 15 dias, $30 \%$ das radiografias foram selecionadas de maneira aleatória e tiveram os pontos novamente demarcados.

Para verificar a concordância intra-examinador foi usado o coeficiente de correlação intraclasse. Para verificar o nível do coeficiente de correlação intraclasse, foi usada seguinte pontuação: ICC $<0,40$ - concordância fraca, ICC de $0.4-0,75$ concordância moderada e ICC > 0,75 alta concordância.

O coeficiente de correlação intraclasse ficou situado entre 0,77 e 1,0 indicando um alto nível de concordância. ( Tabela 13- Apêndice A)

\subsubsection{Análise Estatística}

Os dados obtidos com o programa Dolphin Imaging foram inseridos em uma planilha do programa Microsoft Excel (Microsoft, Califórnia, Estados Unidos) para realização da análise estatística.

Utilizou-se o teste ANOVA de medidas repetidas, com um nível de significância de 0,05 para comparar os dados cefalométricos entre os grupos em T1, em T2 e entre a quantidade de movimentação cirúrgica obtida. Algumas medidas de interesse também foram submetidas ao coeficiente de correlação de Pearson.

Utilizou-se o programa Sigma Plot (Systat Software Inc., Califórnia, Estados Unidos) para todas as análises estatísticas. 


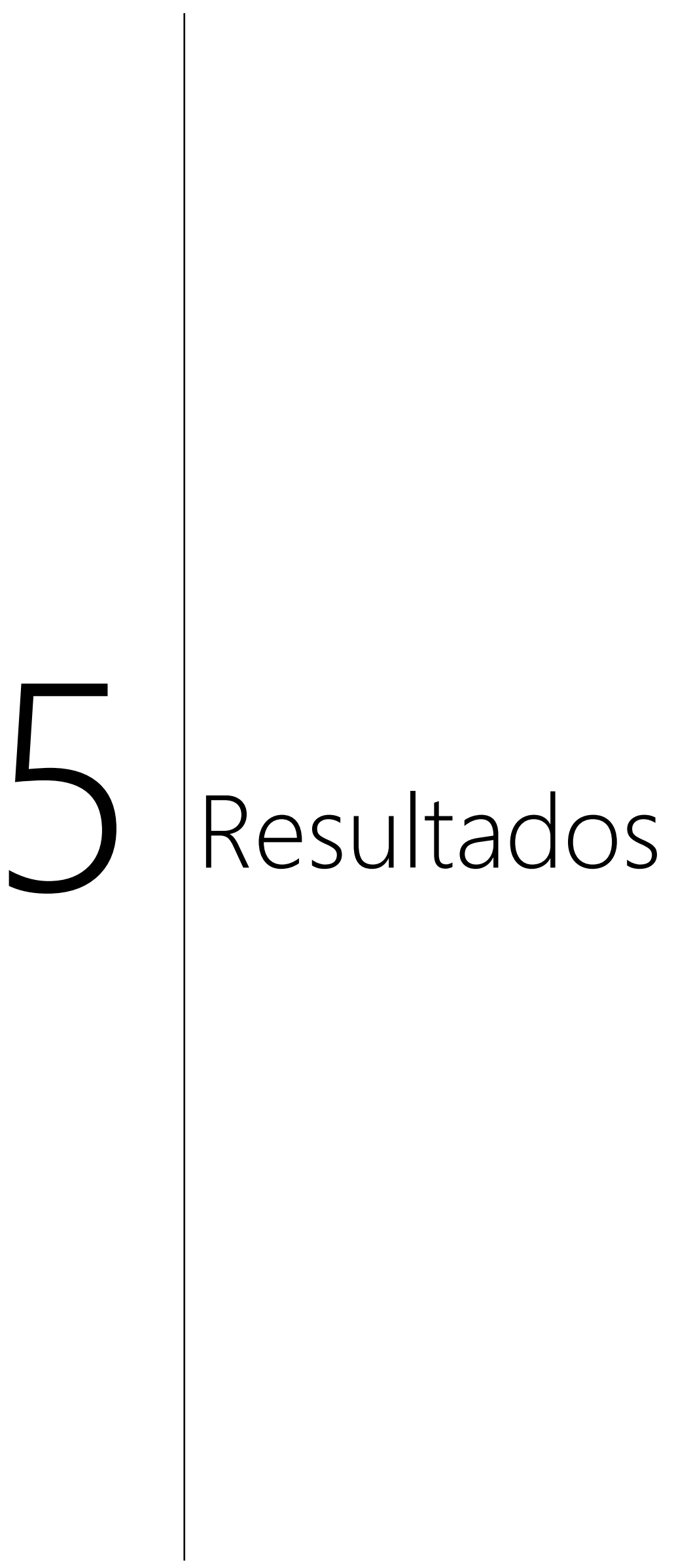





\section{RESULTADOS}

A comparação entre os grupos com relação a idade e sexo não mostrou diferenças com significância estatística, e estão apresentados na Tabela 1 (página 56)

Os indivíduos com fissura de lábio e palato (Grupo experimental) apresentaram, 6 meses após a cirurgia, uma média de 3,00 mm de avanço de maxila e 3,4mm de recuo de mandíbula. Nos indivíduos com fissura isolada de palato (Grupo controle) a média de avanço de maxila foi de $2,2 \mathrm{~mm}$ e a média de recuo mandibular foi de $5,4 \mathrm{~mm}$. As alterações em relação ao avanço de maxila e recuo de mandíbula apresentaram diferenças com significância estatística entre os grupos $(p<0,001)$.

\subsection{Diferenças de tecido duro e mole entre os grupos em T1 e em T2}

Os dois grupos apresentaram as estruturas de tecido duro com dimensões espaciais muito próximas, com exceção da medida N-A (dimensão vertical da maxila) que foi $3,5 \mathrm{~mm}(p=0,034)$ e $4,0 \mathrm{~mm}(p=0,016)$ maior nos indivíduos do grupo experimental em T1 e T2 respectivamente. Os indivíduos do grupo experimental apresentaram, portanto, uma maxila com um maior incremento vertical anterior tanto em T1 como em T2. Estas medidas estão em destaque na Tabela 14 (páginas $72 \mathrm{e}$ 73). A Figura 12 (página 74) mostra a sobreposição dos traçados médios dos grupos controle e experimental em T1 e a Figura 13 (página 75) a sobreposição dos traçados médios dos grupos controle e experimental em T2. 
Tabela 14. Tecido duro. Comparação inicial e final nos grupos experimental e controle:

(continua)

\begin{tabular}{|c|c|c|c|c|}
\hline Medidas de tecido duro & Tempo & $\begin{array}{l}\text { Experimental } \\
\text { (média) }\end{array}$ & $\begin{array}{l}\text { Controle } \\
\text { (média) }\end{array}$ & Valor de $p$ \\
\hline \multicolumn{5}{|l|}{ Base do Crânio } \\
\hline \multirow[t]{2}{*}{$\operatorname{SN}-\operatorname{Ar}\left({ }^{\circ}\right)$} & $\mathrm{T} 1$ & 128,88 & 130,95 & 0,240 \\
\hline & $\mathrm{T} 2$ & 128,83 & 132,13 & 0,240 \\
\hline \multirow[t]{2}{*}{$\mathrm{SN}(\mathrm{mm})$} & $\mathrm{T} 1$ & 65,02 & 64,08 & 0,352 \\
\hline & $\mathrm{T} 2$ & 65,00 & 64,01 & 0,352 \\
\hline \multirow[t]{2}{*}{$\mathrm{S}-\operatorname{Ar}(\mathrm{mm})$} & $\mathrm{T} 1$ & 29,22 & 27,68 & 0,101 \\
\hline & $\mathrm{T} 2$ & 29,42 & 27,99 & 0,101 \\
\hline \multicolumn{5}{|l|}{ Complexo Nasomaxilar } \\
\hline \multirow[t]{2}{*}{ SNA $\left(^{\circ}\right)$} & $\mathrm{T} 1$ & 74,58 & 75,01 & 0,768 \\
\hline & $\mathrm{T} 2$ & 78,07 & 78,83 & 0,598 \\
\hline \multirow[t]{2}{*}{ N-A Horizontal (// LHR) (mm) } & $\mathrm{T} 1$ & $-8,79$ & $-7,69$ & 0,471 \\
\hline & T2 & $-5,15$ & $-4,16$ & 0,518 \\
\hline \multirow[t]{2}{*}{ PoOr-NA $\left(^{\circ}\right)$} & $\mathrm{T} 1$ & 83,48 & 84,29 & 0,580 \\
\hline & $\mathrm{T} 2$ & 86,63 & 87,45 & 0,575 \\
\hline \multirow[t]{2}{*}{ Co-A (mm) } & T1 & 74,57 & 75,23 & 0,705 \\
\hline & $\mathrm{T} 2$ & 77,86 & 78,78 & 0,597 \\
\hline \multicolumn{5}{|l|}{ Morfologia e posição mandibular } \\
\hline \multirow[t]{2}{*}{$\operatorname{SNB}\left({ }^{\circ}\right)$} & $\mathrm{T} 1$ & 79,36 & 81,61 & 0,130 \\
\hline & $\mathrm{T} 2$ & 77,92 & 79,90 & 0,182 \\
\hline \multirow[t]{2}{*}{$\operatorname{Ar}-G_{0}(m m)$} & $\mathrm{T} 1$ & 49,79 & 50,83 & 0,594 \\
\hline & $\mathrm{T} 2$ & 49,94 & 49,07 & 0,654 \\
\hline \multirow[t]{2}{*}{ Go-Me (mm) } & $\mathrm{T} 1$ & 72,64 & 72,31 & 0,989 \\
\hline & $\mathrm{T} 2$ & 71,69 & 71,98 & 0,989 \\
\hline \multirow[t]{2}{*}{ Ar-Go-Me $\left({ }^{\circ}\right)$} & $\mathrm{T} 1$ & 133,20 & 137,46 & 0,066 \\
\hline & $\mathrm{T} 2$ & 130,30 & 134,78 & 0,053 \\
\hline \multirow[t]{2}{*}{ N-B (// LHR) (mm) } & $\mathrm{T} 1$ & $-6,35$ & $-2,19$ & 0,096 \\
\hline & $\mathrm{T} 2$ & $-8,47$ & $-5,05$ & 0,169 \\
\hline \multirow[t]{2}{*}{ N-Pg (// LHR) (mm) } & $\mathrm{T} 1$ & $-4,83$ & 0,63 & 0,096 \\
\hline & $\mathrm{T} 2$ & $-5,80$ & $-1,17$ & 0,096 \\
\hline \multirow[t]{2}{*}{ Co-Gn (mm) } & $\mathrm{T} 1$ & 119,75 & 123,61 & 0,177 \\
\hline & $\mathrm{T} 2$ & 117,45 & 120,41 & 0,299 \\
\hline \multicolumn{5}{|l|}{ Relação inter-maxilar } \\
\hline \multirow[t]{2}{*}{ ANB $\left(^{\circ}\right)$} & $\mathrm{T} 1$ & $-4,78$ & $-6,60$ & 0,113 \\
\hline & $\mathrm{T} 2$ & 0,16 & $-1,05$ & 0,285 \\
\hline \multirow[t]{2}{*}{ Wits (mm) } & $\mathrm{T} 1$ & $-8,32$ & $-10,73$ & 0,063 \\
\hline & $\mathrm{T} 2$ & $-1,01$ & $-3,23$ & 0,087 \\
\hline
\end{tabular}


Tabela 14. Tecido duro. Comparação inicial e final nos grupos experimental e controle:

(conclusão)

\begin{tabular}{|c|c|c|c|c|}
\hline Medidas de tecido duro & Tempo & $\begin{array}{l}\text { Experimental } \\
\text { (média) }\end{array}$ & $\begin{array}{l}\text { Controle } \\
\text { (média) }\end{array}$ & Valor de $p$ \\
\hline \multicolumn{5}{|l|}{ Dimensão vertical } \\
\hline \multirow[t]{2}{*}{$\mathrm{N}-\mathrm{A}$ vertical $(\perp \mathrm{LHR})(\mathrm{mm})$} & T1 & 59,32 & 55,79 & $0,034^{\star}$ \\
\hline & T2 & 59,28 & 55,23 & $0,016^{*}$ \\
\hline \multirow[t]{2}{*}{$\mathrm{N}-\mathrm{Me}(\perp \mathrm{LHR})(\mathrm{mm})$} & $\mathrm{T} 1$ & 117,46 & 115,15 & 0,418 \\
\hline & $\mathrm{T} 2$ & 115,99 & 111,97 & 0,160 \\
\hline \multirow[t]{2}{*}{ SN - GoGn $\left({ }^{\circ}\right)$} & $\mathrm{T} 1$ & 36,18 & 35,53 & 0,771 \\
\hline & $\mathrm{T} 2$ & 34,46 & 33,65 & 0,719 \\
\hline \multirow[t]{2}{*}{ Po- SN $\left({ }^{\circ}\right)$} & $\mathrm{T} 1$ & 16,00 & 15,08 & 0,646 \\
\hline & $\mathrm{T} 2$ & 14,13 & 13,90 & 0,908 \\
\hline \multirow[t]{2}{*}{ SGn-SN $\left(^{\circ}\right)$} & $\mathrm{T} 1$ & 69,74 & 67,30 & 0,125 \\
\hline & $\mathrm{T} 2$ & 69,77 & 67,18 & 0,125 \\
\hline \multirow[t]{2}{*}{ S-Gn (mm) } & $\mathrm{T} 1$ & 129,79 & 129,49 & 0,916 \\
\hline & $\mathrm{T} 2$ & 127,41 & 125,82 & 0,574 \\
\hline \multicolumn{5}{|c|}{$\begin{array}{l}\text { LVR (linha vertical de referência) - Projeções } \\
\text { TD }\end{array}$} \\
\hline \multirow[t]{2}{*}{ LVR-A (mm) } & $\mathrm{T} 1$ & 58,79 & 58,09 & 0,659 \\
\hline & T2 & 61,78 & 60,30 & 0,350 \\
\hline \multirow[t]{2}{*}{ LVR-lis (mm) } & $\mathrm{T} 1$ & 62,91 & 64,07 & 0,522 \\
\hline & $\mathrm{T} 2$ & 66,95 & 66,27 & 0,708 \\
\hline \multirow[t]{2}{*}{ LVR-lii (mm) } & $\mathrm{T} 1$ & 68,53 & 69,60 & 0,577 \\
\hline & $\mathrm{T} 2$ & 64,32 & 63,89 & 0,822 \\
\hline \multirow[t]{2}{*}{ LVR-B (mm) } & $\mathrm{T} 1$ & 63,62 & 65,68 & 0,345 \\
\hline & $\mathrm{T} 2$ & 60,23 & 60,25 & 0,994 \\
\hline \multirow[t]{2}{*}{ LVR-Pog (mm) } & $\mathrm{T} 1$ & 66,21 & 69,27 & 0,247 \\
\hline & $\mathrm{T} 2$ & 63,80 & 64,53 & 0,782 \\
\hline \multicolumn{5}{|l|}{ Relações dentárias } \\
\hline \multirow[t]{2}{*}{ lis-lii ( $\perp$ LVR) (mm) } & $\mathrm{T} 1$ & $-5,63$ & $-5,55$ & 0,920 \\
\hline & $\mathrm{T} 2$ & 2,64 & 2,39 & 0,747 \\
\hline \multirow[t]{2}{*}{ lis-lii (// LVR) (mm) } & $\mathrm{T} 1$ & $-0,47$ & $-0,86$ & 0,419 \\
\hline & $\mathrm{T} 2$ & 1,14 & 1,21 & 0,884 \\
\hline \multirow[t]{2}{*}{ Es-lis (// LVR) (mm) } & $\mathrm{T} 1$ & 2,79 & 3,49 & 0,305 \\
\hline & $\mathrm{T} 2$ & 1,32 & 1,83 & 0,455 \\
\hline \multirow[t]{2}{*}{ Is/SN $\left(^{\circ}\right)$} & $\mathrm{T} 1$ & 100,86 & 105,79 & 0,113 \\
\hline & T2 & 105,01 & 110,63 & 0,072 \\
\hline \multirow[t]{2}{*}{ IMPA (li/GoGn) $\left({ }^{\circ}\right)$} & $\mathrm{T} 1$ & 84,81 & 81,27 & 0,169 \\
\hline & $\mathrm{T} 2$ & 82,39 & 80,75 & 0,169 \\
\hline \multirow[t]{2}{*}{ Is/li $\left(^{\circ}\right)$} & $\mathrm{T} 1$ & 134,75 & 134,13 & 0,512 \\
\hline & $\mathrm{T} 2$ & 134,69 & 131,51 & 0,512 \\
\hline${ }^{*} P<0,05$ & & & & \\
\hline
\end{tabular}


Figura 12: Sobreposição dos traçados médios dos grupos controle (preto) e experimental (vermelho) em T1.

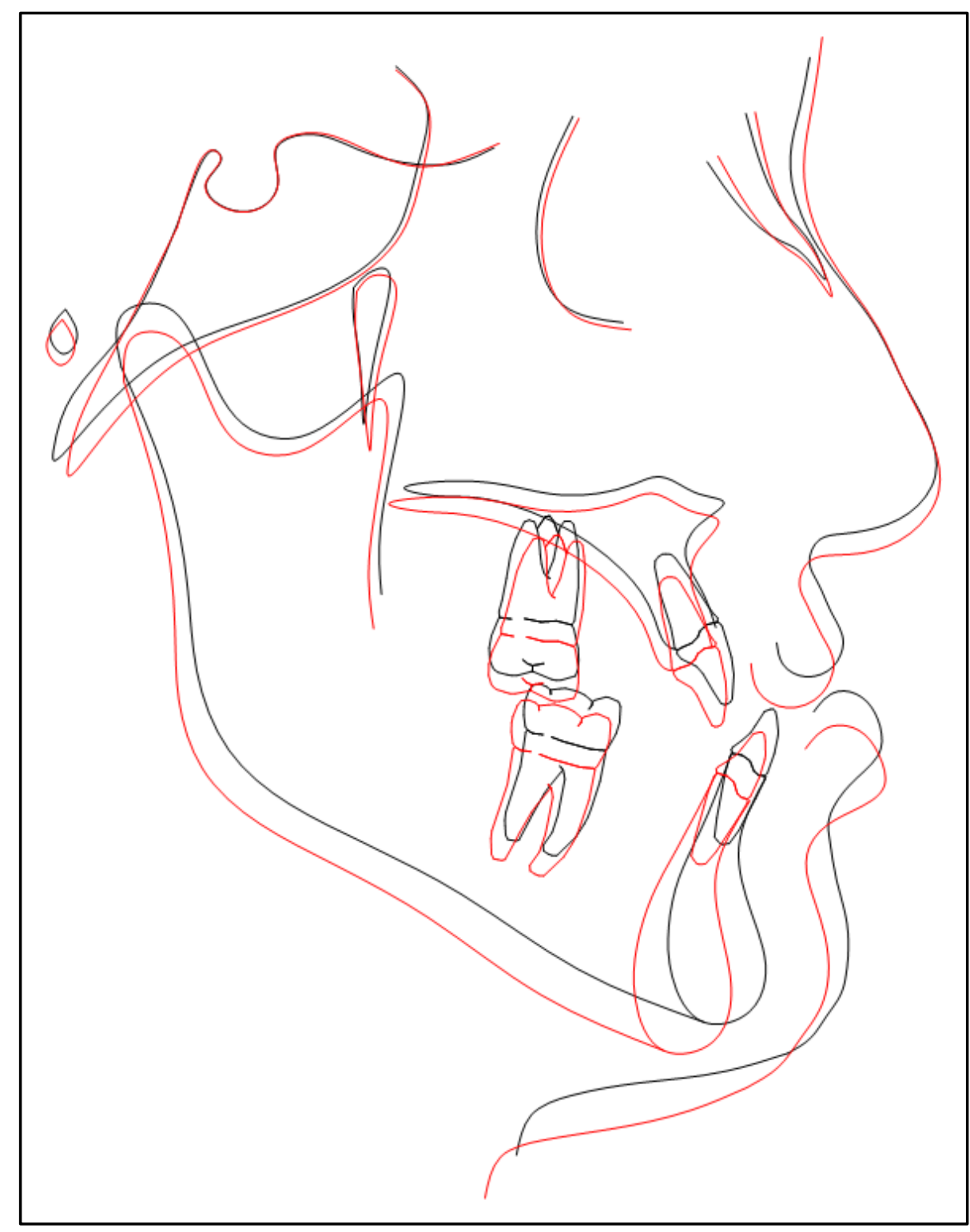


Figura 13: Sobreposição dos traçados médios dos grupos controle (preto) e experimental (vermelho) em T2.

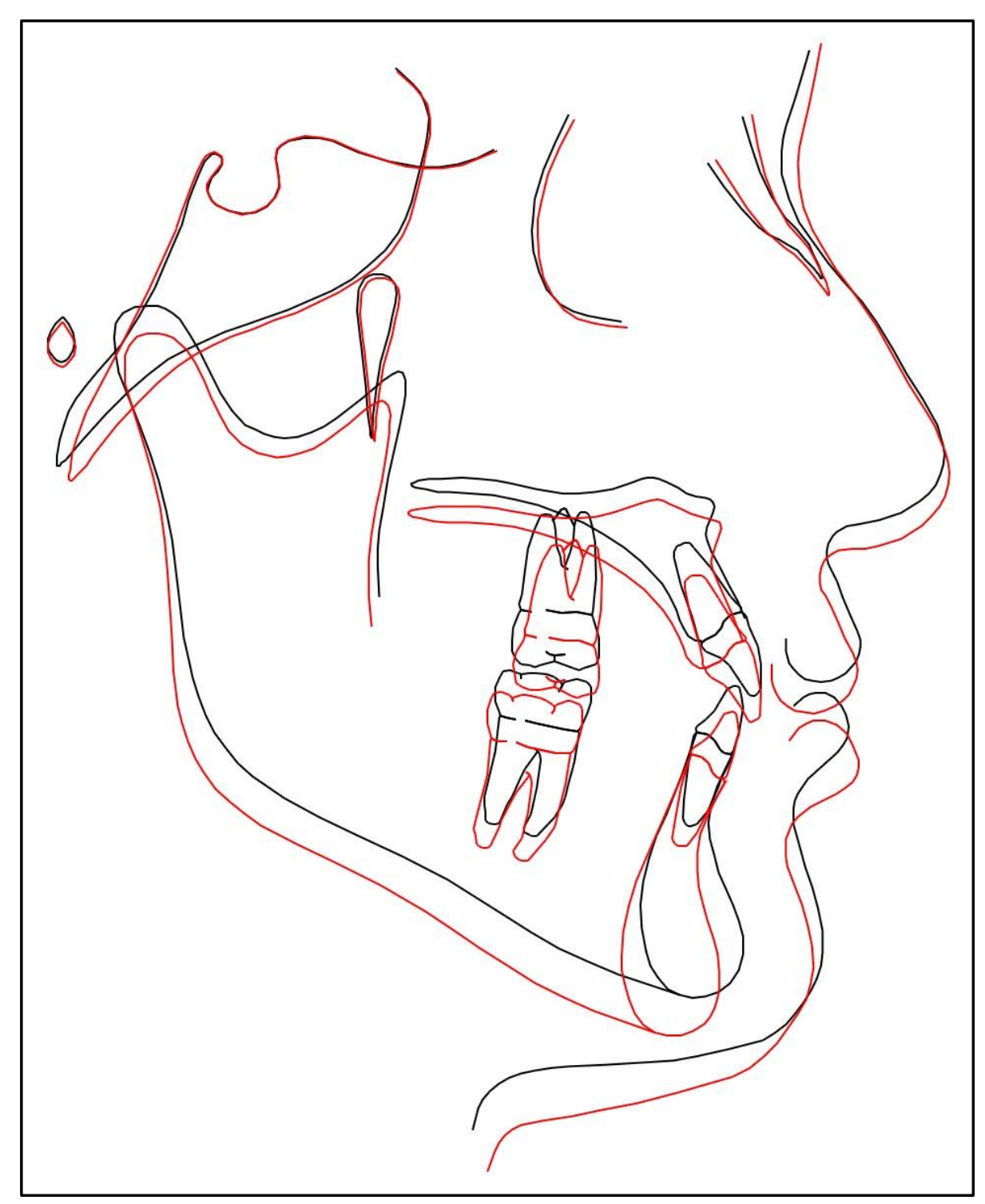

As diferenças de tecido mole encontradas entre os dois grupos em T1 e T2 foram em relação a proeminência subnasal, ao nariz, relação labial, lábio inferior e pogônio.

Em T2 os indivíduos do grupo experimental mostraram a proeminência subnasal, $G^{\prime}-S n 3,4 \mathrm{~mm}(p=0,025)$ menor do que nos indivíduos do grupo controle. 
A norma para essa medida na análise de Legan-Burstone(LEGAN; BURSTONE, 1980), é de $6,00 \mathrm{~mm}$. O grupo experimental atingiu a média de $-0,05 \mathrm{~mm}$ e o grupo controle a média de $3,35 \mathrm{~mm}$ em T2.

Os indivíduos do grupo experimental apresentaram a medida Comprimento nasal (Sn-Pn) $1,7 \mathrm{~mm} \quad(p=0,007)$ e $1,74 \mathrm{~mm} \quad(p=0,06)$ maior em T1 e T2 respectivamente.

A medida Distância sagital lábios superior-inferior (Ls-Li), era mais discrepante inicialmente em T1 no grupo experimental, $-7,13 \mathrm{~mm}(\mathrm{p}=0,00)$ do que no grupo controle, -4,55. A magnitude da correção foi similar nos dois grupos (do grupo experimental $=6,6 \mathrm{~mm}$ e grupo controle $=6,5 \mathrm{~mm}$ ), com isso, em T2, o grupo controle teve a relação entre os lábios normalizada, $1,96 \mathrm{~mm}$ (valor normativo= $1,8 \mathrm{~mm})(\mathrm{LEGAN}$; BURSTONE, 1980), enquanto que o grupo experimental ficou com uma medida bem abaixo do valor normativo (-0,53 mm). O grupo experimental, em T2, permaneceu com o lábio inferior a frente do superior.

Nos indivíduos do grupo experimental o lábio inferior se mostrou mais protruso (Li-SnPog') do que no grupo controle em T1, 2,25mm ( $p=0,005)$ e em T2, $2,56 \mathrm{~mm}(\mathrm{p}=0,002)$. Além da maior protrusão o lábio inferior dos indivíduos do grupo experimental também se mostrou mais espesso (Vli-Li) em T1, 2,4mm ( $p=0,029)$, e em $\mathrm{T} 2,2,2 \mathrm{~mm}(\mathrm{p}=0,045)$.

Com relação a medida Inclinação do lábio inferior (Li-B'/LHR) os indivíduos do grupo controle mostraram medidas maiores em T1, 13,5 $(p<0,001)$ e em T2, $12,2^{\circ}(p<0,001)$, assim como na medida Ângulo mentolabial ( $\mathrm{Li}^{-} \mathrm{B}^{\prime}-\mathrm{Pog}$ ) que foi maior para os indivíduos deste grupo em T1, 16,9 $(p<0,001)$ e em T2 13,0 $(p<0,001)$. Ângulos menores para essas medidas indicam lábio inferior evertido.

O lábio inferior, portanto, se mostrou mais protruso, espesso e evertido nos indivíduos do grupo experimental em T1 e em T2, com uma magnitude muito parecida.

O tecido mole na região do pogônio, (Pog-Pog') também foi mais espesso para os indivíduos do grupo experimental em T1, 2,7mm ( $p=0,03)$ e em T2, 2,2mm $(p=0,013)$. As medidas estão descritas na Tabela 15 (páginas 77 e 78). A Figura 12 (página 74) mostra a sobreposição dos traçados médios dos grupos controle e 
experimental em T1 e a Figura 13 (página 75), a sobreposição dos traçados médios dos grupos controle e experimental em T2.

Tabela15. Tecido mole. Comparação inicial e final nos grupos experimental e controle:

(continua)

\begin{tabular}{|c|c|c|c|c|}
\hline Medidas de tecido mole & Tempo & $\begin{array}{l}\text { Experimental } \\
\text { (média) }\end{array}$ & $\begin{array}{l}\text { Controle } \\
\text { (média) }\end{array}$ & Valor de $p$ \\
\hline \multicolumn{5}{|l|}{ Perfil facial e morfologia nasal } \\
\hline \multirow[t]{2}{*}{$\mathrm{Na}^{\prime}-\mathrm{Me}^{\prime}(\mathrm{mm})$} & T1 & 162,13 & 161,66 & 0,93 \\
\hline & T2 & 164,02 & 163,88 & 0,93 \\
\hline \multirow[t]{2}{*}{$S n^{\prime}-M_{e}^{\prime}(m m)$} & T1 & 131,46 & 132,25 & 0,57 \\
\hline & T2 & 133,46 & 135,29 & 0,57 \\
\hline \multirow[t]{2}{*}{ G'-Sn (mm) } & T1 & $-2,52$ & 0,13 & 0,08 \\
\hline & $\mathrm{T} 2$ & $-0,05$ & 3,35 & $0,025^{\star}$ \\
\hline \multirow[t]{2}{*}{$\mathrm{G}^{\prime}-\mathrm{A}^{\prime}(\perp \mathrm{LVR})(\mathrm{mm})$} & $\mathrm{T} 1$ & 1,65 & 4,20 & 0,05 \\
\hline & T2 & 3,92 & 4,81 & 0,49 \\
\hline \multirow[t]{2}{*}{ G'-Pog' ( $\perp$ LVR) $(\mathrm{mm})$} & T1 & 6,57 & 8,85 & 0,33 \\
\hline & T2 & 3,31 & 3,01 & 0,90 \\
\hline \multirow[t]{2}{*}{ G'-Pn-Pog' $\left(^{\circ}\right)$} & T1 & 27,12 & 28,09 & 0,66 \\
\hline & T2 & 31,50 & 32,87 & 0,54 \\
\hline \multirow[t]{2}{*}{ G'-Sn'-Pog' $\left(^{\circ}\right)$} & $\mathrm{T} 1$ & 184,20 & 181,19 & 0,29 \\
\hline & T2 & 177,51 & 173,64 & 0,17 \\
\hline \multirow[t]{2}{*}{$\mathrm{A}^{\prime}-\mathrm{N}^{\prime}-\mathrm{B}^{\prime}\left({ }^{\circ}\right)$} & $\mathrm{T} 1$ & 0,06 & 1,07 & 0,27 \\
\hline & T2 & 5,30 & 6,55 & 0,18 \\
\hline \multirow[t]{2}{*}{ Sn-Pn ( $\perp$ LVR) (mm) } & T1 & 18,58 & 16,87 & $0,007^{\star}$ \\
\hline & T2 & 17,80 & 16,07 & $0,006^{*}$ \\
\hline \multirow[t]{2}{*}{$\mathrm{Pn}-\mathrm{N}^{\prime}-\mathrm{Sn}\left({ }^{\circ}\right)$} & T1 & 22,04 & 20,26 & 0,08 \\
\hline & T2 & 20,90 & 19,11 & 0,08 \\
\hline \multicolumn{5}{|l|}{ Relação intermaxilar } \\
\hline \multirow[t]{2}{*}{ Pog'-Sn'( $\perp$ LVR) $(\mathrm{mm})$} & $\mathrm{T} 1$ & $-4,91$ & $-4,66$ & 0,91 \\
\hline & T2 & $-0,14$ & 1,67 & 0,40 \\
\hline \multirow[t]{2}{*}{$\left(\mathrm{A}^{\prime}-\mathrm{B}^{\prime}\right)(\perp \mathrm{LVR})(\mathrm{mm})$} & T1 & $-1,47$ & $-1,95$ & 0,71 \\
\hline & T2 & 4,74 & 5,47 & 0,57 \\
\hline \multirow[t]{2}{*}{ Ls-Li ( $\perp$ LVR) (mm) } & T1 & $-7,13$ & $-4,55$ & $0, \mathbf{0 0 3}^{*}$ \\
\hline & T2 & $-0,53$ & 1,96 & $0,005^{\star}$ \\
\hline \multirow[t]{2}{*}{ Es-Ei (// LVR)(mm) } & T1 & 2,55 & 1,95 & 0,28 \\
\hline & T2 & 1,05 & 1,45 & 0,48 \\
\hline
\end{tabular}


Tabela15. Tecido mole. Comparação inicial e final nos grupos experimental e controle:

\begin{tabular}{|c|c|c|c|c|}
\hline Medidas de tecido mole & Tempo & $\begin{array}{l}\text { Experimental } \\
\text { (média) }\end{array}$ & $\begin{array}{l}\text { Controle } \\
\text { (média) }\end{array}$ & Valor de $\mathrm{p}$ \\
\hline \multicolumn{5}{|c|}{ Relação nasolabial e morfologia labial } \\
\hline \multirow[t]{2}{*}{ Col-Sn-UL $\left(^{\circ}\right)$} & $\mathrm{T} 1$ & 91,60 & 92,65 & 0,82 \\
\hline & $\mathrm{T} 2$ & 92,39 & 99,09 & 0,15 \\
\hline \multirow[t]{2}{*}{ Ls-SnPog' (mm) } & $\mathrm{T} 1$ & 2,56 & 2,84 & 0,72 \\
\hline & $\mathrm{T} 2$ & 4,26 & 3,88 & 0,63 \\
\hline \multirow[t]{2}{*}{ Li-SnPog' (mm) } & $\mathrm{T} 1$ & 8,41 & 6,16 & $0,005^{\star}$ \\
\hline & $\mathrm{T} 2$ & 4,90 & 2,34 & $0,002^{*}$ \\
\hline \multirow[t]{2}{*}{ Sn-Es $(\perp$ Po-Or $)(m m)$} & $\mathrm{T} 1$ & 18,84 & 18,08 & 0,46 \\
\hline & $\mathrm{T} 2$ & 20,28 & 19,81 & 0,65 \\
\hline \multirow[t]{2}{*}{ B'-Ei ( $\perp$ Po-Or) (mm) } & $\mathrm{T} 1$ & 20,28 & 20,92 & 0,52 \\
\hline & $\mathrm{T} 2$ & 17,37 & 18,45 & 0,28 \\
\hline \multirow[t]{2}{*}{ VIs-Ls (mm) } & $\mathrm{T} 1$ & 14,15 & 14,79 & 0,43 \\
\hline & $\mathrm{T} 2$ & 12,76 & 12,88 & 0,89 \\
\hline \multirow[t]{2}{*}{ Vli-Li (mm) } & $\mathrm{T} 1$ & 22,63 & 20,24 & $0,029^{*}$ \\
\hline & $\mathrm{T} 2$ & 14,99 & 12,81 & $0,045^{\star}$ \\
\hline \multirow[t]{2}{*}{ B-B' (mm) } & $\mathrm{T} 1$ & 11,80 & 11,71 & 0,49 \\
\hline & $\mathrm{T} 2$ & 11,58 & 10,99 & 0,49 \\
\hline \multirow[t]{2}{*}{ Ls-Sn/Po-Or $\left({ }^{\circ}\right)$} & $\mathrm{T} 1$ & 104,25 & 105,49 & 0,90 \\
\hline & $\mathrm{T} 2$ & 105,26 & 103,09 & 0,90 \\
\hline \multirow[t]{2}{*}{ Li-B'/Po-Or) $\left({ }^{\circ}\right)$} & $\mathrm{T} 1$ & 46,08 & 59,54 & $<0,001^{\star}$ \\
\hline & T2 & 46,56 & 58,71 & $<0,001^{\star}$ \\
\hline \multicolumn{5}{|l|}{ Morfologia do mento } \\
\hline \multirow[t]{2}{*}{$\mathrm{Pg}-\mathrm{Pg}^{\prime}(\mathrm{mm})$} & $\mathrm{T} 1$ & 13,27 & 10,59 & $0,01^{*}$ \\
\hline & $\mathrm{T} 2$ & 12,53 & 10,36 & $0,013^{*}$ \\
\hline \multirow[t]{2}{*}{ Li-B'-Pog' $\left({ }^{\circ}\right)$} & $\mathrm{T} 1$ & 124,56 & 141,45 & $<0,001^{*}$ \\
\hline & $\mathrm{T} 2$ & 123,18 & 136,14 & $<0,001^{*}$ \\
\hline \multicolumn{5}{|l|}{$\begin{array}{l}\text { LVR (linha vertical de referência) - } \\
\text { Projeções tecido mole }\end{array}$} \\
\hline \multirow[t]{2}{*}{ LVR-Pn (mm) } & $\mathrm{T} 1$ & 89,16 & 89,18 & 0,99 \\
\hline & $\mathrm{T} 2$ & 90,36 & 89,70 & 0,68 \\
\hline \multirow[t]{2}{*}{ LVR-A' (mm) } & $\mathrm{T} 1$ & 73,38 & 74,94 & 0,37 \\
\hline & $\mathrm{T} 2$ & 76,21 & 76,41 & 0,91 \\
\hline \multirow[t]{2}{*}{ LVR-Ls (mm) } & $\mathrm{T} 1$ & 77,08 & 78,71 & 0,41 \\
\hline & $\mathrm{T} 2$ & 79,80 & 79,64 & 0,94 \\
\hline \multirow[t]{2}{*}{ LVR-Li (mm) } & $\mathrm{T} 1$ & 84,22 & 83,26 & 0,65 \\
\hline & $\mathrm{T} 2$ & 80,31 & 77,68 & 0,21 \\
\hline \multirow[t]{2}{*}{ LVR-B' (mm) } & $\mathrm{T} 1$ & 74,86 & 76,90 & 0,35 \\
\hline & $\mathrm{T} 2$ & 71,47 & 70,94 & 0,81 \\
\hline \multirow[t]{2}{*}{ LVR-Pog' (mm) } & $\mathrm{T} 1$ & 78,31 & 79,59 & 0,62 \\
\hline & $\mathrm{T} 2$ & 75,62 & 74,63 & 0,70 \\
\hline${ }^{*} P<0,05$ & & & & \\
\hline
\end{tabular}




\subsection{Alterações do tecido duro e mole do grupo experimental T1xT2}

Todas as medidas relacionadas ao Complexo naso-maxilar sofreram alterações significativas $(p<0,001)$ : ângulo SNA aumentou $3,49^{\circ}$, Posição anteroposterior da maxila $\mathrm{N}-\mathrm{A}$ diminuiu $3,6 \mathrm{~mm}$, ângulo Profundidade Maxilar aumentou $3,15^{\circ}$ e Comprimento da maxila (Co-A) aumentou 3,3mm.

Algumas medidas relacionadas à Morfologia e posição mandibular sofreram alterações, os ângulos SNB, com diminuição de $1,45^{\circ}(p=0,001)$ e o Ângulo Goníaco com diminuição de 2,9 $(p<0,001)$. A medida N-B diminuiu 2,13mm ( $p=0,017)$ e o Comprimento da mandíbula (Co-Gn) diminuiu 2,3mm ( $p=0,006)$.

A Relação Inter-Maxilar representada pelas medidas ANB e Wits apresentaram alterações $(p<0,001)$. O ângulo ANB passou de $-4,78^{\circ}$ para $0,16^{\circ}$ e a discrepância da medida Wits passou de $-8,32 \mathrm{~mm}$ para $-1,01 \mathrm{~mm}$.

Com relação a Dimensão Vertical, a altura facial total anterior (N-Me) diminuiu $1,5 \mathrm{~mm}(\mathrm{p}=0,05)$, o ângulo do plano mandibular com a base do crânio (SNGoGn) diminuiu $1,72^{\circ}(p=0,004)$ e o ângulo do plano oclusal com a base do crânio ( Po-SN) diminuiu $1,87^{\circ}(p=0,028)$. Já a medida linear do eixo $Y(S-G n)$ diminuiu $2,4 \mathrm{~mm}$ $(p<0,001)$.

As medidas das projeções sagitais em relação a linha vertical de referência (LVR-Projeções tecido duro), tiveram as seguintes alterações: medida da projeção sagital do ponto $A$ (LVR-A) aumentou $2,99 \mathrm{~mm}(p<0,001)$, medida da projeção sagital dos incisivos superiores (LVR- lis) aumentou $4 \mathrm{~mm}(p<0,001)$, medida da da projeção sagital dos incisivos inferiores (LVR-lii) diminuiu 4,2mm $(p<0,001)$ e a medida da da projeção sagital do ponto $B(L V R-B)$ diminuiu $3,4 \mathrm{~mm}(p=0,003)$.

As Relações dentárias também sofreram alterações, o trespasse horizontal (lis-lii $(\perp$ LVR) ) diminuiu $8,3 \mathrm{~mm}(\mathrm{p}<0,001)$, o trespasse vertical (lis-lii (// LVR) aumentou $1,61 \mathrm{~mm}(\mathrm{p}<0,001)$, a exposição do incisivo superior (Es-lis (//LVR)) diminuiu $1,47 \mathrm{~mm}(p<0,001)$ e a inclinação do incisivo superior em relação a base do crânio (Is/SN) aumentou $4,15^{\circ}(p=0,004)$

O tecido mole também apresentou uma mudança significativa no grupo experimental de T1 para T2. 
Em relação às medidas do_Perfil facial e morfologia nasal, a medida Proeminência subnasal ( $G$ '-Sn) foi 2,5mm projetada para anterior $(p<0,001)$.

A medida Projeção tecido mole maxila ( $\left.G^{\prime}-A^{\prime}\right)$ aumentou 2,3mm $(p<0,001)$ e a medida Projeção tecido mole mandíbula ( $\left.G^{\prime}-P^{\prime} g^{\prime}\right)$ diminuiu $3,26 \mathrm{~mm}(p=0,002)$.

O ângulo da medida da convexidade facial total (G'-Pn-Pog') aumentou, $4,4^{\circ}(p<0,001)$ e o ângulo da medida da convexidade facial (G'-Sn'-Pog') diminuiu 6,7 $(p<0,001)$. O ângulo $A^{\prime}-N^{\prime}-B^{\prime}$ aumentou $5,24^{\circ}(p<0,001)$. A medida do Comprimento do nariz $(\mathrm{Sn}-\mathrm{Pn})$ diminuiu $0,78 \mathrm{~mm}(\mathrm{p}<0,001)$ e o Ângulo nasal $\left(\mathrm{Pn}-\mathrm{N}^{\prime}-\mathrm{Sn}\right)$, diminuiu $1,15^{\circ}(\mathrm{p}=0,001)$

Todas as medidas referentes a Relação intermaxilar sofreram alterações significantes $(p<0,001)$, a distância pogônio mole-subnasal (Pog'-Sn'), passou de 4,91 mm para $-0,14 \mathrm{~mm}$, a distância entre os pontos $A^{\prime}-B^{\prime}$ ( $\left(A^{\prime}-B^{\prime}\right)$ passou de $-1,47 \mathrm{~mm}$ para $4,74 \mathrm{~mm}$ e a Distância sagital dos lábios superior e inferior (Ls-Li) passou de 7,3mm para -0,53mm. Já o Espaço interlabial (Es-Ei) diminuiu 1,5mm.

Algumas medidas referentes a Relação nasolabial e morfologia labial sofreram alterações, todas com $p<0,001$. A medida Protrusão do lábio superior (LsSnPog') aumentou 1,71 mm, a medida Protrusão do lábio inferior (Li-SnPog') diminuiu $3,5 \mathrm{~mm}$, a medida Comprimento do lábio superior (Sn-Es) aumentou $1,44 \mathrm{~mm}$, a medida comprimento do lábio inferior (B'-Ei) diminuiu 2,91 mm.

As medidas Espessura do lábio superior (Vls-Ls) e Espessura do lábio inferior (Li-lii) diminuíram 1,39mm e 7,64 mm respectivamente.

A Morfologia do mento foi alterada apenas com relação a medida Espessura do mento (Pog-Pog'), que diminuiu 0,737mm ( $p=0,036)$.

Todas as medidas referentes a projeção em relação a linha vertical de referência (LVR-Projeções tecido mole) sofreram alterações.

A Projeção nasal (LVR-Pn) aumentou 1,2mm ( $p<0,001)$, a Projeção do ponto A' (LVR-A') aumentou 2,83mm ( $p<0,001)$, a Projeção do lábio superior (LVR-Ls) aumentou $2,72 \mathrm{~mm}(p<0,001)$. Já as medidas relacionadas a mandíbula diminuíram, houve um recuo do lábio inferior (LVR-Li) de $3,91 \mathrm{~mm} \quad(p<0,001)$, do ponto $B$ (LVR-B) de $3,39 \mathrm{~mm}(p=0,003)$ e do pogônio mole (LVR-Pg') de $2,69 \mathrm{~mm}(p=0,021)$. As medidas 
estão nas Tabelas 16(Apêndice B) e 17 (Apêndice C) e são representadas na Figura 14 (página 81).

Figura 14: Sobreposição dos traçados médios do grupo experimental em T1 (preto) e T2 (vermelho)

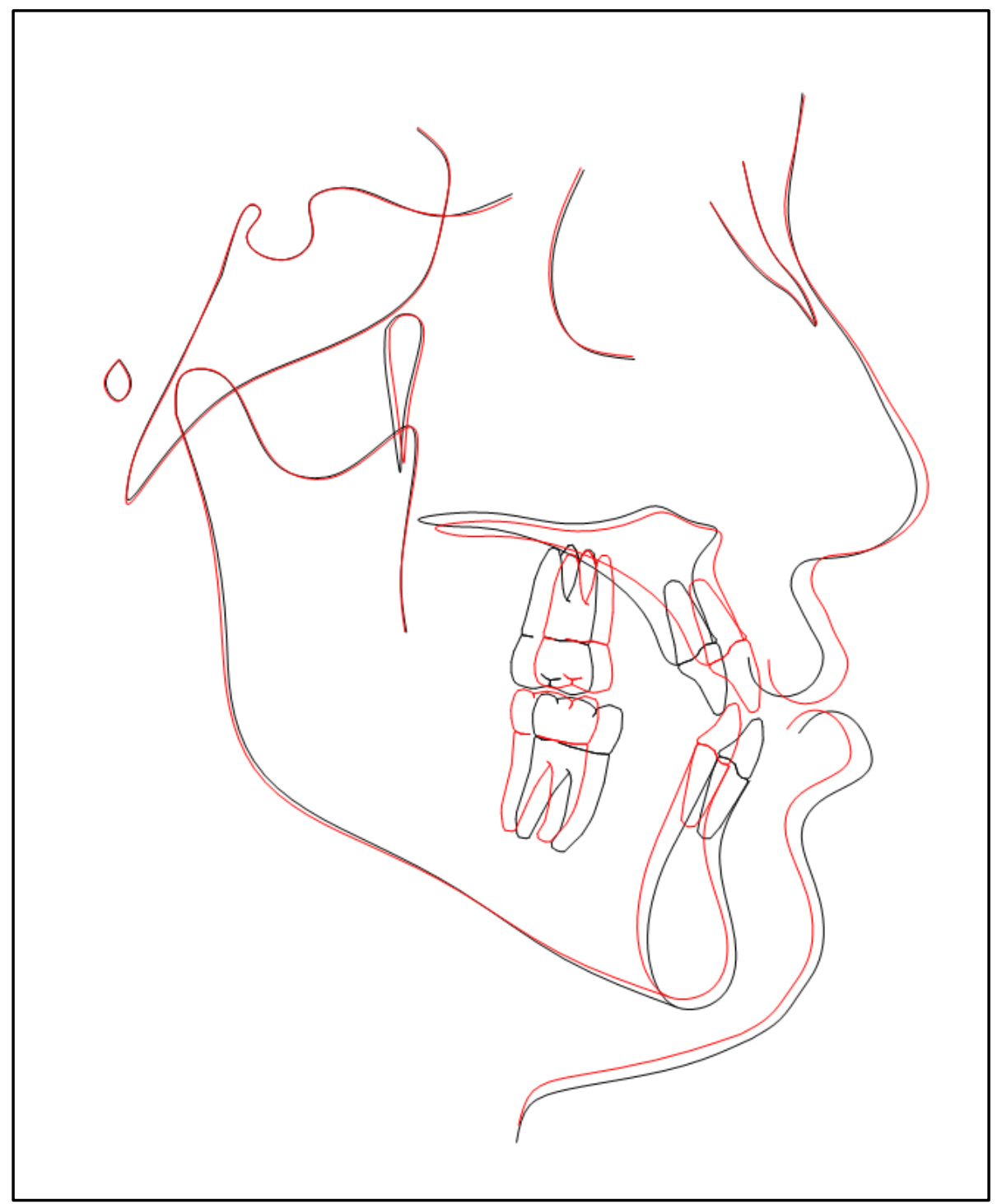

5.3 Alterações do tecido duro e mole do grupo controle T1xT2

Todas as medidas relacionadas ao Complexo naso-maxilar sofreram alterações significativas $(p<0,001)$ : ângulo SNA aumentou $3,83^{\circ}$, Posição 
ânteroposterior da maxila $\mathrm{N}-\mathrm{A}$ diminuiu $3,53 \mathrm{~mm}$, ângulo Profundidade Maxilar aumentou $3,16^{\circ}$ e Comprimento da maxila (Co-A) aumentou $3,55 \mathrm{~mm}$.

A maioria das medidas relacionadas à Morfologia e posição mandibular sofreram alterações, o ângulo SNB, diminuiu $1,71^{\circ}(p=0,022)$, a altura do ramo mandibular (Ar-Go) diminuiu 1,77mm ( $p=0,025)$ e o Ângulo Goníaco diminuiu de 2,70 $(p<0,016)$. A medida Posição anteroposterior da mandíbula (N-B) diminuiu 2,86mm $(p=0,022)$ e o Comprimento da mandíbula (Co-Gn) diminuiu $3,2 \mathrm{~mm}(p=0,006)$.

A Relação Inter-Maxilar representada pelas medidas ANB e Wits apresentou alterações $(p<0,001)$. $O$ ângulo ANB passou de $-6,60^{\circ}$ para $-1,05^{\circ}$ e a discrepância da medida Wits passou de $-10,73 \mathrm{~mm}$ para $-3,23 \mathrm{~mm}$.

As medidas referentes à Dimensão Vertical apresentaram as seguintes alterações: Altura facial anterior total $(\mathrm{N}-\mathrm{Me})$ diminuiu $3,19 \mathrm{~mm}(\mathrm{p}<0,001)$ e o Ângulo do plano mandibular com a base do crânio ( $S N-G o G n)$ diminuiu $1,88^{\circ}(p=0,024)$. Já a medida Comprimento do eixo Y (S-Gn) diminuiu 3,67mm ( $p<0,001)$.

Todas as medidas das projeções sagitais em relação a linha vertical de referência (LVR-Projeções tecido duro) tiveram alterações: medida Projeção sagital do ponto A (LVR-A) aumentou $2,21 \mathrm{~mm}(\mathrm{p}=0,006)$, medida Projeção sagital do incisivo superior (LVR-lis) aumentou 2,2mm $(p=0,028)$, medida Projeção sagital do incisivo inferior (LVR-lii) diminuiu $5,71 \mathrm{~mm}$ ( $p<0,001)$, a medida Projeção sagital do ponto $B$ (LVR-B) diminuiu 5,43mm $(p<0,001)$ e a medida Projeção sagital do ponto pogônio (LVR-Pog) diminuiu $4,75 \mathrm{~mm}(\mathrm{p}=0,008)$.

As alterações nas Relações dentárias foram as seguintes: o trespasse horizontal (lis-lii) diminuiu 7,94mm ( $<<0,001)$, o trespasse vertical (lis-lii // LVR) aumentou $2,07 \mathrm{~mm} \quad(p<0,001)$, a exposição do incisivo superior (Es-lis) diminuiu $1,66 \mathrm{~mm}(p=0,003)$ e a inclinação do incisivo superior em relação a base do crânio (Is/SN) aumentou $4,83^{\circ}(p=0,014)$

O grupo controle também apresentou uma grande diferença nas medidas de tecido mole de T1 para T2.

Em relação às medidas do Perfil facial e morfologia nasal, a medida Proeminência subnasal $\left(G^{\prime}-S n\right)$ foi $3,21 \mathrm{~mm}$ projetada para anterior $(p<0,001)$. 
O ponto Pog' apresentou um recuo em relação a Glabela' (G'-Pog') de $5,84 \mathrm{~mm}(\mathrm{p}=0,0013)$.

O ângulo da medida da Convexidade facial total aumentou, G'-Pn-Pog', $4,78^{\circ}$ ( $\left.p<0,001\right)$ e o ângulo da medida da Convexidade facial diminuiu G'-Sn'-Pog', $7,55^{\circ}$ ( $\left.p<0,001\right)$. O ângulo $A^{\prime}-N^{\prime}-B^{\prime}$ aumentou, $5,48^{\circ} \quad(p<0,001)$. A medida do Comprimento do nariz $(\mathrm{Sn}-\mathrm{Pn})$ diminuiu $0,81 \mathrm{~mm}(\mathrm{p}=0,011)$ e o Ângulo nasal $\left(\mathrm{Pn}-\mathrm{N}^{\prime}\right.$ Sn) diminuiu $1,15^{\circ}(p=0,016)$

As medidas referentes a Análise intermaxilar sofreram alterações significantes, a medida Distância pogônio mole-subnasal (Pog'-Sn') passou de $4,66 \mathrm{~mm}$ para $1,67 \mathrm{~mm}$, a medida Distância entre os pontos $A^{\prime}-B$ ( $\left(A^{\prime}-B^{\prime}\right)$ passou de $1,95 \mathrm{~mm}$ para $5,47 \mathrm{~mm}$ e a medida Distância sagital dos lábios superior e inferior (LsLi) passou de $-4,55$ para $1,96 \mathrm{~mm}$.

A maioria das medidas referentes a Relação nasolabial e morfologia labial sofreram alterações.

O Ângulo nasolabial (Col-Sn-Ls) aumentou 6,44 $(\mathrm{p}=0008)$, a Protrusão do lábio superior (Ls-SnPog') aumentou 1,04mm ( $p=0,009)$, a Protrusão do lábio inferior (Li-SnPog') diminuiu 3,82mm ( $p<0,001)$.

As medidas Comprimento do lábio superior (Sn-Es) e Comprimento do lábio inferior ( $\left.B^{\prime}-E i\right)$ diminuíram $(p<0,001)$ respectivamente $1,73 \mathrm{~mm}$ e $2,47 \mathrm{~mm}$.

As medidas Espessura do lábio superior (Vls-Ls) e Espessura do lábio inferior (Li-lii) também diminuíram $(p<0,001)$, respectivamente, $1,91 \mathrm{~mm}$ e 7,43mm.

Algumas medidas referentes a Projeção em relação a linha vertical de referência, LVR-Projeções tecido mole sofreram alterações.

A Projeção sagital do ponto A' (LVR-A') aumentou 1,47mm ( $p=0,039)$, a Projeção sagital do lábio inferior (LVR-Li) recuou $5,58 \mathrm{~mm}(p<0,001)$, a projeção sagital do ponto B'(LVR-B') recuou $5,96 \mathrm{~mm}(p<0,001)$ e a Projeção sagital do mento (LVRPog') recuou 4,96mm ( $p=0,003$ ). As medidas estão nas Tabelas 18 (Apêndice $D$ ) e 19 (Apêndice E) e são representadas na Figura 15 (página 84). 
Figura 15: Sobreposição dos traçados médios do grupo controle em T1 (preto) e T2 (vermelho)

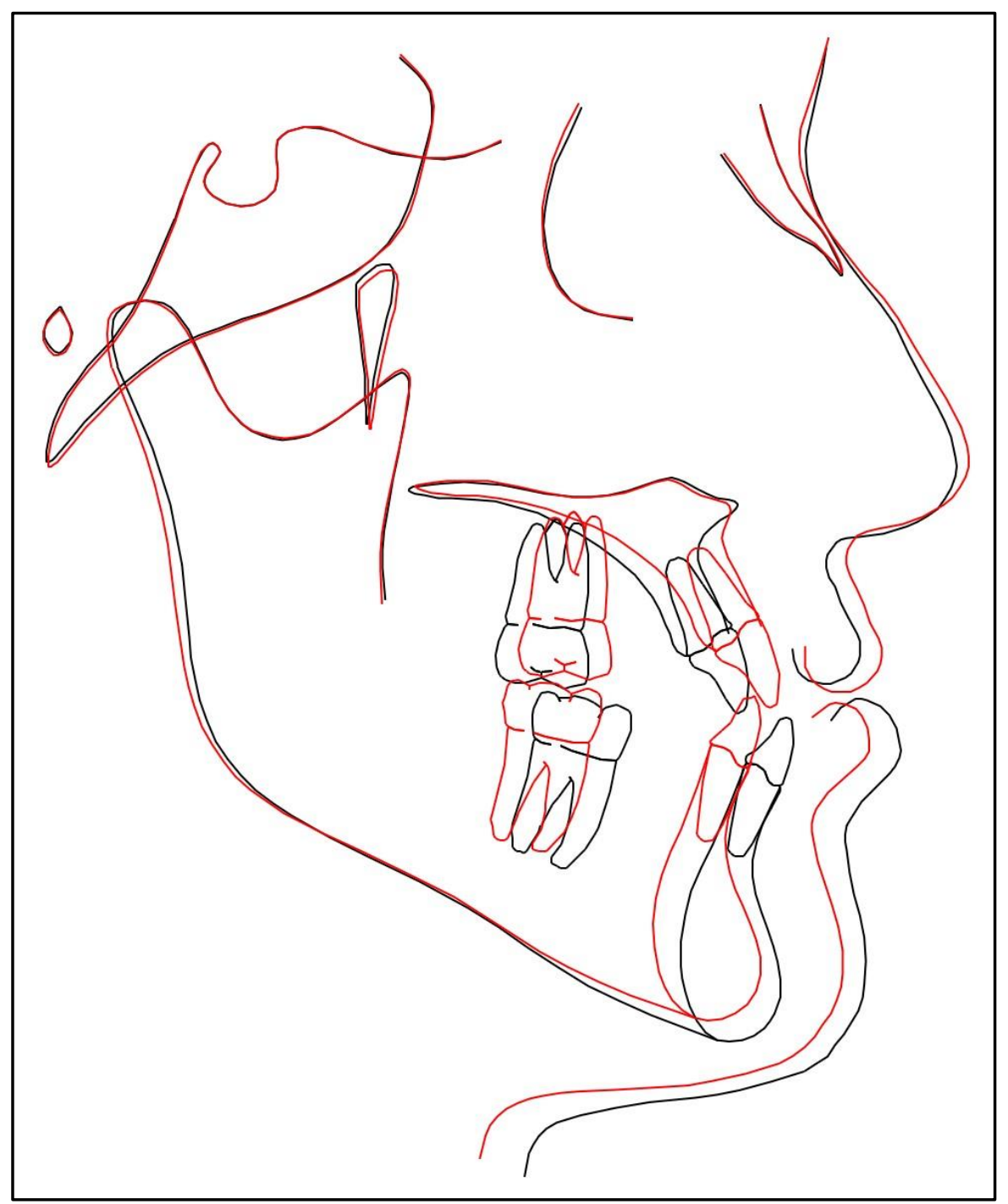

\subsection{Comparação entre as alterações de tecido duro e mole ocorridas nos grupos} experimental e controle

Os efeitos da cirurgia ortognática no tecido duro foram muito parecidos nos dois grupos. A maioria das medidas mostraram diferenças com significância estatística, porém, sem relevância clínica, visto que foram menores do que $1 \mathrm{~mm}$ ou $2^{\circ}$. As medidas com diferenças estatisticamente e clinicamente significantes serão descritas abaixo e estão em destaque na Tabela 20 (páginas 85 e 86).

Em relação a Dimensão vertical, as medidas Altura facial anterior total ( $\mathrm{N}$ Me) e Comprimento do eixo $Y(S-G n)$ apresentaram diferenças com relevância 
estatística $(p<0,001)$ e relevância clínica. O grupo controle apresentou uma diminuição de $1,72 \mathrm{~mm}$ maior para N-Me e $1,29 \mathrm{~mm}$ maior para S-Gn.

As projeções em relação a linha vertical de referência (LVR-Projeções tecido duro) apresentaram diferenças com relevância estatística, a medida Projeção sagital do incisivo superior, LVR-Is $(p<0,001)$ apresentou um avanço $1,84 \mathrm{~mm}$ maior para o grupo experimental.

As medidas Projeção sagital do incisivo inferior, LVR-Ili ( $p<0,001)$, Projeção sagital do ponto $B$, LVR-B $(p<0,001)$ e Projeção sagital do pogônio LVR-Pog $(p=0,001)$ apresentaram recuos, $1,5 \mathrm{~mm}, 2,0 \mathrm{~mm}$ e $2,34 \mathrm{~mm}$ respectivamente maiores no grupo controle.

Tabela 20. Diferença entre as alterações de tecido duro entre os grupos experimental e controle.

(continua)

\begin{tabular}{|c|c|c|c|}
\hline \multirow[b]{2}{*}{ Medidas de tecido duro } & \multicolumn{3}{|c|}{ Diferença T2-T1 } \\
\hline & Experimental & Controle & Valor de $p$ \\
\hline \multicolumn{4}{|l|}{ Base do Crânio } \\
\hline $\mathrm{SN}-\operatorname{Ar}\left(^{\circ}\right)$ & $-0,05$ & 1,18 & 0,383 \\
\hline $\mathrm{SN}(\mathrm{mm})$ & $-0,02$ & $-0,07$ & 0,832 \\
\hline S-Ar (mm) & 0,19 & 0,31 & 0,873 \\
\hline \multicolumn{4}{|l|}{ Complexo Nasomaxilar } \\
\hline SNA $\left({ }^{\circ}\right)$ & 3,49 & 3,827 & $<0,001^{*}$ \\
\hline N-A Horizontal (// LHR) (mm) & 3,64 & 3,527 & $<0,001^{*}$ \\
\hline PoOr-NA $\left({ }^{\circ}\right)$ & 3,15 & 3,16 & $<0,001^{\star}$ \\
\hline Co-A (mm) & 3,287 & 3,547 & $<0,001^{*}$ \\
\hline \multicolumn{4}{|l|}{ Morfologia e posição mandibular } \\
\hline $\operatorname{SNB}\left({ }^{\circ}\right)$ & 1,443 & 1,713 & $0,001^{*}$ \\
\hline Ar-Go (mm) & 0,153 & 1,767 & 0,09 \\
\hline Go-Me (mm) & $-0,95$ & $-0,33$ & 0,618 \\
\hline $\operatorname{Ar}-\mathrm{Go}-\mathrm{Me}\left({ }^{\circ}\right)$ & 2,9 & 2,68 & $<0,001^{*}$ \\
\hline N-B (// LHR) (mm) & 2,127 & 2,86 & $0,002^{\star}$ \\
\hline $\mathrm{N}-\mathrm{Pg}(/ / \mathrm{LHR})(\mathrm{mm})$ & $-0,97$ & $-1,80$ & 0,63 \\
\hline Co-Gn (mm) & 2,297 & 3,2 & $<0,001^{*}$ \\
\hline \multicolumn{4}{|l|}{ Relação inter-maxilar } \\
\hline ANB $\left(^{\circ}\right)$ & 4,947 & 5,547 & $<0,001^{\star}$ \\
\hline Wits (mm) & 7,31 & 7,507 & $<0,001^{*}$ \\
\hline
\end{tabular}


Tabela 20. Diferença entre as alterações de tecido duro entre os grupos experimental e controle.

(conclusão)

\begin{tabular}{|c|c|c|c|}
\hline \multirow[b]{2}{*}{ Medidas de tecido duro } & \multicolumn{3}{|c|}{ Diferença T2-T1 } \\
\hline & Experimental & Controle & Valor de $p$ \\
\hline \multicolumn{4}{|l|}{ Dimensão vertical } \\
\hline $\mathrm{N}-\mathrm{A}$ vertical $(\perp \mathrm{LHR})(\mathrm{mm})$ & 0,04 & 0,56 & 0,475 \\
\hline $\mathrm{N}-\mathrm{Me}(\perp \mathrm{LHR})(\mathrm{mm})$ & 1,47 & 3,187 & $<0,001^{*}$ \\
\hline SN - GoGn $\left(^{\circ}\right)$ & 1,72 & 1,873 & $<0,001^{*}$ \\
\hline Po- SN $\left(^{\circ}\right)$ & 1,867 & 1,18 & $0,037^{*}$ \\
\hline SGn-SN $\left(^{\circ}\right)$ & 0,04 & $-0,12$ & 0,852 \\
\hline S-Gn (mm) & 2,383 & 3,673 & $<0,001^{*}$ \\
\hline \multicolumn{4}{|c|}{$\begin{array}{l}\text { LVR (linha vertical de referência)-Projeções } \\
\text { tecido duro }\end{array}$} \\
\hline LVR-A (mm) & 2,99 & 2,207 & $<0,001^{*}$ \\
\hline LVR-lis (mm) & 4,037 & 2,2 & $<0,001^{*}$ \\
\hline LVR-lii (mm) & 4,217 & 5,713 & $<0,001^{*}$ \\
\hline LVR-B (mm) & 3,387 & 5,433 & $<0,001^{*}$ \\
\hline LVR-Pog (mm) & 2,41 & 4,747 & $0,001^{*}$ \\
\hline \multicolumn{4}{|l|}{ Relações dentárias } \\
\hline lis-lii $(\perp$ LVR) $(\mathrm{mm})$ & 8,277 & 7,94 & $<0,001^{\star}$ \\
\hline lis-lii (// LVR) (mm) & 1,607 & 2,067 & $<0,001^{*}$ \\
\hline Es-lis (// LVR) (mm) & 1,47 & 1,66 & $<0,001^{*}$ \\
\hline Is/SN $\left(^{\circ}\right)$ & 4,15 & 4,833 & $<0,001^{\star}$ \\
\hline IMPA (li/GoGn) $\left(^{\circ}\right)$ & $-2,41$ & $-0,52$ & 0,251 \\
\hline Is/li $\left(^{\circ}\right)$ & $-0,06$ & $-2,62$ & 0,314 \\
\hline${ }^{*} P<0,05$ & & & \\
\hline
\end{tabular}

Com relação ao tecido mole, a cirurgia ortognática provocou mais alterações com diferenças significativas entre os grupos experimental e controle. As medidas com diferenças estatisticamente e/ou clinicamente significantes serão descritas abaixo e estão em destaque na Tabela 21 (páginas 88 e 89).

Com relação às medidas do Perfil facial e morfologia nasal, ocorreram alterações com relevância estatística na comparação entre as medidas Projeção tecido mole maxila, $G^{\prime}-A^{\prime}(p=0,008)$ e Projeção tecido mole mandíbula G'$\operatorname{Pog}^{\prime}(p<0,001)$, com implicações clínicas. A medida referente a projeção de tecido mole maxila ( $\left(G^{\prime}-A^{\prime}\right)$ teve um avanço $1,66 \mathrm{~mm}$ maior no grupo experimental, enquanto a medida projeção tecido mole mandíbula (G'-Pog') teve um recuo $2,58 \mathrm{~mm}$ maior no grupo controle. Em T2 essas medidas ficaram similares. 
Duas medidas do conjunto Relação intermaxilar apresentaram alterações estatisticamente $(p<0,001)$ e clinicamente significativas. Foram as medidas Distância pogônio mole-subnasal (Pog'-Sn') e Distância dos pontos A' e B' (A'-B'), sendo que o grupo controle apresentou uma amplitude maior de correção tanto para Pog'-Sn' , $1,56 \mathrm{~mm}$, como para A'-B' $, 1,21 \mathrm{~mm}$.

Medidas da Relação nasolabial e morfologia labial que apresentaram alterações foram o Ângulo nasolabial (Col-Sn-Ls), com alterações com significância estatística $(p=0,015)$ e com relevância clínica. No grupo controle essa medida demonstrou uma alteração $5,66^{\circ}$ maior.

A medida Inclinação do lábio superior (Ls-Sn/Po-Or), não apresentou relevância estatística $(p=0,216)$, porém, clinicamente a diferença foi de $3,41^{\circ}$. Enquanto o grupo experimental a medida aumentou $1,01^{\circ}$ no grupo controle ela diminuiu $2,40^{\circ}$.

As alterações ocorridas na medida Ângulo mentolabial (Li-B'-Pog') não apresentaram diferença estatística $(0,072)$, porém, clinicamente, no grupo controle a redução foi $3,92^{\circ}$ maior.

Medidas relacionadas a linha vertical de referência (LVR-Projeções tecido mole) apresentaram alterações com significância estatística $(p<0,001)$ e relevância clínica.

O grupo experimental mostrou alterações diferentes para as medidas Projeção do ponto A' (LVR-A') e Projeção lábio superior (LVR-Ls) que foram mais projetados para anterior $1,36 \mathrm{~mm}$ e $1,78 \mathrm{~mm}$ respectivamente.

Já o grupo controle apresentou um maior recuo para as medidas Projeção lábio inferior (LVR-Li), 1,67 mm, Projeção do ponto B' (LVR-B'), 2,57 mm e Projeção do mento (LVR-Pog'), 2,27 mm. 
Tabela 21- Diferença entre as alterações de tecido mole entre os grupos experimental e controle.

(continua)

\begin{tabular}{|c|c|c|c|}
\hline \multirow[b]{2}{*}{ Medidas de tecido mole } & \multicolumn{3}{|c|}{ Diferença T2-T1 } \\
\hline & Experimental & Controle & Valor de $p$ \\
\hline \multicolumn{4}{|l|}{ Perfil facial e morfologia nasal } \\
\hline $\mathrm{Na}^{\prime}-\mathrm{Me}^{\prime}(\mathrm{mm})$ & 1,89 & 2,22 & 0,926 \\
\hline Sn'-Me' (mm) & 2 & 3,12 & 0,786 \\
\hline G'-Sn (mm) & 2,477 & 3,213 & $<0,001^{\star}$ \\
\hline $\mathrm{G}^{\prime}-\mathrm{A}^{\prime}(\perp \mathrm{LVR})(\mathrm{mm})$ & 2,27 & 0,613 & $0,008^{*}$ \\
\hline 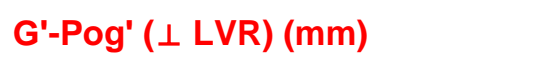 & 3,257 & 5,84 & $<0,001^{*}$ \\
\hline 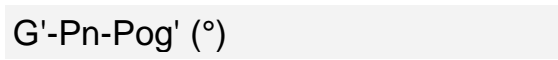 & 4,377 & 4,78 & $<0,001^{*}$ \\
\hline G'-Sn'-Pog' $\left({ }^{\circ}\right)$ & 6,693 & 7,547 & $<0,001^{*}$ \\
\hline$A^{\prime}-N^{\prime}-B^{\prime}\left({ }^{\circ}\right)$ & 5,243 & 5,48 & $<0,001^{*}$ \\
\hline Sn-Pn $(\perp$ LVR) $(\mathrm{mm})$ & 0,777 & 0,807 & $<0,001^{*}$ \\
\hline Pn-N'-Sn $\left({ }^{\circ}\right)$ & 1,147 & 1,153 & $<0,001^{\star}$ \\
\hline \multicolumn{4}{|l|}{ Relação intermaxilar } \\
\hline Pog'-Sn' ( $\perp$ LVR) (mm) & 4,77 & 6,333 & $<0,001^{*}$ \\
\hline$\left(A^{\prime}-B^{\prime}\right)(\perp L V R)(m m)$ & 6,213 & 7,427 & $<0,001^{*}$ \\
\hline Ls-Li ( $\perp$ LVR) $(\mathrm{mm})$ & 6,607 & 6,513 & $<0,001^{*}$ \\
\hline Es-Ei (// LVR)(mm) & 1,497 & 0,507 & $0,007^{*}$ \\
\hline \multicolumn{4}{|l|}{ Relação nasolabial e morfologia labial } \\
\hline Col-Sn-UL $\left(^{\circ}\right)$ & 0,783 & 6,44 & $0,015^{\star}$ \\
\hline Ls-SnPog' (mm) & 1,707 & 1,04 & $<0,001^{*}$ \\
\hline Li-SnPog' (mm) & 3,513 & 3,82 & $<0,001^{*}$ \\
\hline Sn-Es $(\perp$ Po-Or $)(\mathrm{mm})$ & 1,443 & 1,733 & $<0,001^{*}$ \\
\hline B'-Ei ( $(\perp$ Po-Or) $(m m)$ & 2,907 & 2,467 & $<0,001^{*}$ \\
\hline Vls-Ls (mm) & 1,387 & 1,913 & $<0,001^{*}$ \\
\hline Vli-Li(mm) & 7,637 & 7,427 & $<0,001^{*}$ \\
\hline $\mathrm{B}-\mathrm{B}^{\prime}(\mathrm{mm})$ & $-0,21$ & $-0,72$ & 0,34 \\
\hline Ls-Sn/Po-Or $\left({ }^{\circ}\right)$ & 1,01 & $-2,40$ & 0,216 \\
\hline Li-B'/Po-Or) $\left(^{\circ}\right)$ & 0,473 & 0,827 & 0,908 \\
\hline \multicolumn{4}{|l|}{ Morfologia do mento } \\
\hline $\mathrm{Pg}-\mathrm{Pg}(\mathrm{mm})$ & 0,737 & 0,233 & $0,036^{*}$ \\
\hline Li-B'-Pog' $\left({ }^{\circ}\right)$ & 1,387 & 5,307 & 0,072 \\
\hline \multicolumn{4}{|c|}{$\begin{array}{l}\text { LVR (linha vertical de referência) - Projeções } \\
\text { tecido mole }\end{array}$} \\
\hline LVR-Pn (mm) & 1,203 & 0,52 & $0,001^{*}$ \\
\hline LVR-A' (mm) & 2,83 & 1,473 & $<0,001^{*}$ \\
\hline LVR-Ls (mm) & 2,717 & 0,933 & $<0,001^{*}$ \\
\hline LVR-Li (mm) & 3,91 & 5,58 & $<0,001^{*}$ \\
\hline LVR-B' (mm) & 3,393 & 5,96 & $<0,001^{*}$ \\
\hline LVR-Pog' (mm) & 2,69 & 4,96 & $<0,001^{*}$ \\
\hline${ }^{*} P<0,05$ & & & \\
\hline
\end{tabular}




\subsection{Correlação de Pearson}

Com o objetivo de avaliar correlações entre algumas variáveis de interesse em T2 foram obtidos os gráficos a seguir através do coeficiente de correlação de Pearson:

\subsubsection{Maxila com ponto subnasal}

Gráfico 1: Correlação da posição sagital da maxila com o ponto subnasal no grupo experimental.

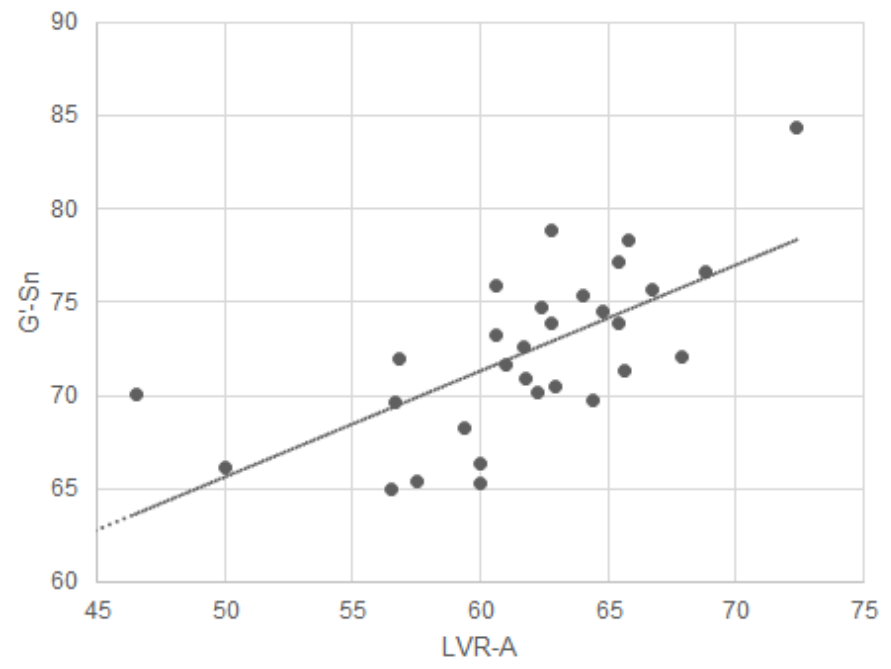

Gráfico 2: Correlação da posição sagital da maxila com o ponto subnasal no grupo controle.

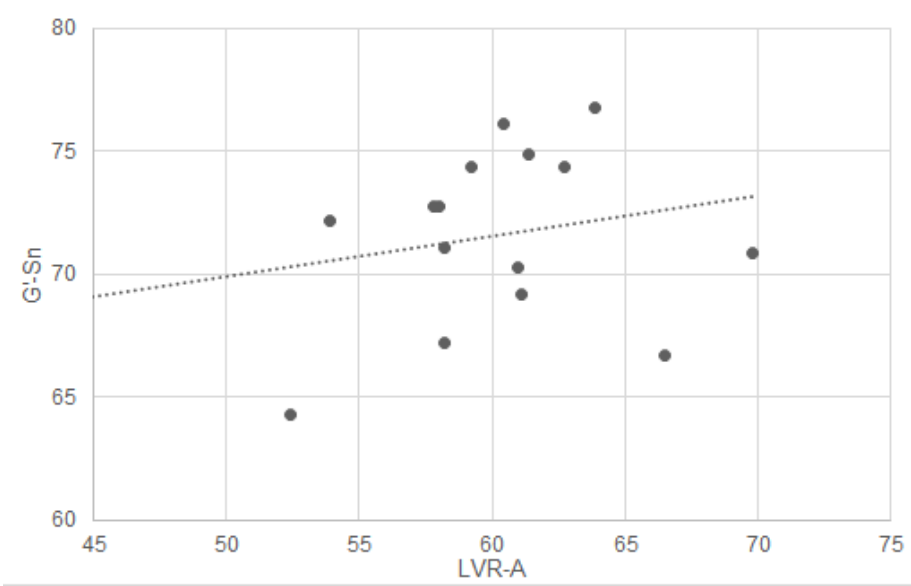


No grupo experimental houve correlação positiva moderada entre as medidas em T2 (0,651). Nestes indivíduos, após a cirurgia ortognática, a posição sagital da maxila tem maior influência na posição do ponto subnasal. As medidas não tiveram correlação para o grupo controle em T2._Gráficos 1 e 2 (página 89).

\subsubsection{Incisivo superior com lábio superior}

Gráfico 3: Correlação da posição sagital do incisivo superior com o lábio superior no grupo experimental.

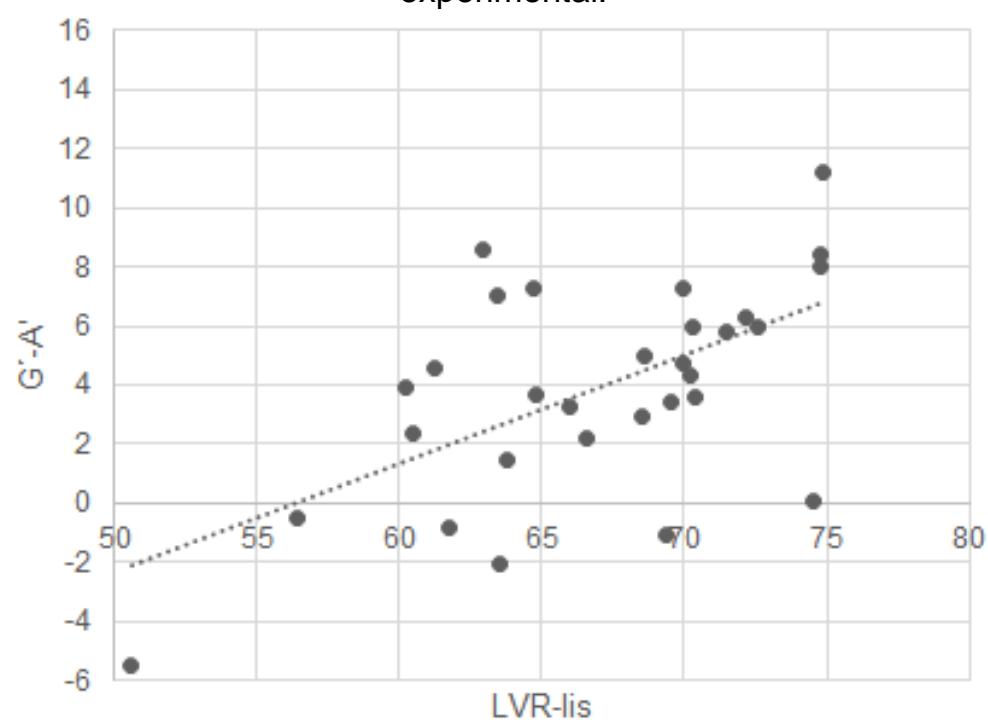

Gráfico 4: Correlação da posição sagital do incisivo superior com o lábio superior no grupo controle.

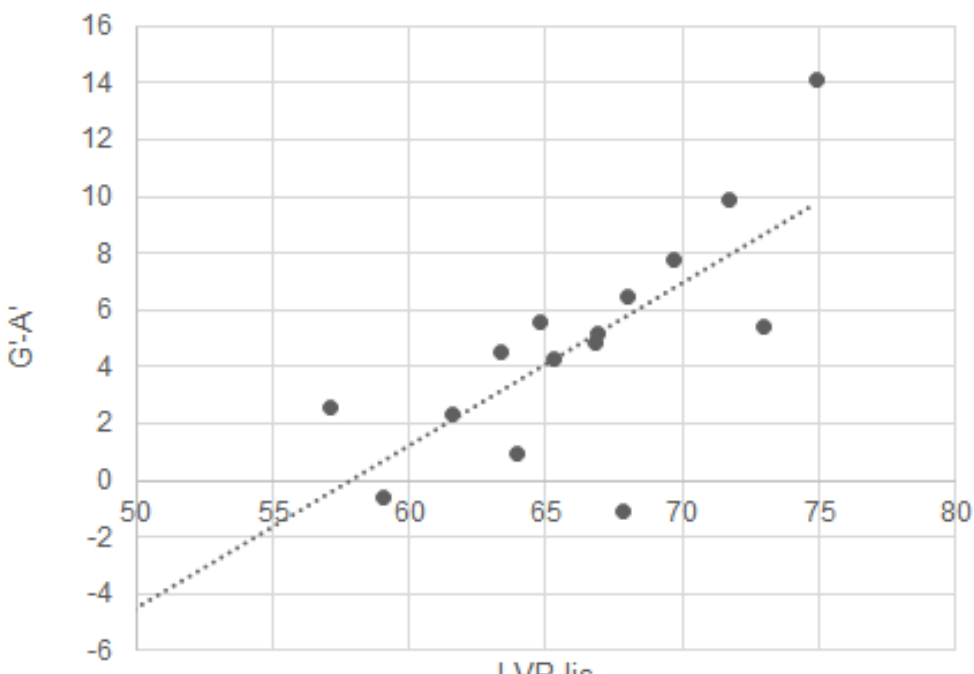

LVR-lis 
Indivíduos do grupo experimental apresentaram uma correlação positiva moderada em T2 $(0,586)$. Indivíduos do grupo controle apresentaram uma correlação positiva forte em T2 $(0,722)$. A posição sagital do incisivo superior influencia a posição sagital do lábio superior após a cirurgia ortognática nos dois grupos. Gráficos 3 e 4 (página 90)

\subsubsection{Relação intermaxilar óssea angular com a relação intermaxilar sagital de} tecido mole

Gráfico 5: Correlação da relação intermaxilar óssea angular e da relação intermaxilar sagital de tecido mole no grupo experimental

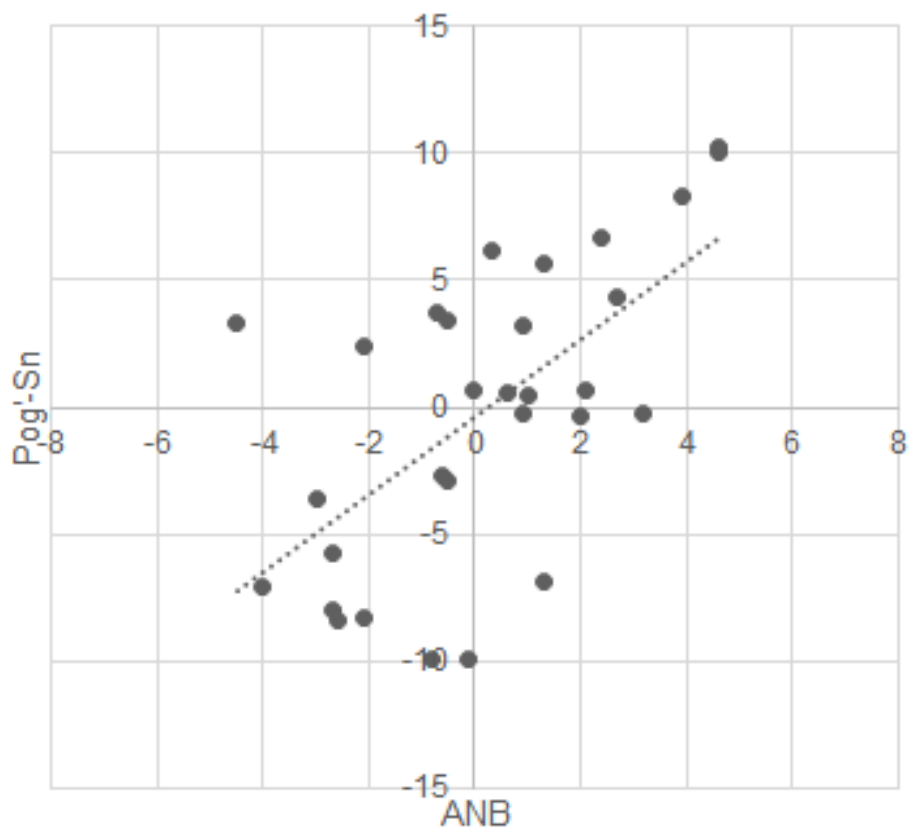


Gráfico 6: Correlação da relação intermaxilar óssea angular e da relação intermaxilar sagital de tecido mole no grupo controle

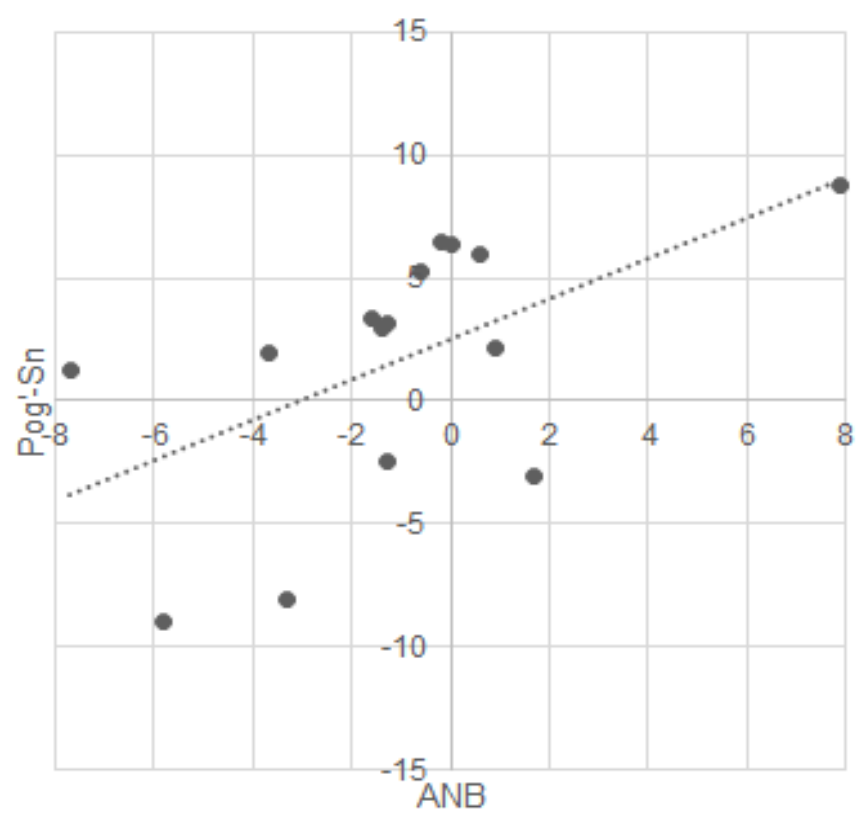

Indivíduos do grupo experimental $(0,553)$ e controle $(0,623)$ apresentaram correlação positiva moderada em T2. A variação da relação intermaxilar óssea angular é acompanhada pela variação intermaxilar sagital de tecido mole nos dois grupos após a cirurgia ortognática. Gráficos 5 (página 91) e 6 (página 92)

\subsubsection{Relação intermaxilar óssea angular com a relação sagital entre os lábios}

Gráfico 7: Correlação da relação intermaxilar óssea angular com a relação sagital entre os lábios no grupo experimental.

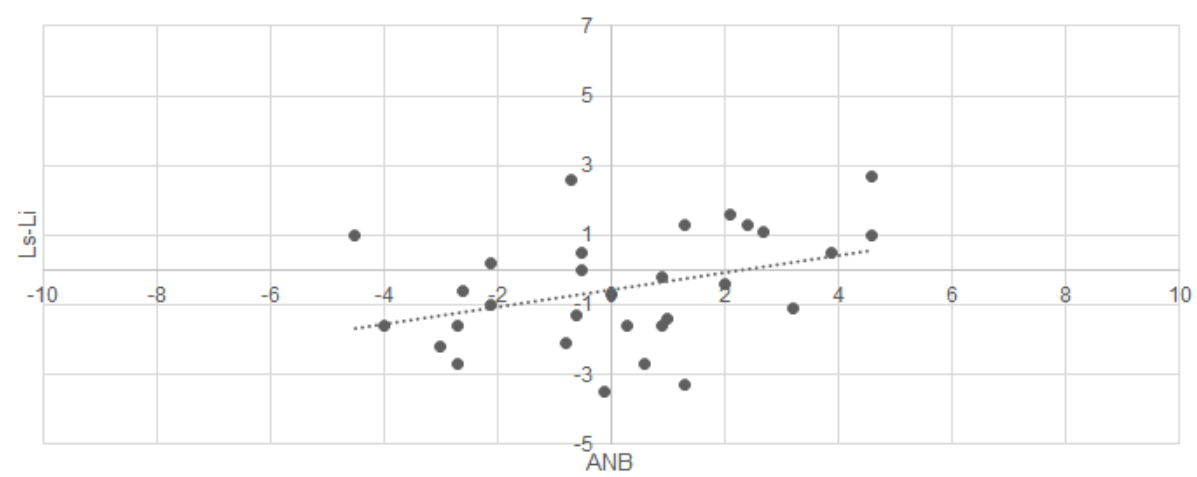


Gráfico 8: Correlação da relação intermaxilar óssea angular com a relação sagital entre os lábios no grupo controle.

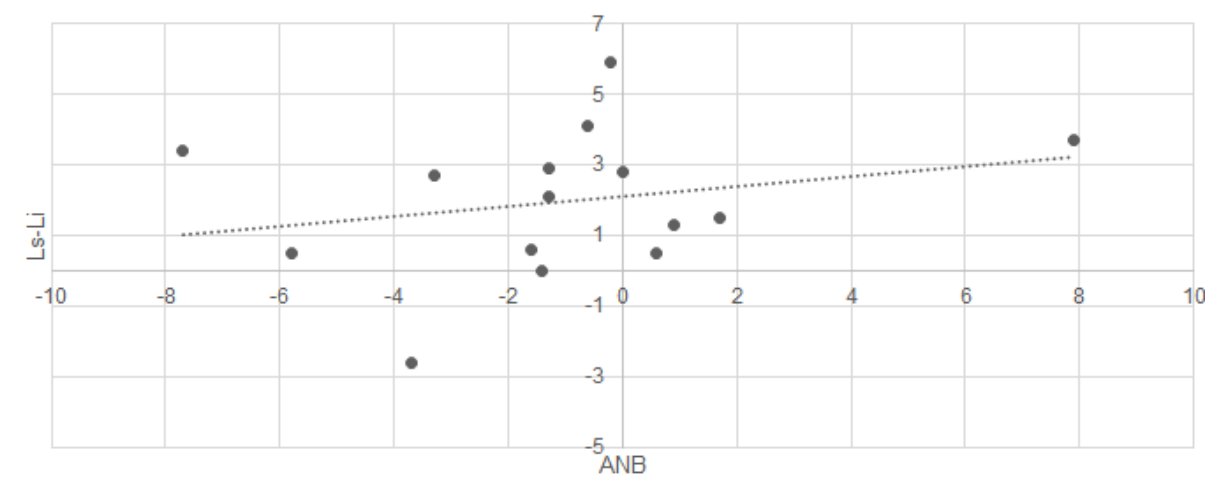

Indivíduos do grupo experimental apresentaram correlação positiva fraca em T2 (0,368). Indivíduos do grupo controle não apresentaram correlação entre as medidas em T2. A variação da relação intermaxilar óssea angular é acompanhada levemente pela variação na relação entre os lábios no grupo experimental e não é acompanhada no grupo controle após a cirurgia ortognática. Gráficos 7 (página 92) e 8 (página 93)

\subsubsection{Relação intermaxilar óssea linear com a relação intermaxilar sagital de tecido mole}

Gráfico 9: Correlação da relação intermaxilar óssea linear com a relação intermaxilar sagital de tecido mole no grupo experimental

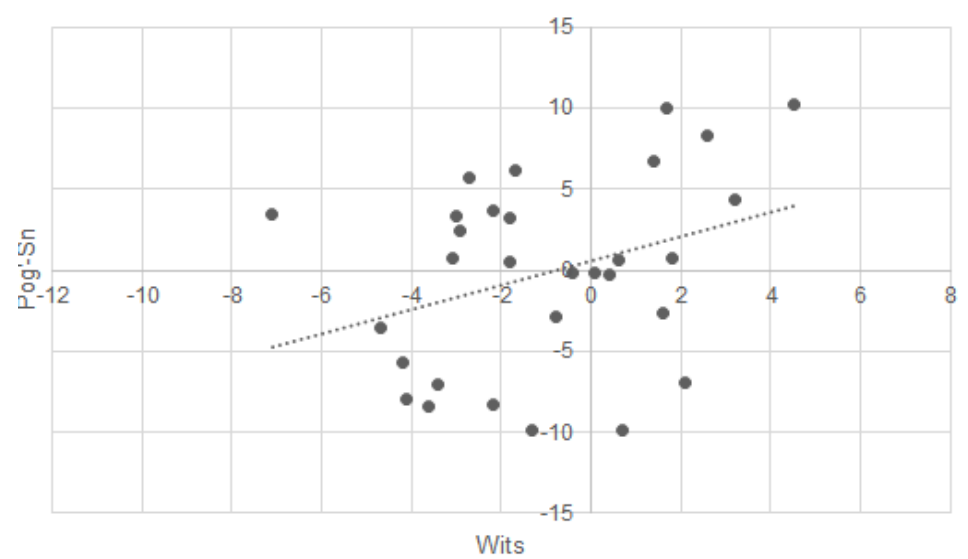


Gráfico 10: Correlação da relação intermaxilar óssea linear com a relação intermaxilar sagital de tecido mole no grupo controle

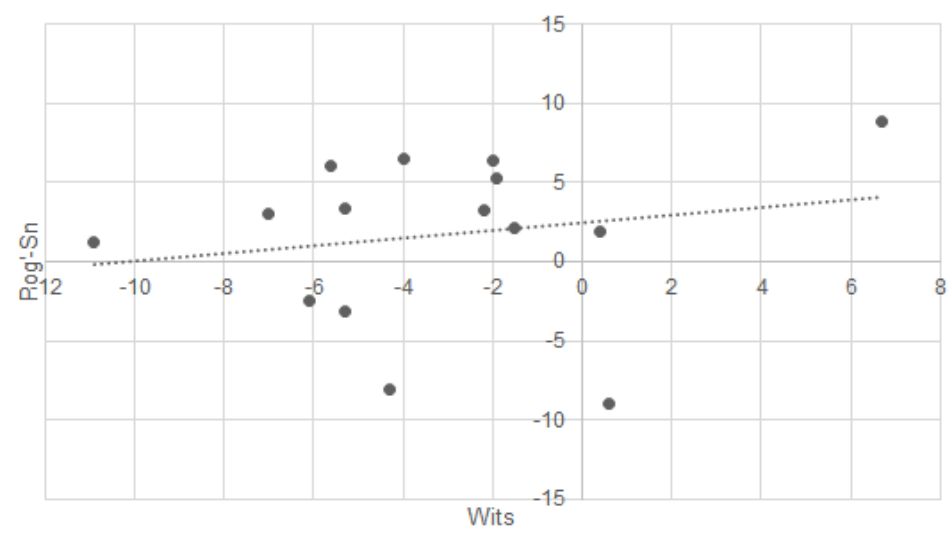

Indivíduos do grupo experimental e controle não apresentaram correlação entre as variações na relação intermaxilar óssea linear e a relação intermaxilar sagital de tecido mole após a cirurgia ortognática. Gráficos 9 (página 93) e 10 (página 94).

\subsubsection{Relação intermaxilar óssea linear com a relação sagital entre os lábios}

Gráfico 11: Correlação da relação intermaxilar óssea linear com a relação sagital entre os lábios no grupo experimental

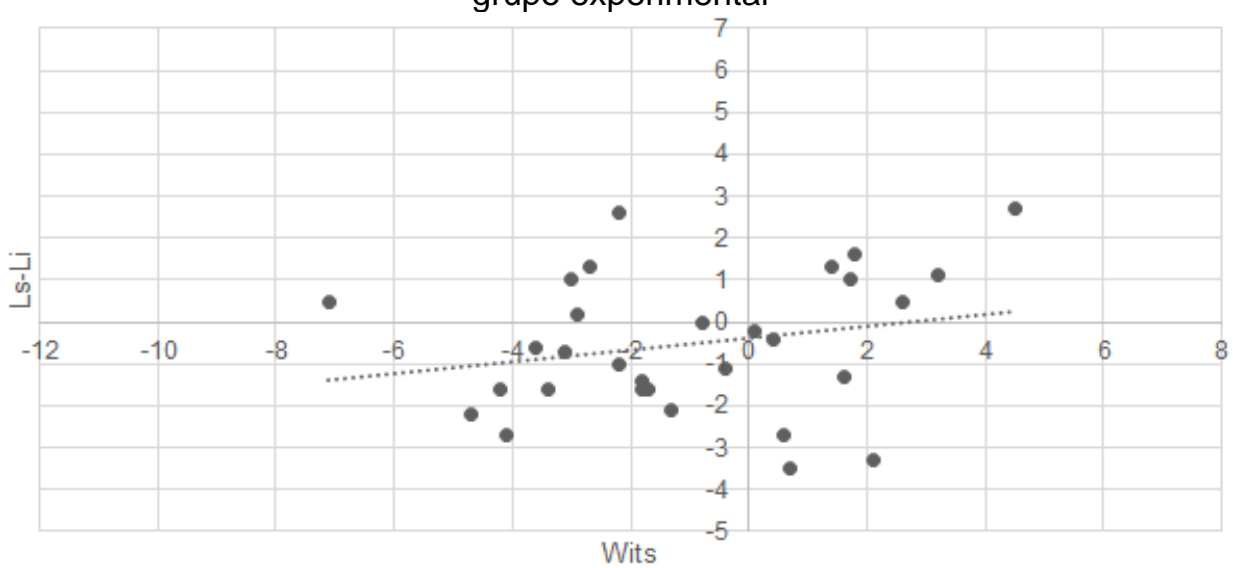


Gráfico 12: Correlação da relação intermaxilar óssea linear com a relação sagital entre os lábios no grupo controle

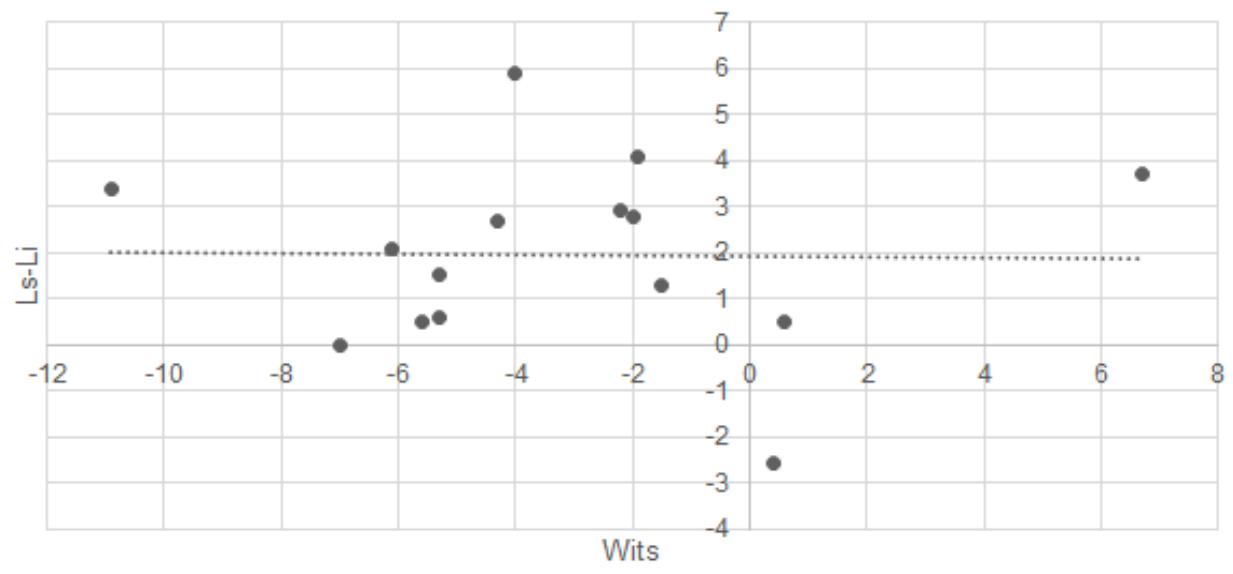

Indivíduos do grupo experimental e controle não apresentaram correlação entre as variações na relação intermaxilar óssea linear e na relação sagital entre os lábios após a cirurgia ortognática. Gráficos 11 (página 94) e 12 (página 95).

\subsubsection{Posição sagital mandibular e protrusão, espessura e inclinação do lábio} inferior

Gráfico 13: Correlação entre a relação sagital mandibular e a protrusão do lábio inferior no grupo experimental

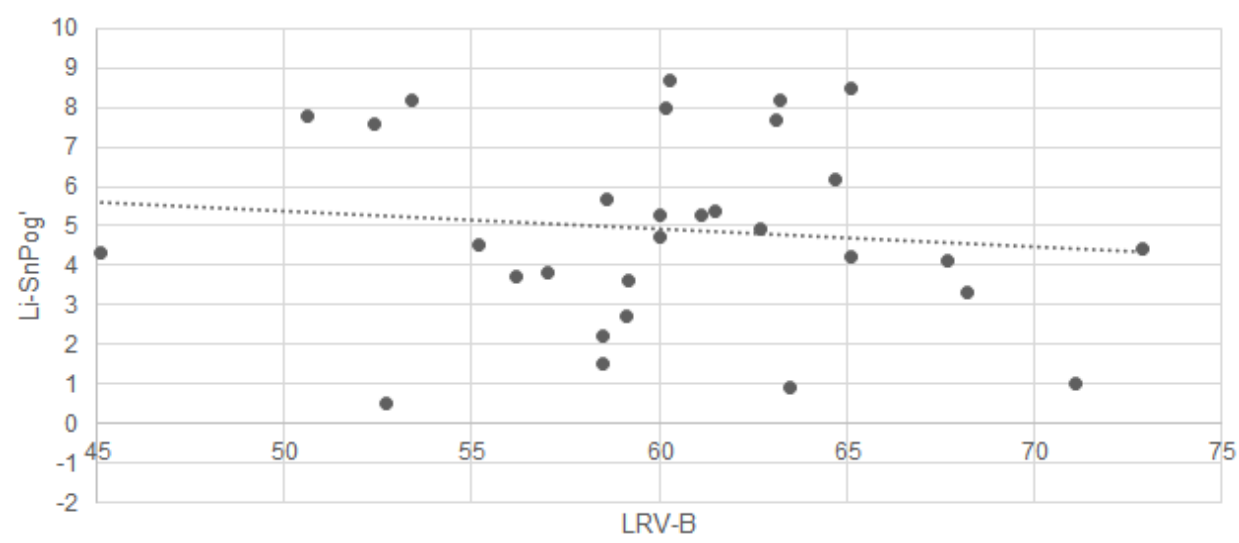


Gráfico 14: Correlação entre a relação sagital mandibular e a protrusão do lábio inferior no grupo controle

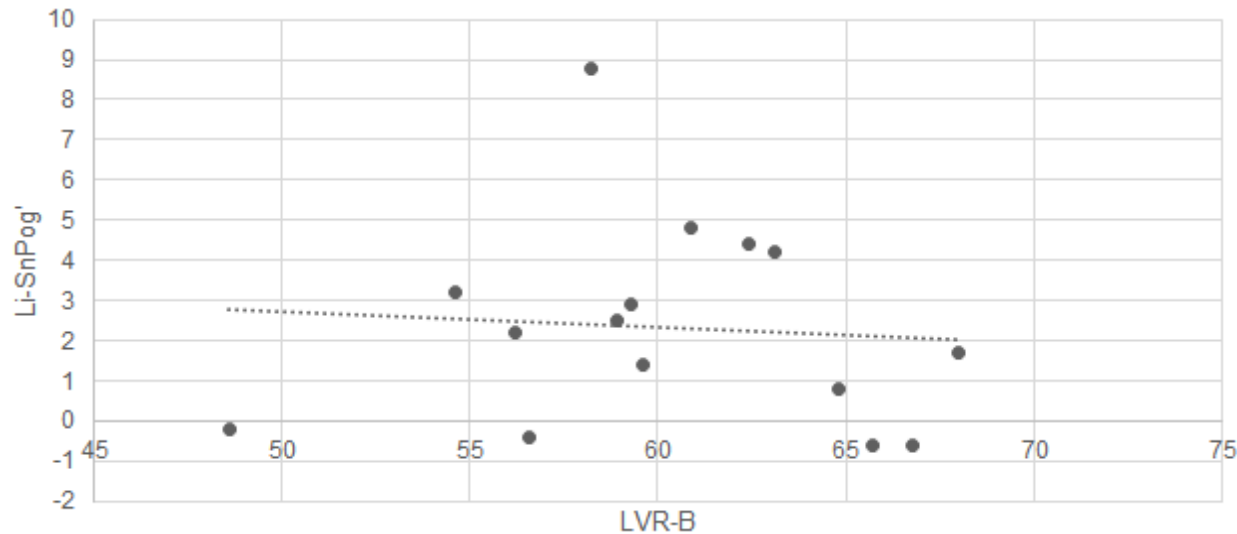

Gráfico 15: Correlação entre a relação sagital mandibular e a espessura do lábio inferior no grupo experimental

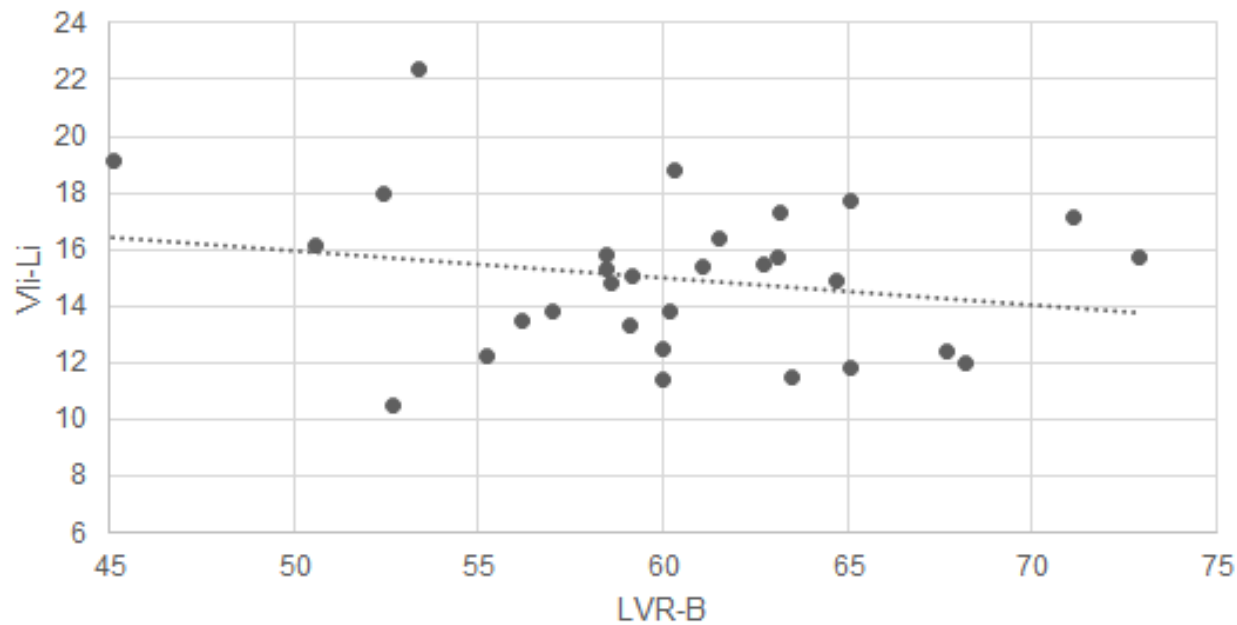


Gráfico 16: Correlação entre a relação sagital mandibular e a espessura do lábio inferior no grupo controle

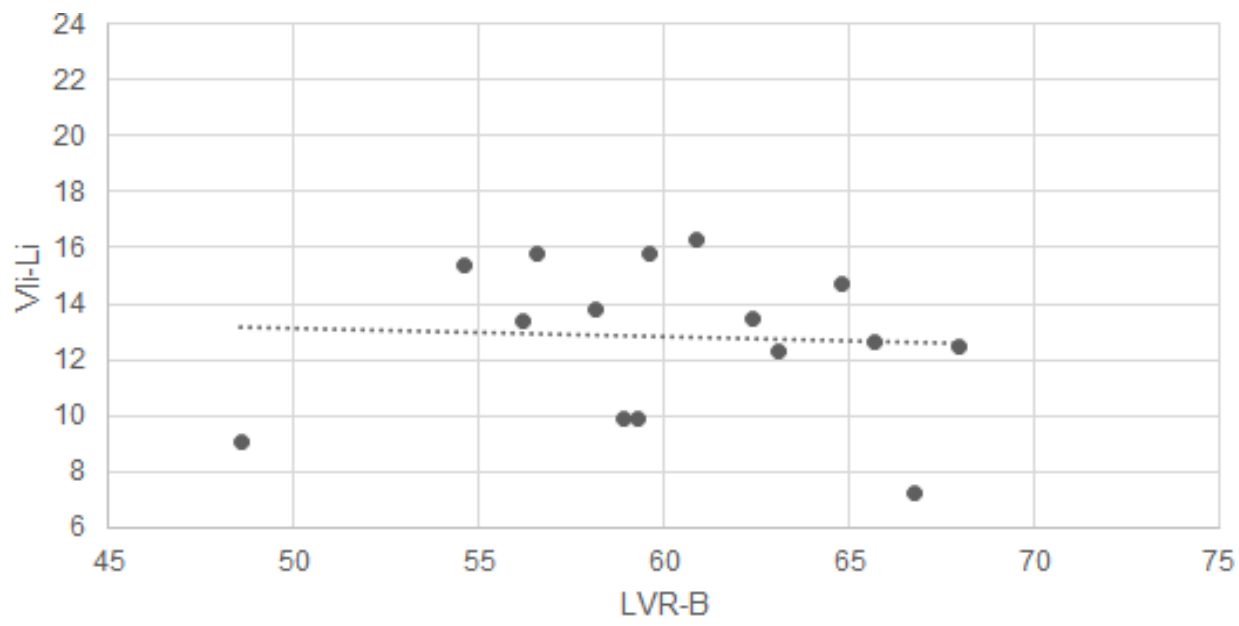

Gráfico 17: Correlação entre a relação sagital mandibular e a inclinação do lábio inferior no grupo experimental

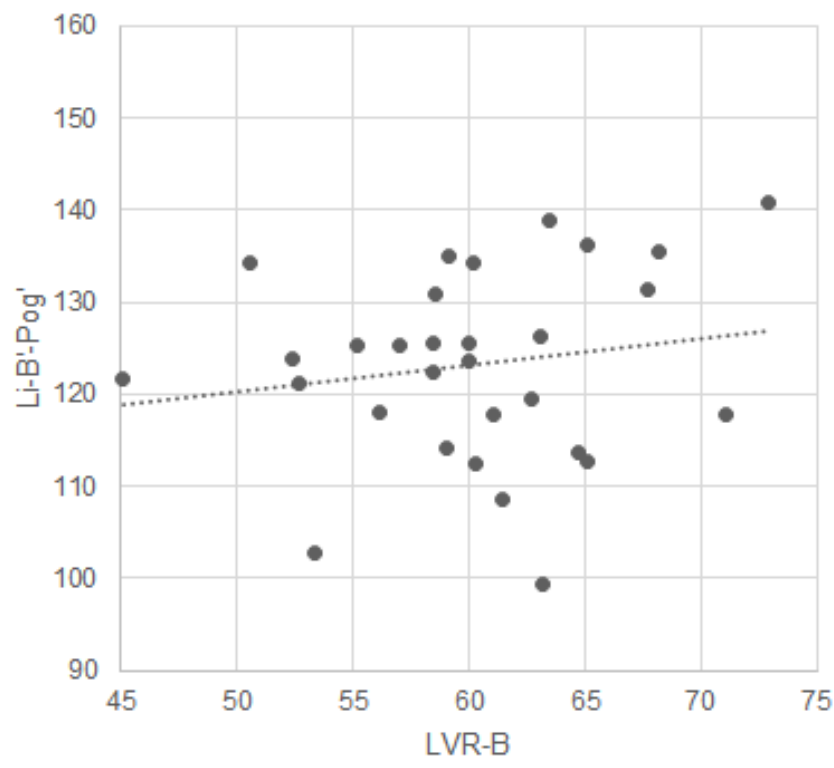


Gráfico 18: Correlação entre a relação sagital mandibular e a inclinação do lábio inferior no grupo controle

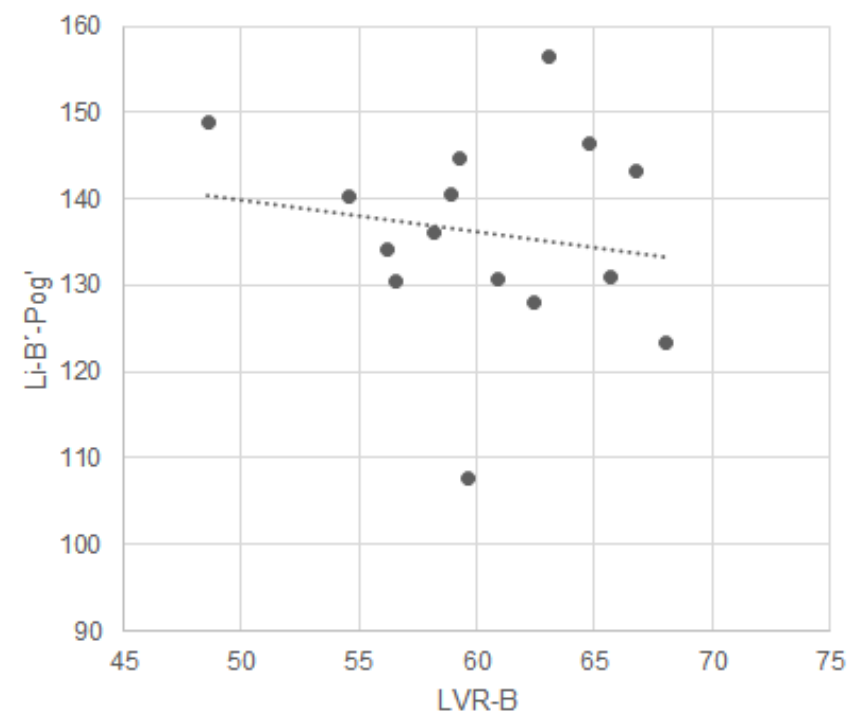

Os indivíduos do grupo experimental e do grupo controle não apresentaram correlação entre as variações na posição sagital mandibular e na protrusão, espessura e inclinação do lábio inferior após a cirurgia ortognática. Gráficos 13 (página 95), 14 e 15 (página 96), 16 e 17 (página 97) e Gráfico 18 (página 98). 
6 Discussão 



\section{DISCUSSÃO}

Já se comprovou a excelente acuidade e confiabilidade das imagens em 3 dimensões obtidas pela tomografia computadorizada de feixe cônico (BERCO et al., 2009). As imagens obtidas dessa forma inclusive, podem ser convertidas em cefalogramas de 2 dimensões para permitir 0 uso de medidas ortodônticas convencionais com uma melhor qualidade em termos de distorções e magnificações em relação aos cefalogramas convencionais (KUMAR et al., 2007). Porém, no presente estudo, se utilizou de imagens em duas dimensões porque o planejamento da cirurgia ortognática ainda acontece em duas dimensões e posteriormente segue para um fluxo tridimensional. Isto acontece em virtude da previsibilidade e reprodutibilidade que se tem nas imagens bidimensionais e não se consegue ainda na cefalometria tridimensional.

O grupo controle foi composto de 15 indivíduos com fissura isolada de palato (4 com fissura completa de palato, $5 \mathrm{com}$ envolvimento parcial do palato duro e 6 com envolvimento apenas de palato mole). Esse tipo de fissura não causa comprometimento no nariz, lábios e no padrão facial, uma vez que acomete apenas o palato, não chegando ao rebordo alveolar e a musculatura perioral.(DA SILVA FILHO; ROSA; LAURIS, 2007), sendo portanto uma boa referência de comparação.

$\mathrm{Na}$ literatura não há estudos que comparam indivíduos com fissura completa de lábio e palato unilateral e indivíduos com fissura isolada de palato submetidos a cirurgia ortognática, apenas se comparam indivíduos com fissura de lábio e palato e indivíduos sem fissura lábio palatina submetidos a cirurgia ortognática.(FREIHOFER, 1976; HUI; HÄGG; TIDEMAN, 1994; PARK; KOH; CHOI, 2015), com isso, esses estudos serviram de referência para realização da discussão.

Todos os indivíduos foram operados por um mesmo cirurgião, o que reduziu a chance de erros relacionados a técnicas cirúrgicas(JEONG et al., 2018; SUSARLA et al., 2020), habilidade, planejamento e experiência entre diferentes cirurgiões.(KALAAJl et al., 1996)

A presença da fissura de lábio e rebordo alveolar em comparação com a presença da fissura apenas no palato parece não causar grandes diferenças em relação ao tamanho e forma das estruturas de tecido duro do crânio entre os grupos 
em T1 e em T2. Apenas uma estrutura, a posição vertical da maxila (N-A), apresentou diferença estatisticamente significante na comparação entre os grupos. $O$ maior incremento vertical tanto em T1 $(3,5 \mathrm{~mm})$ como em T2 $(4,0 \mathrm{~mm})$, apresentado pelo grupo experimental, foi diferente do relatado na literatura. (LINTON, 1998; LIN et al., 2016) não encontraram diferença na posição vertical da maxila entre indivíduos com fissura de lábio e palato unilateral completa e indivíduos sem fissura. Já outros estudos mostraram que a maxila de indivíduos com fissura de lábio e palato tem menor incremento vertical (TOYGAR; AKÇAM; ARMAN, 2004) do que indivíduos sem fissura, porém, não há dados sobre a comparação entre os indivíduos com fissura de lábio palato e com fissura isolada de palato.

Os dois grupos apresentaram medidas referentes a Base do crânio e Complexo naso maxilar parecidas. A literatura mostra não haver diferença entre a base do crânio de indivíduos com e sem fissura labiopalatina (HARRIS, 1993; TINANO et al., 2015; LIN et al., 2016). Diversos estudos mostram haver diferença no comportamento da maxila em indivíduos com e sem fissura de lábio e palato com Classe III, (NORMANDO; DA SILVA FILHO; CAPELOZZA FILHO, 1992; DOĞAN; ÖNÇAĞ; AKIN, 2006; YE et al., 2015; LIN et al., 2016) assim como nos indivíduos com fissura isolada de palato em comparação com indivíduos sem fissura(BECKER et al., 2001; PARIKAKIS; LARSON; KARSTEN, 2020). A presença da fissura de lábio e palato ou isolada de palato, seguida do seu reparo pelas cirurgias plásticas primárias, promove um desequilíbrio no crescimento sagital, vertical e transversal da maxila. O complexo nasomaxilar de ambos os grupos teve essa característica evidenciada no mesmo sentido e com magnitude parecida.

Mesmo com os dois grupos apresentando relação esquelética de Classe III, a mandíbula do grupo experimental foi menor do que a mandíbula do grupo controle, em T1 (3,87mm) e em T2 (2,97mm). (LIN et al., 2016) não encontraram diferenças em relação ao tamanho mandibular de indivíduos com fissura de lábio e palato completa classe III. Já (TINANO et al., 2015), ao contrário do relatado nesse estudo, encontraram valores $2 \mathrm{~mm}$ maiores para o comprimento mandibular de indivíduos com fissura de lábio e palato completa quando comparados aos indivíduos sem fissura classe III.

O eixo Y de crescimento (SGn-SN) também foi clinicamente maior no grupo experimental, sem significância estatística, em T1, 2,44 e em T2, 2,59 . Esse 
predomínio vertical de crescimento craniofacial do grupo de indivíduos com envolvimento de lábio e rebordo alveolar já foi demonstrado na literatura em relação a indivíduos sem fissura. (LIN et al., 2016) relataram que indivíduos com fissura unilateral completa de lábio e palato apresentam esse ângulo, $3,36^{\circ}$ maior do que indivíduos sem fissura Classe III.

As diferenças de tecido mole encontradas entre os dois grupos em T1 e T2 foram em relação a proeminência subnasal(G'-Sn), ao nariz, a relação sagital entre os lábios, lábio inferior e pogônio.

A proeminência subnasal que já era $2,66 \mathrm{~mm}$ menor em T1 no grupo experimental, ficou ainda menor em T2, 3,4mm. Sabe-se que a cicatriz provocada pela queiloplastia (NORMANDO; DA SILVA FILHO; CAPELOZZA FILHO, 1992; LIN et al., 2016) causa restrições no posicionamento anteroposterior da maxila, associado a isso, a remoção da espinha nasal anterior dos indivíduos do grupo experimental durante a cirurgia, devido a assimetria que esta estrutura apresenta nestes indivíduos (SURI et al., 2008), diminuiu o suporte do tecido mole nessa região. (MARIANETTI; BOCCIERI; PASCALI, 2016), mostram a importante relação da espinha nasal anterior com o tecido mole adjacente (ponta nasal, columela e lábio superior), nos casos de hiperplasia, desvio e hipoplasia dessa estrutura.

De fato, nos indivíduos do grupo experimental, em T2, a posição óssea sagital maxilar teve uma relação mais íntima com a região subnasal, sendo a única relação entre estruturas de tecido duro e mole com resultados diferentes quando submetidos ao coeficiente de correlação de Pearson.

A menor proeminência do ponto subnasal de indivíduos com fissura de lábio e palato unilateral completa também já foi relatado por (LIN et al., 2016).

Como a proeminência subnasal serve de referência para a medida do comprimento nasal, essa medida está aumentada nos indivíduos do grupo experimental, não significando que o nariz desses indivíduos esteja maior do que os do grupo controle.

Outros trabalhos (STOLL et al., 2002; LIN et al., 2016), não mostraram diferenças no comprimento nasal de indivíduos com fissura de lábio e palato unilateral 
completa quando comparados com indivíduos sem fissura, usando a mesma referência do ponto subnasal, porém, sem analisar o efeito da cirurgia ortognática.

A cirurgia ortognática bimaxilar normalizou a relação entre os lábios no grupo controle, melhorou a relação entre os lábios no grupo experimental, porém, não o suficiente para normalizar essa relação. Em concordância com a literatura, o lábio inferior do grupo experimental em T1 era mais protruso, espesso e evertido (CHAISRISOOKUMPORN; STELLA; EPKER, 1995; STOLL et al., 2002; TOYGAR; AKÇAM; ARMAN, 2004; LIN et al., 2016). Em T2 o lábio inferior permaneceu ligeiramente à frente do superior, o que já foi descrito na literatura no pós operatório de cirurgia ortognática bimaxilar de indivíduos com fissura de lábio e palato unilateral. (PARK; KOH; CHOI, 2015; YIM; BAEK, 2019) O comportamento do lábio inferior do grupo experimental pode ser associado ao fato do músculo orbicular segmentado também ter o seu funcionamento alterado, a fisiologia muscular não é a mesma de um músculo íntegro (SZYSZKA-SOMMERFELD et al., 2017).

Como o pós operatório analisado foi de apenas 6 meses, essa posição do lábio inferior a frente do superior pode ser devido a um motivo postural, e não anatômico. São necessários estudos para avaliar essa relação entre os lábios em um pós operatório mais tardio e após uma terapia de motricidade oral para melhora da hipotonicidade labial. A postura do lábio depende da função e relação com as estruturas anatômicas. No paciente com fissura labiopalatina existe um desequilíbrio destas estruturas e isso impede no pós-operatório precoce uma correção deste hábito e tonicidade labial.

O tecido mole na região do pogônio, foi mais espesso no grupo experimental em T1 e em T2. Parece que nos indivíduos do grupo experimental, como o lábio inferior é mais espesso, protruso e evertido, há uma certa hipoplasia de tecido mole no terço inferior da face. Esse achado foi diferente do demonstrado por (TOYGAR; AKÇAM; ARMAN, 2004) e (PARK; KOH; CHOI, 2015), que não encontraram diferença para esta estrutura.

Na literatura indivíduos com fissura de lábio e palato submetidos a cirurgia ortognática bimaxilar apresentaram um avanço de maxila entre $3,6 \mathrm{~mm}$ a $4 \mathrm{~mm}$, e um recuo de mandíbula de 4,0mm a 5,2mm(BAUMANN; SINKO, 2003; YUN et al., 2015; PARK; $\mathrm{KOH}$; CHOI, 2015; WONG et al., 2016). 
O grupo experimental apresentou um avanço maxilar com média de $2,99 \mathrm{~mm}$ e um recuo mandibular $3,4 \mathrm{~mm}$ e o grupo controle um avanço de 2,2 $\mathrm{mm}$ e um recuo mandibular de $5,4 \mathrm{~mm}$. O maior recuo mandibular no grupo controle refletiu numa maior diminuição da medida linear do eixo $\mathrm{Y}$ e das dimensões mandibulares relacionadas a linha vertical de referência.

De modo parecido com o grupo controle, na literatura, uma comparação entre indivíduos com e sem fissura labiopalatina submetidos a cirurgia bimaxilar demonstrou a necessidade de maior recuo mandibular para os indivíduos sem fissura. (PARK; KOH; $\mathrm{CHOI}, 2015)$ Este fato e os dados do presente estudo corroboram com o comportamento das estruturas de tecido mole e duro em indivíduos com fissura isolada de palato ser mais próximo de indivíduos sem fissura labiopalatina do que de indivíduos com fissura completa de lábio e palato.

A correção da relação oclusal, um dos requisitos para avaliar o sucesso da reabilitação cirúrgica (PROFFIT; TURVEY; PHILLIPS, 1996), foi efetiva nos dois grupos, porém, não foi acompanhada de uma correção plena das relações de algumas estruturas do tecido mole.

O grupo experimental apresentava uma deficiência maxilar levemente maior e o grupo controle uma mandíbula mais protruída, o que está de acordo com o relatado na literatura nas comparação entre indivíduos com fissura completa unilateral de lábio e palato e indivíduos sem fissura(STOLL et al., 2002; DOĞAN; ÖNÇAĞ; AKIN, 2006; MOREIRA et al., 2014; LIN et al., 2016). Isso resultou numa necessidade de um maior avanço sagital do ponto $A$ ' no grupo experimental e num maior recuo do ponto Pog' no grupo controle para atingir os objetivos oclusais que permitissem uma estabilidade pós-cirúrgica.(PROFFIT; TURVEY; PHILLIPS, 1996)

Com relação ao ângulo nasolabial é importante lembrar que no indivíduo com fissura de lábio e palato completa geralmente não há apoio da columela e a ponta do nariz fica sem suporte, desta forma, quando há indicação para avanço da maxila neste grupo de indivíduos, o lábio superior não está sendo suportado pelos incisivos superiores, mas sim pelos incisivos inferiores ou mesmo pelo lábio inferior. Desta forma o ângulo nasolabial fica mais fechado o que, de forma geral, contra indicaria o avanço da maxila. (TANAKA, 2015) demonstrou esse comportamento para o lábio superior em indivíduos com fissura completa de lábio e palato. A autora também 
demonstrou que a mudança do ângulo nasolabial, bem como do suporte do lábio superior, acontece apenas em avanços acima de $5 \mathrm{~mm}$ o que não é observado no presente estudo. Os dados obtidos no atual estudo corroboram com os trabalhos de (TANAKA, 2015) e (DIAS, 2020). 


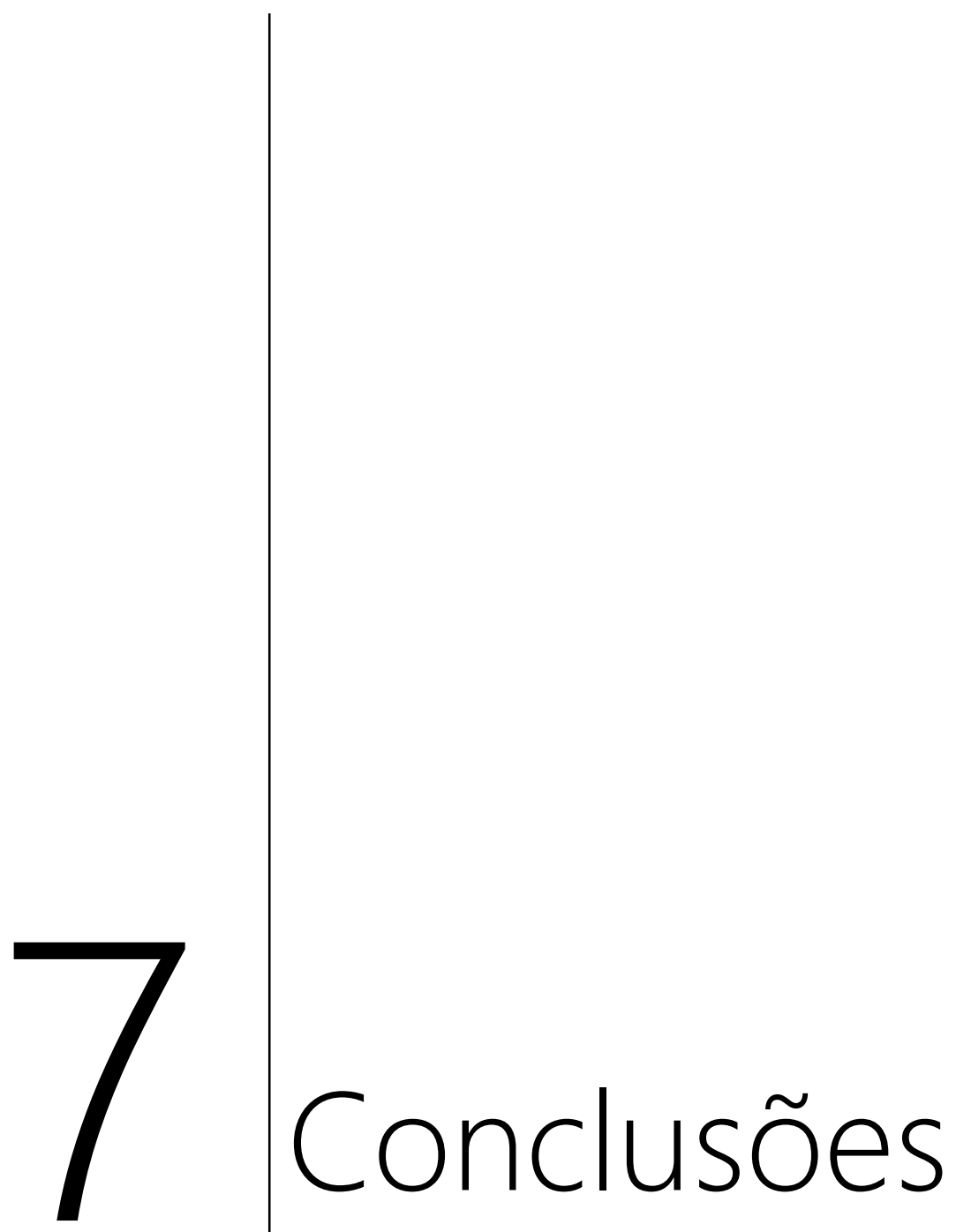





\section{CONCLUSÕES}

Indivíduos com fissura de lábio e palato unilateral e indivíduos com fissura isolada de palato, classe III, preparados para cirurgia ortognática e operados apresentam as seguintes diferenças entre a morfologia craniofacial:

- Os dois grupos apresentaram características de tecido duro muito próximas, com exceção de um maior incremento vertical de maxila no grupo experimental, antes e após a cirurgia.

- Os indivíduos do grupo experimental apresentaram uma maior retrusão da região subnasal, uma maior discrepância na relação sagital inter-labial, um lábio inferior mais protruso, espesso e evertido e uma maior espessura de tecido mole na região do mento, antes e após a cirurgia.

- O efeito da cirurgia ortognática foi positivo nos dois grupos com uma melhora na oclusão, relação de tecidos duros e tecidos moles, porém, mesmo com essa melhora, nos indivíduos do grupo experimental o perfil tegumentar não atingiu a harmonia encontrada no grupo controle, principalmente na região do lábio inferior. 

Referências 



\section{REFERÊNCIAS}

ALMUKHTAR, A. et al. Comparison of the accuracy of voxel based registration and surface based registration for $3 \mathrm{D}$ assessment of surgical change following orthognathic surgery. PloS one, v. 9, n. 4, p. e93402, abr. de 2014.

BAUMANN, A.; SINKO, K. Importance of soft tissue for skeletal stability in maxillary advancement in patients with cleft lip and palate. The Cleft palate-craniofacial journal: official publication of the American Cleft Palate-Craniofacial Association, v. 40, n. 1, p. 65-70, jan. de 2003.

BECKER, M. et al. Adult skeletal profile in isolated cleft palate: a comparison of the von Langenbeck and Wardill procedures for primary repair of the palate. Scandinavian journal of plastic and reconstructive surgery and hand surgery / Nordisk plastikkirurgisk forening [and] Nordisk klubb for handkirurgi, v. 35, n. 4, p. 387-397, dez. de 2001.

BERCO, M. et al. Accuracy and reliability of linear cephalometric measurements from cone-beam computed tomography scans of a dry human skull. American journal of orthodontics and dentofacial orthopedics: official publication of the American Association of Orthodontists, its constituent societies, and the American Board of Orthodontics, v. 136, n. 1, p. 17.e1-9; discussion 17-8, jul. de 2009.

BICHARA, L. M. et al. Impact of primary palatoplasty on the maxillomandibular sagittal relationship in patients with unilateral cleft lip and palate: a systematic review and meta-analysis. International journal of oral and maxillofacial surgery, v. 44, n. 1, p. 50-56, jan. de 2015.

CAPELOZZA FILHO, L. Normas para diagnóstico. Capelozza Filho L. Diagnóstico em Ortodontia. Maringá: Dental Press, 2004.

CHAISRISOOKUMPORN, N.; STELLA, J. P.; EPKER, B. N. Cephalometric profile evaluations in patients with cleft lip and palate. Oral surgery, oral medicine, oral pathology, oral radiology, and endodontics, v. 80, n. 2, p. 137-144, ago. de 1995.

CHANG, Y.-J. et al. Soft Tissue Changes Measured With Three-Dimensional Software Provides New Insights for Surgical Predictions. Journal of oral and maxillofacial surgery: official journal of the American Association of Oral and Maxillofacial Surgeons, v. 75, n. 10, p. 2191-2201, out. de 2017.

CHEMELLO, P. D.; WOLFORD, L. M.; BUSCHANG, P. H. Occlusal plane alteration in orthognathic surgery--Part II: Long-term stability of results. American journal of orthodontics and dentofacial orthopedics: official publication of the American Association of Orthodontists, its constituent societies, and the American Board of Orthodontics, v. 106, n. 4, p. 434-440, out. de 1994. 
DA SILVA FILHO, O. G.; ROSA, L. A. de A.; LAURIS, R. de C. M. C. Influence of isolated cleft palate and palatoplasty on the face. Journal of applied oral science: revista FOB, v. 15, n. 3, p. 199-208, jun. de 2007.

DASKALOGIANNAKIS, J.; MEHTA, M. The need for orthognathic surgery in patients with repaired complete unilateral and complete bilateral cleft lip and palate. The Cleft palate-craniofacial journal: official publication of the American Cleft PalateCraniofacial Association, v. 46, n. 5, p. 498-502, set. de 2009.

DIAS, B. S. Avaliação tridimensional das alterações do lábio superior após osteotomia Le Fort I de maxila em pacientes com fissura transforame unilateral. 2020. Universidade de São Paulo, 2020.

DOĞAN, S.; ÖNÇAĞ, G.; AKIN, Y. Craniofacial development in children with unilateral cleft lip and palate. The British journal of oral \& maxillofacial surgery, v. 44, n. 1, p. 28-33, fev. de 2006.

FREIHOFER, H. P., Jr. The lip profile after correction of retromaxillism in cleft and noncleft patients. Journal of maxillofacial surgery, v. 4, n. 3, p. 136-141, mai. de 1976.

FREIHOFER, H. P., Jr. Changes in nasal profile after maxillary advancement in cleft and non-cleft patients. Journal of maxillofacial surgery, v. 5, n. 1, p. 20-27, fev. de 1977.

FREITAS, J. A. de S. et al. Rehabilitative treatment of cleft lip and palate: experience of the Hospital for Rehabilitation of Craniofacial Anomalies-USP (HRAC-USP)-Part 2: Pediatric Dentistry and Orthodontics. Journal of applied oral science: revista FOB, v. 20, n. 2, p. 268-281, 2012.

GABRIEL DA SILVA FILHO, O.; CORRÊA NORMANDO, A. D.; FILHO, L. C. Mandibular growth in patients with cleft lip and/or cleft palate-the influence of cleft type. American journal of orthodontics and dentofacial orthopedics: official publication of the American Association of Orthodontists, its constituent societies, and the American Board of Orthodontics, v. 104, n. 3, p. 269-275, set. de 1993.

HARRIS, E. F. Size and form of the cranial base in isolated cleft lip and palate. The Cleft palate-craniofacial journal: official publication of the American Cleft PalateCraniofacial Association, v. 30, n. 2, p. 170-174, mar. de 1993.

HATHAWAY, R. et al. The Americleft study: an inter-center study of treatment outcomes for patients with unilateral cleft lip and palate part 2. Dental arch relationships. The Cleft palate-craniofacial journal: official publication of the American Cleft Palate-Craniofacial Association, v. 48, n. 3, p. 244-251, mai. de 2011. 
HIRANO, A.; SUZUKI, H. Factors related to relapse after Le Fort I maxillary advancement osteotomy in patients with cleft lip and palate. The Cleft palatecraniofacial journal: official publication of the American Cleft Palate-Craniofacial Association, v. 38, n. 1, p. 1-10, jan. de 2001.

HUI, E.; HÄGG, E. U.; TIDEMAN, H. Soft tissue changes following maxillary osteotomies in cleft lip and palate and non-cleft patients. Journal of cranio-maxillofacial surgery: official publication of the European Association for CranioMaxillo-Facial Surgery, v. 22, n. 3, p. 182-186, jun. de 1994.

JEONG, W. S. et al. Cleft-Related Orthognathic Surgery Based on Maxillary Vertical Lengthening of the Anterior Facial Height. Plastic and reconstructive surgery, $v$. 141 , n. 3, p. 736-746, mar. de 2018.

KALAAJI, A. et al. Bone grafting in the mixed and permanent dentition in cleft lip and palatepatients: long-term results and the role of the surgeon's experience. Journal of cranio-maxillo-facial surgery: official publication of the European Association for Cranio-Maxillo-Facial Surgery, v. 24, n. 1, p. 29-35, fev. de 1996.

KUMAR, V. et al. Comparison of conventional and cone beam CT synthesized cephalograms. Dento maxillo facial radiology, v. 36, n. 5, p. 263-269, jul. de 2007.

LEGAN, H. L.; BURSTONE, C. J. Soft tissue cephalometric analysis for orthognathic surgery. Journal of oral surgery , v. 38, n. 10, p. 744-751, out. de 1980.

LINTON, J. L. Comparative study of diagnostic measures in borderline surgical cases of unilateral cleft lip and palate and noncleft Class III malocclusions. American journal of orthodontics and dentofacial orthopedics: official publication of the American Association of Orthodontists, its constituent societies, and the American Board of Orthodontics, v. 113, n. 5, p. 526-537, mai. de 1998.

LIN, Y. et al. Cone-beam computed tomography-synthesized cephalometric study of operated unilateral cleft lip and palate and noncleft children with Class III skeletal relationship. American journal of orthodontics and dentofacial orthopedics: official publication of the American Association of Orthodontists, its constituent societies, and the American Board of Orthodontics, v. 150, n. 5, p. 802-810, nov. de 2016.

LÓPEZ-GIMÉNEZ, A. et al. Craniofacial cephalometric morphologies in different cleft types: a retrospective cross-sectional study of 212 patients. Oral radiology, v. 34, n. 2, p. 127-135, mai. de 2018.

LU, D.-W. et al. The comparative study of craniofacial structural characteristic of individuals with different types of cleft palate. Annals of plastic surgery, v. 59, n. 4, p. 382-387, out. de 2007. 
MANSOUR, S.; BURSTONE, C.; LEGAN, H. An evaluation of soft-tissue changes resulting from Le Fort I maxillary surgery. American journal of orthodontics, v. 84, n. 1, p. 37-47, jul. de 1983.

MARIANETTI, T. M.; BOCCIERI, A.; PASCALI, M. Reshaping of the Anterior Nasal Spine: An Important Step in Rhinoplasty. Plastic and reconstructive surgery. Global open, v. 4, n. 9, p. e1026, set. de 2016.

MOREIRA, I. et al. Soft-tissue profile growth in patients with repaired complete unilateral cleft lip and palate: A cephalometric comparison with normal controls at ages 7, 11, and 18 years. American journal of orthodontics and dentofacial orthopedics: official publication of the American Association of Orthodontists, its constituent societies, and the American Board of Orthodontics, v. 145, n. 3, p. 341-358, mar. de 2014.

NORMANDO, A. D.; DA SILVA FILHO, O. G.; CAPELOZZA FILHO, L. Influence of surgery on maxillary growth in cleft lip and/or palate patients. Journal of craniomaxillo-facial surgery: official publication of the European Association for Cranio-Maxillo-Facial Surgery, v. 20, n. 3, p. 111-118, abr. de 1992.

PARIKAKIS, K.; LARSON, O.; KARSTEN, A. Facial growth in patients with isolated cleft palate treated with minimal incision technique compared to a normal populationa cephalometric study at 10 and 16 years of age. European journal of orthodontics, v. 42 , n. 1, p. 36-43, jan. de 2020.

PARK, J. S.; KOH, K. S.; CHOI, J. W. Lower lip deformity in patients with cleft and noncleft Class III malocclusion before and after orthognathic surgery. Journal of craniomaxillo-facial surgery: official publication of the European Association for Cranio-Maxillo-Facial Surgery, v. 43, n. 8, p. 1638-1642, out. de 2015.

PROFFIT. Ortodontia contemporânea 4a edição. Elsevier Brasil, 2007. 720p.

PROFFIT, W. R.; TURVEY, T. A.; PHILLIPS, C. Orthognathic surgery: a hierarchy of stability. The International journal of adult orthodontics and orthognathic surgery, v. 11, n. 3, p. 191-204, 1996.

SCHULTES, G.; GAGGL, A.; KÄRCHER, H. A comparison of growth impairment and orthodontic results in adult patients with clefts of palate and unilateral clefts of lip, palate and alveolus. The British journal of oral \& maxillofacial surgery, v. 38, n. 1, p. 26-32, fev. de 2000.

SILVA FILHO, O. G. da; CAVASSAN, A. de O.; SAMPAIO, L. L. Avaliação do padrão cefalométrico em pacientes portadores de fissura pós-forame incisivo, não operados. Revista brasileira de cirurgia, v. 79, n. 3, p. 137-147, 1989.

STOLL, C. et al. The soft-tissue facial profile of patients with unilateral clefts of the lip, 
alveolus, and palate compared with healthy adults. Journal of orofacial orthopedics = Fortschritte der Kieferorthopadie: Organ/official journal Deutsche Gesellschaft fur Kieferorthopadie, v. 63, n. 3, p. 179-189, mai. de 2002.

SURI, S. et al. Craniofacial computerized tomography analysis of the midface of patients with repaired complete unilateral cleft lip and palate. American journal of orthodontics and dentofacial orthopedics: official publication of the American Association of Orthodontists, its constituent societies, and the American Board of Orthodontics, v. 134, n. 3, p. 418-429, set. de 2008.

SUSARLA, S. M. et al. Technical Modifications Specific to the Cleft Le Fort I Osteotomy. The Journal of craniofacial surgery, abr. de 2020.

SZYSZKA-SOMMERFELD, L. et al. Electromyographic analysis of superior orbicularis oris muscle function in children surgically treated for unilateral complete cleft lip and palate. Journal of cranio-maxillo-facial surgery: official publication of the European Association for Cranio-Maxillo-Facial Surgery, v. 45, n. 9, p. 1547-1551, set. de 2017.

TANAKA, A. K. de O. Alterações dos tecidos moles após avanço de maxila em pacientes com fissura labiopalatina. 2015. Universidade de São Paulo, 2015.

TINANO, M. M. et al. Base of the skull morphology and Class III malocclusion in patients with unilateral cleft lip and palate. Dental press journal of orthodontics, $v$. 20, n. 1, p. 79-84, jan. de 2015.

TOYGAR, T. U.; AKÇAM, M. O.; ARMAN, A. A cephalometric evaluation of lower lip in patients with unilateral cleft lip and palate. The Cleft palate-craniofacial journal: official publication of the American Cleft Palate-Craniofacial Association, v. 41, n. 5, p. 485-489, set. de 2004.

VASUDAVAN, S.; JAYARATNE, Y. S. N.; PADWA, B. L. Nasolabial soft tissue changes after Le Fort I advancement. Journal of oral and maxillofacial surgery: official journal of the American Association of Oral and Maxillofacial Surgeons, v. 70, n. 4, p. e270-7, abr. de 2012.

WOLFORD, L. M.; CHEMELLO, P. D.; HILLIARD, F. Occlusal plane alteration in orthognathic surgery--Part I: Effects on function and esthetics. American journal of orthodontics and dentofacial orthopedics: official publication of the American Association of Orthodontists, its constituent societies, and the American Board of Orthodontics, v. 106, n. 3, p. 304-316, set. de 1994.

WONG, F. X. et al. Skeletal stability of maxillary advancement with and without a mandibular reduction in the cleft lip and palate patient. International journal of oral and maxillofacial surgery, v. 45, n. 12, p. 1501-1507, dez. de 2016. 
YE, B. et al. A comparative cephalometric study for adult operated cleft palate and unoperated cleft palate patients. Journal of cranio-maxillo-facial surgery: official publication of the European Association for Cranio-Maxillo-Facial Surgery, v. 43, n. 7, p. 1218-1223, set. de 2015.

YIM, S.; BAEK, S.-H. Difference in Degrees of Satisfaction with Orthognathic Surgery and Orthodontic Treatment between Skeletal Class III and Cleft Patients. The Journal of craniofacial surgery, v. 30, n. 4, p. 985-991, jun. de 2019.

YUN, Y. S. et al. Bone and Soft Tissue Changes after Two-Jaw Surgery in Cleft Patients. Archives of plastic surgery, v. 42, n. 4, p. 419-423, jul. de 2015. 
Apêndice(s) 



\section{APÊNDICE A -Tabela 13 - Erro do método da análise cefalométrica}

(Continua)

\begin{tabular}{|c|c|c|c|c|c|c|c|c|}
\hline Medidas cefalométricas & média 1 & DP1(+-) & média 2 & DP2(+-) & Dhalberg & Teste t & $p$ & icc \\
\hline $\mathrm{Na}^{\prime}-\mathrm{Me}^{\prime}(\mathrm{mm})$ & 159,57 & 8,99 & 158,7 & 8,05 & 1,94 & 1,7 & 0,1 & 0,96 \\
\hline $\mathrm{Sn}-\mathrm{Me}$ (mm) & 129,39 & 9,29 & 129,12 & 8,27 & 2,36 & 0,42 & 0,68 & 0,93 \\
\hline G'-Sn (mm) & 71,22 & 3,98 & 71,06 & 4,11 & 0,43 & 1,46 & 0,16 & 0,99 \\
\hline $\mathrm{G}^{\prime}-\mathrm{A}^{\prime}(\perp \mathrm{LVR})(\mathrm{mm})$ & 3,54 & 3,89 & 3,79 & 3,82 & 0,65 & 1,42 & 0,17 & 0,97 \\
\hline G'-Pog' ( $($ LVR) $(\mathrm{mm})$ & 7,5 & 6,04 & 7,63 & 6,11 & 0,78 & 0,59 & 0,56 & 0,98 \\
\hline G'-Pn-Pog' $\left(^{\circ}\right)$ & 28,14 & 6,46 & 28,1 & 6,51 & 0,65 & 0,25 & 0,81 & 0,99 \\
\hline G'-Sn'-Pog' $\left({ }^{\circ}\right)$ & 181,98 & 8,08 & 181,84 & 8,36 & 0,81 & 0,6 & 0,56 & 0,99 \\
\hline$A^{\prime}-N^{\prime}-B^{\prime}\left({ }^{\circ}\right)$ & 2,08 & 3,17 & 2,13 & 3,12 & 0,45 & 0,44 & 0,66 & 0,98 \\
\hline Sn-Pn $(\perp$ LVR) (mm) & 17,63 & 2,24 & 17,52 & 2,04 & 0,55 & 0,71 & 0,48 & 0,94 \\
\hline $\mathrm{Pn}-\mathrm{N}^{\prime}-\mathrm{Sn}\left({ }^{\circ}\right)$ & 21,36 & 3,5 & 21,1 & 3,19 & 0,62 & 1,58 & 0,13 & 0,97 \\
\hline Pog'-Sn' ( $\perp$ LVR) (mm) & $-4,34$ & 6,05 & $-4,33$ & 6,22 & 0,56 & 0,12 & 0,91 & 0,99 \\
\hline$\left(\mathrm{A}^{\prime}-\mathrm{B}^{\prime}\right)(\perp \mathrm{LVR})(\mathrm{mm})$ & 0,46 & 4,19 & 0,54 & 4,38 & 0,55 & 0,54 & 0,59 & 0,98 \\
\hline Ls-Li ( $\perp$ LVR) (mm) & $-3,87$ & 3,64 & $-3,81$ & 3,51 & 0,3 & 0,76 & 0,45 & 0,99 \\
\hline Es-Ei (// LVR)(mm) & 1,47 & 1,3 & 1,71 & 1,69 & 0,46 & 2,11 & 0,04 & 0,95 \\
\hline Col-Sn-UL $\left(^{\circ}\right)$ & 91,53 & 13,03 & 93,28 & 15,38 & 3,11 & 2,22 & 0,04 & 0,97 \\
\hline Ls-SnPog' (mm) & 2,93 & 2,4 & 2,96 & 2,32 & 0,41 & 0,26 & 0,8 & 0,97 \\
\hline Li-SnPog' (mm) & 5,79 & 2,72 & 5,76 & 2,78 & 0,22 & 0,37 & 0,72 & 0,99 \\
\hline Sn-Es $(\perp$ Po-Or $)(m m)$ & 18,87 & 3,68 & 18,59 & 3,51 & 0,64 & 1,62 & 0,12 & 0,97 \\
\hline B'-Ei ( $(\perp$ Po-Or) $(m m)$ & 18,63 & 3,05 & 18,98 & 3,11 & 0,72 & 1,85 & 0,08 & 0,95 \\
\hline Vls-Ls (mm) & 13,99 & 3 & 13,76 & 3,33 & 0,48 & 1,87 & 0,07 & 0,98 \\
\hline Li-Ili (mm) & 19,04 & 5,31 & 18,99 & 5,24 & 0,32 & 0,59 & 0,56 & 1 \\
\hline B-B' (mm) & 11,51 & 1,53 & 11,55 & 1,58 & 0,35 & 0,38 & 0,7 & 0,95 \\
\hline Ls-Sn/Po-Or $\left({ }^{\circ}\right)$ & 105,37 & 10,93 & 105,77 & 11,84 & 2,15 & 0,67 & 0,51 & 0,97 \\
\hline Li-B'/Po-Or) ( $\left.{ }^{\circ}\right)$ & 51,02 & 12,43 & 52,1 & 12,55 & 1,88 & 2,28 & 0,03 & 0,98 \\
\hline $\mathrm{Pg}-\mathrm{Pg}^{\prime}(\mathrm{mm})$ & 11,71 & 2,56 & 12,79 & 2,47 & 1,61 & 2,74 & 0,01 & 0,77 \\
\hline Li-B'-Pog' $\left({ }^{\circ}\right)$ & 127,27 & 12,22 & 128,38 & 12,81 & 1,95 & 2,26 & 0,03 & 0,98 \\
\hline LVR-Pn (mm) & 89,25 & 4,8 & 89,16 & 4,8 & 0,37 & 0,85 & 0,4 & 0,99 \\
\hline LVR-A' (mm) & 74,77 & 5,98 & 74,85 & 6,01 & 0,48 & 0,61 & 0,55 & 0,99 \\
\hline LVR-Ls (mm) & 78,31 & 6,52 & 78,31 & 6,54 & 0,41 & 0 & 1 & 1 \\
\hline LVR-Li (mm) & 82,2 & 6,15 & 82,13 & 6,14 & 0,47 & 0,55 & 0,59 & 0,99 \\
\hline LVR-B' (mm) & 74,3 & 6,74 & 74,32 & 6,87 & 0,53 & 0,13 & 0,9 & 0,99 \\
\hline LVR-Pog' (mm) & 78,72 & 7,74 & 78,67 & 7,83 & 0,62 & 0,3 & 0,77 & 0,99 \\
\hline $\mathrm{SN}-\operatorname{Ar}\left({ }^{\circ}\right)$ & 131,34 & 7,13 & 130,78 & 7,4 & 1,67 & 1,25 & 0,22 & 0,95 \\
\hline $\mathrm{SN}(\mathrm{mm})$ & 64,53 & 2,92 & 64,44 & 2,98 & 0,33 & 0,92 & 0,37 & 0,99 \\
\hline S-Ar (mm) & 29,13 & 3,09 & 29,32 & 3,43 & 1,05 & 0,66 & 0,51 & 0,9 \\
\hline $\operatorname{SNA}\left({ }^{\circ}\right)$ & 75,24 & 5,15 & 75,41 & 5,32 & 0,51 & 1,21 & 0,24 & 0,99 \\
\hline $\begin{array}{l}\text { N-A Horizontal (// LHR) } \\
(\mathrm{mm})\end{array}$ & $-7,94$ & 5,32 & $-7,74$ & 5,39 & 0,73 & 1,05 & 0,3 & 0,98 \\
\hline PoOr-NA $\left({ }^{\circ}\right)$ & 84,66 & 4,14 & 84,83 & 4,16 & 0,6 & 1,08 & 0,29 & 0,98 \\
\hline Co-A (mm) & 75,73 & 5,68 & 76,27 & 5,69 & 1,12 & 1,83 & 0,08 & 0,96 \\
\hline $\operatorname{SNB}\left({ }^{\circ}\right)$ & 79,39 & 4,88 & 79,59 & 4,79 & 0,38 & 2,04 & 0,05 & 0,99 \\
\hline $\operatorname{Ar}-G_{0}(\mathrm{~mm})$ & 51,02 & 5,65 & 51,86 & 5,33 & 1,37 & 2,44 & 0,02 & 0,95 \\
\hline Go-Me (mm) & 72,71 & 5,47 & 71,33 & 5,71 & 1,5 & 4,37 & 0 & 0,96 \\
\hline $\operatorname{Ar}-\mathrm{Go}-\mathrm{Me}\left({ }^{\circ}\right)$ & 132,82 & 7,3 & 133,46 & 6,47 & 1,27 & 1,95 & 0,06 & 0,98 \\
\hline
\end{tabular}


Tabela 13- Erro do método da análise cefalométrica

(conclusão)

\begin{tabular}{|c|c|c|c|c|c|c|c|c|}
\hline $\begin{array}{c}\text { Medidas } \\
\text { cefalométricas }\end{array}$ & média 1 & DP1(+-) & média 2 & DP2(+-) & Dhalberg & Teste t & $\mathrm{p}$ & icc \\
\hline N-B (// LHR) (mm) & $-6,28$ & 8,17 & $-5,93$ & 7,78 & 1,08 & 1,22 & 0,23 & 0,98 \\
\hline N-Pg (// LHR) (mm) & $-3,03$ & 10,17 & $-2,76$ & 9,93 & 1,2 & 0,81 & 0,42 & 0,99 \\
\hline Co-Gn (mm) & 120,58 & 8,82 & 120,53 & 8,53 & 1,02 & 0,2 & 0,85 & 0,99 \\
\hline $\operatorname{ANB}\left({ }^{\circ}\right)$ & $-4,14$ & 4,56 & $-4,18$ & 4,65 & 0,42 & 0,35 & 0,73 & 0,99 \\
\hline Wits (mm) & $-6,8$ & 5,23 & $-6,9$ & 5,19 & 0,78 & 0,45 & 0,66 & 0,98 \\
\hline $\begin{array}{l}\mathrm{N}-\mathrm{A} \text { vertical }(\perp \\
\text { LHR) }(\mathrm{mm})\end{array}$ & 58 & 4,8 & 57,94 & 4,83 & 0,77 & 0,31 & 0,76 & 0,97 \\
\hline $\mathrm{N}-\mathrm{Me}(\perp \mathrm{LHR})(\mathrm{mm})$ & 115,88 & 8,43 & 115,86 & 8,43 & 0,54 & 0,12 & 0,9 & 1 \\
\hline $\mathrm{SN}-\mathrm{GoGn}\left({ }^{\circ}\right)$ & 34,47 & 6,94 & 33,84 & 7,14 & 0,74 & 3,78 & 0 & 0,99 \\
\hline Po- SN $\left({ }^{\circ}\right)$ & 14,89 & 6,61 & 14,71 & 6,76 & 0,88 & 0,7 & 0,49 & 0,98 \\
\hline SGn-SN $\left({ }^{\circ}\right)$ & 61,74 & 5,53 & 61,45 & 5,51 & 0,35 & 3,77 & 0 & 1 \\
\hline S-Gn (mm) & 128,78 & 8,31 & 128,12 & 8,42 & 0,86 & 3,27 & 0 & 0,99 \\
\hline LVR-A (mm) & 59,09 & 4,88 & 59,06 & 4,97 & 0,52 & 0,15 & 0,88 & 0,99 \\
\hline LVR-lis (mm) & 64,26 & 6,12 & 64,21 & 6,27 & 0,48 & 0,34 & 0,74 & 0,99 \\
\hline LVR-lii (mm) & 66,8 & 5,34 & 66,69 & 5,42 & 0,43 & 0,92 & 0,37 & 0,99 \\
\hline LVR-B (mm) & 63,24 & 6,72 & 63,28 & 6,74 & 0,57 & 0,26 & 0,8 & 0,99 \\
\hline LVR-Pog (mm) & 67,62 & 7,67 & 67,53 & 7,75 & 0,65 & 0,54 & 0,6 & 0,99 \\
\hline lis-lii ( $\perp$ LVR) (mm) & $-2,56$ & 4,92 & $-2,47$ & 4,94 & 0,28 & 1,05 & 0,3 & 1 \\
\hline lis-lii (// LVR) (mm) & 0,09 & 1,8 & 0,3 & 1,85 & 0,36 & 2,4 & 0,02 & 0,97 \\
\hline Es-lis (// LVR) (mm) & 2,58 & 2,2 & 2,9 & 2,17 & 0,44 & 3,18 & 0 & 0,97 \\
\hline Is/SN $\left({ }^{\circ}\right)$ & 102,71 & 11,68 & 103,61 & 11,81 & 1,31 & 2,84 & 0,01 & 0,99 \\
\hline IMPA (li/GoGn) $\left(^{\circ}\right)$ & 81,99 & 5,8 & 82,36 & 5,4 & 1,33 & 1,03 & 0,31 & 0,95 \\
\hline Is/li $\left({ }^{\circ}\right)$ & 137,45 & 9,63 & 136,87 & 9,17 & 1,81 & 1,18 & 0,25 & 0,96 \\
\hline
\end{tabular}




\section{APÊNDICE B -Tabela 16- Tecido duro grupo experimental T1xT2}

\begin{tabular}{|c|c|c|c|c|c|}
\hline \multirow[b]{2}{*}{ Medidas de tecido duro } & \multicolumn{5}{|c|}{ Grupo experimental } \\
\hline & T1 média & $\mathrm{Dp}$ & T2 média & $\mathrm{Dp}$ & Valor de $p$ \\
\hline \multicolumn{6}{|l|}{ Base do Crânio } \\
\hline $\mathrm{SN}-\operatorname{Ar}\left({ }^{\circ}\right)$ & 128,88 & 7,81 & 128,83 & 8,18 & 0,383 \\
\hline $\mathrm{SN}(\mathrm{mm})$ & 65,02 & 3,33 & 65,00 & 3,37 & 0,694 \\
\hline S-Ar (mm) & 29,22 & 2,66 & 29,42 & 2,99 & 0,48 \\
\hline \multicolumn{6}{|l|}{ Complexo Nasomaxilar } \\
\hline $\operatorname{SNA}\left({ }^{\circ}\right)$ & 74,58 & 4,63 & 78,07 & 4,63 & $<0,001^{\star}$ \\
\hline N-A Horizontal (// LHR) (mm) & $-8,79$ & 4,86 & $-5,15$ & 4,80 & $<0,001^{*}$ \\
\hline PoOr-NA $\left({ }^{\circ}\right)$ & 83,48 & 4,81 & 86,63 & 4,53 & $<0,001^{\star}$ \\
\hline Co-A (mm) & 74,57 & 5,51 & 77,86 & 5,09 & $<0,001^{\star}$ \\
\hline \multicolumn{6}{|l|}{ Morfologia e posição mandibular } \\
\hline $\operatorname{SNB}\left({ }^{\circ}\right)$ & 79,36 & 5,75 & 77,92 & 4,65 & $0,007^{\star}$ \\
\hline $\operatorname{Ar}-\mathrm{Go}(\mathrm{mm})$ & 49,79 & 7,04 & 49,94 & 6,46 & 0,777 \\
\hline Go-Me (mm) & 72,64 & 6,29 & 71,69 & 4,65 & 0,311 \\
\hline $\operatorname{Ar}-\mathrm{Go}-\mathrm{Me}\left({ }^{\circ}\right)$ & 133,20 & 6,64 & 130,30 & 6,71 & $<0,001^{\star}$ \\
\hline N-B (// LHR) (mm) & $-6,35$ & 9,73 & $-8,47$ & 7,69 & 0,017 \\
\hline N-Pg (// LHR) (mm) & $-4,83$ & 12,31 & $-5,80$ & 9,49 & 0,113 \\
\hline Co-Gn (mm) & 119,75 & 9,78 & 117,45 & 7,45 & $0,006^{\star}$ \\
\hline \multicolumn{6}{|l|}{ Relação inter-maxilar } \\
\hline ANB $\left(^{\circ}\right)$ & $-4,78$ & 3,93 & 0,16 & 2,44 & $<0,001^{\star}$ \\
\hline Wits (mm) & $-8,32$ & 4,45 & $-1,01$ & 2,69 & $<0,001^{\star}$ \\
\hline \multicolumn{6}{|l|}{ Dimensão vertical } \\
\hline $\mathrm{N}-\mathrm{A}$ vertical $(\perp \mathrm{LHR})(\mathrm{mm})$ & 59,32 & 5,65 & 59,28 & 5,11 & 0,934 \\
\hline $\mathrm{N}-\mathrm{Me}(\perp \mathrm{LHR})(\mathrm{mm})$ & 117,46 & 8,85 & 115,99 & 8,02 & $0,005^{\star}$ \\
\hline SN - GoGn $\left(^{\circ}\right)$ & 36,18 & 7,68 & 34,46 & 7,24 & $0,004^{\star}$ \\
\hline Po- SN $\left(^{\circ}\right)$ & 16,00 & 7,22 & 14,13 & 5,79 & $0,028^{*}$ \\
\hline SGn-SN $\left(^{\circ}\right)$ & 69,74 & 6,16 & 69,78 & 5,22 & 0,921 \\
\hline S-Gn (mm) & 129,79 & 9,70 & 127,41 & 8,38 & $<0,001^{\star}$ \\
\hline \multicolumn{6}{|c|}{$\begin{array}{l}\text { LVR (linha vertical de referência)-Projeções } \\
\text { tecido duro }\end{array}$} \\
\hline LVR-A (mm) & 58,79 & 5,30 & 61,78 & 5,22 & $<0,001^{\star}$ \\
\hline LVR-lis (mm) & 62,91 & 6,16 & 66,95 & 5,82 & $<0,001^{\star}$ \\
\hline LVR-lii (mm) & 68,53 & 7,11 & 64,32 & 5,60 & $<0,001^{\star}$ \\
\hline LVR-B (mm) & 63,62 & 8,31 & 60,23 & 6,02 & $0,003^{\star}$ \\
\hline LVR-Pog (mm) & 66,21 & 10,26 & 63,80 & 6,65 & 0,05 \\
\hline \multicolumn{6}{|l|}{ Relações dentárias } \\
\hline lis-lii $(\perp$ LVR) $(\mathrm{mm})$ & $-5,63$ & 3,51 & 2,64 & 0,87 & $<0,001^{\star}$ \\
\hline lis-lii (// LVR) (mm) & $-0,47$ & 1,62 & 1,14 & 0,94 & $<0,001^{*}$ \\
\hline Es-lis (// LVR) (mm) & 2,79 & 1,89 & 1,32 & 1,97 & $<0,001^{\star}$ \\
\hline Is/SN $\left(^{\circ}\right)$ & 100,86 & 10,40 & 105,01 & 10,05 & $0,004^{\star}$ \\
\hline IMPA (li/GoGn) $\left(^{\circ}\right)$ & 84,81 & 5,72 & 82,39 & 5,42 & 0,079 \\
\hline Is/li $\left(^{\circ}\right)$ & 134,75 & 10,05 & 134,69 & 9,88 & 0,291 \\
\hline${ }^{*} P<0,05$ & & & & & \\
\hline
\end{tabular}


APÊNDICE C -Tabela 17. Tecido mole grupo experimental T1xT2

\begin{tabular}{|c|c|c|c|c|c|}
\hline \multirow[b]{2}{*}{ Medidas tecido mole } & \multicolumn{5}{|c|}{ Grupo experimental } \\
\hline & T1 média & Dp & T2 média & $\mathrm{Dp}$ & Valor de $\mathrm{p}$ \\
\hline \multicolumn{6}{|c|}{ Perfil facial e morfologia nasal } \\
\hline $\mathrm{Na}^{\prime}-\mathrm{Me}^{\prime}(\mathrm{mm})$ & 162,13 & 11,07 & 164,02 & 8,04 & 0,255 \\
\hline Sn'-Me' (mm) & 131,46 & 10,52 & 133,46 & 7,92 & 0,193 \\
\hline G'-Sn (mm) & $-2,52$ & 4,33 & $-0,05$ & 5,21 & $<0,001^{*}$ \\
\hline $\mathrm{G}^{\prime}-\mathrm{A}^{\prime}(\perp \mathrm{LVR})(\mathrm{mm})$ & 1,65 & 4,44 & 3,92 & 3,64 & $<0,001^{*}$ \\
\hline G'-Pog' ( $($ LVR) $(\mathrm{mm})$ & 6,57 & 9,05 & 3,31 & 6,40 & $0,002^{*}$ \\
\hline G'-Pn-Pog' $\left(^{\circ}\right)$ & 27,12 & 7,61 & 31,50 & 5,79 & $<0,001^{*}$ \\
\hline G'-Sn'-Pog' $\left({ }^{\circ}\right)$ & 184,20 & 9,48 & 177,51 & 8,11 & $<0,001^{\star}$ \\
\hline$A^{\prime}-N^{\prime}-B^{\prime}\left({ }^{\circ}\right)$ & 0,06 & 3,30 & 5,30 & 2,55 & $<0,001^{\star}$ \\
\hline Sn-Pn $(\perp$ LVR) $(m m)$ & 18,58 & 2,15 & 17,80 & 2,16 & $<0,001^{*}$ \\
\hline Pn-N'-Sn $\left({ }^{\circ}\right)$ & 22,04 & 3,79 & 20,90 & 3,50 & $0,001^{*}$ \\
\hline \multicolumn{6}{|l|}{ Relação intermaxilar } \\
\hline Pog'-Sn' ( $\perp$ LVR) $(\mathrm{mm})$ & $-4,91$ & 7,85 & $-0,14$ & 5,93 & $<0,001^{*}$ \\
\hline$\left(\mathrm{A}^{\prime}-\mathrm{B}^{\prime}\right)(\perp \mathrm{LVR})(\mathrm{mm})$ & $-1,47$ & 5,13 & 4,74 & 3,56 & $<0,001^{*}$ \\
\hline Ls-Li ( $\perp$ LVR) $(m m)$ & $-7,13$ & 3,55 & $-0,53$ & 1,66 & $<0,001^{\star}$ \\
\hline Es-Ei (// LVR)(mm) & 2,55 & 2,44 & 1,05 & 1,00 & $<0,001^{*}$ \\
\hline \multicolumn{6}{|c|}{ Relação nasolabial e morfologia labial } \\
\hline Col-Sn-UL $\left({ }^{\circ}\right)$ & 91,60 & 15,56 & 92,39 & 11,35 & 0,635 \\
\hline Ls-SnPog' (mm) & 2,56 & 2,46 & 4,26 & 2,05 & $<0,001^{*}$ \\
\hline Li-SnPog' (mm) & 8,41 & 2,36 & 4,90 & 2,41 & $<0,001^{*}$ \\
\hline Sn-Es $(\perp$ Po-Or) $(\mathrm{mm})$ & 18,84 & 3,29 & 20,28 & 2,64 & $<0,001^{\star}$ \\
\hline $\mathrm{B}^{\prime}-\mathrm{Ei}(\perp$ Po-Or) $(\mathrm{mm})$ & 20,28 & 2,70 & 17,37 & 2,82 & $<0,001^{\star}$ \\
\hline VIs-Ls (mm) & 14,15 & 1,81 & 12,76 & 1,94 & $<0,001^{*}$ \\
\hline Li-Ili (mm) & 22,52 & 3,59 & 14,99 & 2,70 & $<0,001^{*}$ \\
\hline $\mathrm{B}^{-\mathrm{B}^{\prime}}(\mathrm{mm})$ & 11,80 & 2,05 & 11,58 & 1,68 & 0,082 \\
\hline Ls-Sn/Po-Or $\left({ }^{\circ}\right)$ & 104,25 & 13,26 & 105,26 & 9,14 & 0,612 \\
\hline Li-B'/Po-Or) ( $\left.{ }^{\circ}\right)$ & 46,08 & 9,79 & 46,56 & 10,26 & 0,788 \\
\hline \multicolumn{6}{|l|}{ Morfologia do mento } \\
\hline $\mathrm{Pg}-\mathrm{Pg}(\mathrm{mm})$ & 13,27 & 3,00 & 12,53 & 2,55 & $0,007^{*}$ \\
\hline Li-B'-Pog' $\left({ }^{\circ}\right)$ & 124,56 & 11,10 & 123,18 & 10,36 & 0,512 \\
\hline \multicolumn{6}{|c|}{$\begin{array}{l}\text { LVR (linha vertical de referência)-Projeções tecido } \\
\text { mole }\end{array}$} \\
\hline LVR-Pn (mm) & 89,16 & 5,48 & 90,36 & 5,08 & $<0,001^{*}$ \\
\hline LVR-A' (mm) & 73,38 & 6,04 & 76,21 & 5,31 & $<0,001^{*}$ \\
\hline LVR-Ls (mm) & 77,08 & 6,50 & 79,80 & 5,62 & $<0,001^{*}$ \\
\hline LVR-Li (mm) & 84,22 & 7,88 & 80,31 & 5,86 & $<0,001^{*}$ \\
\hline LVR-B' (mm) & 74,86 & 8,59 & 71,47 & 6,16 & $0,003^{*}$ \\
\hline LVR-Pog' (mm) & 78,31 & 9,78 & 75,62 & 7,01 & $0,021^{*}$ \\
\hline${ }^{*} P<0,05$ & & & & & \\
\hline
\end{tabular}


APÊNDICE D -Tabela 18- Tecido duro grupo controle T1xT2

\begin{tabular}{|c|c|c|c|c|c|}
\hline \multirow[b]{2}{*}{ Medidas tecido duro } & \multicolumn{5}{|c|}{ Grupo controle } \\
\hline & T1 média & $\mathrm{Dp}$ & T2 média & $\mathrm{Dp}$ & Valor de $p$ \\
\hline \multicolumn{6}{|l|}{ Base do Crânio } \\
\hline $\mathrm{SN}-\operatorname{Ar}\left(^{\circ}\right)$ & 130,95 & 5,99 & 132,13 & 5,93 & 0,383 \\
\hline $\mathrm{SN}(\mathrm{mm})$ & 64,08 & 3,06 & 64,01 & 3,03 & 0,694 \\
\hline S-Ar (mm) & 27,68 & 3,38 & 27,99 & 3,36 & 0,48 \\
\hline \multicolumn{6}{|l|}{ Complexo Nasomaxilar } \\
\hline SNA $\left(^{\circ}\right)$ & 75,01 & 3,65 & 78,83 & 5,02 & $<0,001^{\star}$ \\
\hline N-A Horizontal (// LHR) (mm) & $-7,69$ & 4,32 & $-4,16$ & 5,15 & $<0,001^{*}$ \\
\hline PoOr-NA $\left({ }^{\circ}\right)$ & 84,29 & 3,78 & 87,45 & 4,99 & $<0,001^{\star}$ \\
\hline Co-A (mm) & 75,23 & 5,82 & 78,78 & 5,80 & $<0,001^{*}$ \\
\hline \multicolumn{6}{|l|}{ Morfologia e posição mandibular } \\
\hline $\operatorname{SNB}\left({ }^{\circ}\right)$ & 81,61 & 3,50 & 79,90 & 2,52 & $0,022^{*}$ \\
\hline $\operatorname{Ar}-G_{0}(\mathrm{~mm})$ & 50,83 & 4,43 & 49,07 & 4,90 & $0,025^{\star}$ \\
\hline Go-Me (mm) & 72,31 & 5,93 & 71,98 & 6,73 & 0,311 \\
\hline $\operatorname{Ar}-G o-M e\left({ }^{\circ}\right)$ & 137,46 & 8,09 & 134,78 & 8,06 & $0,016^{\star}$ \\
\hline N-B (// LHR) (mm) & $-2,19$ & 5,66 & $-5,05$ & 4,36 & $0,022^{\star}$ \\
\hline N-Pg (// LHR) (mm) & 0,63 & 7,20 & $-1,17$ & 5,83 & 0,113 \\
\hline Co-Gn (mm) & 123,61 & 9,31 & 120,41 & 9,38 & $0,006^{\star}$ \\
\hline \multicolumn{6}{|l|}{ Relação inter-maxilar } \\
\hline ANB $\left(^{\circ}\right)$ & $-6,60$ & 4,62 & $-1,05$ & 3,54 & $<0,001^{\star}$ \\
\hline Wits (mm) & $-10,73$ & 5,25 & $-3,23$ & 4,06 & $<0,001^{*}$ \\
\hline \multicolumn{6}{|l|}{ Dimensão vertical } \\
\hline $\mathrm{N}-\mathrm{A}$ vertical $(\perp \mathrm{LHR})(\mathrm{mm})$ & 55,79 & 4,79 & 55,23 & 4,19 & 0,414 \\
\hline $\mathrm{N}-\mathrm{Me}(\perp \mathrm{LHR})(\mathrm{mm})$ & 115,15 & 10,32 & 111,97 & 9,20 & $<0,001^{*}$ \\
\hline SN - GoGn $\left(^{\circ}\right)$ & 35,53 & 6,59 & 33,65 & 5,79 & $0,024^{\star}$ \\
\hline Po- SN $\left(^{\circ}\right)$ & 15,08 & 5,42 & 13,90 & 5,97 & 0,314 \\
\hline SGn-SN $\left(^{\circ}\right)$ & 67,30 & 4,54 & 67,18 & 3,75 & 0,921 \\
\hline S-Gn (mm) & 129,49 & 8,69 & 125,82 & 8,08 & $<0,001^{*}$ \\
\hline \multicolumn{6}{|c|}{$\begin{array}{l}\text { LVR (linha vertical de referência)-Projeções } \\
\text { tecido duro }\end{array}$} \\
\hline LVR-A (mm) & 58,09 & 4,15 & 60,30 & 4,43 & $0,006^{\star}$ \\
\hline LVR-lis (mm) & 64,07 & 5,07 & 66,27 & 4,93 & $0,028^{*}$ \\
\hline LVR-lii (mm) & 69,60 & 5,50 & 63,89 & 4,66 & $<0,001^{\star}$ \\
\hline LVR-B (mm) & 65,68 & 6,64 & 60,25 & 5,15 & $<0,001^{*}$ \\
\hline LVR-Pog (mm) & 69,27 & 8,06 & 64,53 & 6,94 & $0,008^{\star}$ \\
\hline \multicolumn{6}{|l|}{ Relações dentárias } \\
\hline lis-lii ( $\perp$ LVR) (mm) & $-5,55$ & 3,17 & 2,39 & 1,20 & $<0,001^{\star}$ \\
\hline lis-lii (// LVR) (mm) & $-0,86$ & 2,32 & 1,21 & 1,23 & $<0,001^{\star}$ \\
\hline Es-lis (// LVR) (mm) & 3,49 & 2,65 & 1,83 & 2,34 & $0,003^{\star}$ \\
\hline Is/SN $\left(^{\circ}\right)$ & 105,79 & 7,95 & 110,63 & 9,02 & $0,014^{\star}$ \\
\hline IMPA (li/GoGn) $\left(^{\circ}\right)$ & 81,27 & 6,67 & 80,75 & 8,89 & 0,079 \\
\hline Is/li $\left(^{\circ}\right)$ & 134,13 & 9,15 & 131,51 & 10,42 & 0,291 \\
\hline${ }^{*} P<0,05$ & & & & & \\
\hline
\end{tabular}




\section{APÊNDICE E -Tabela 19- Tecido mole grupo controle T1xT2}

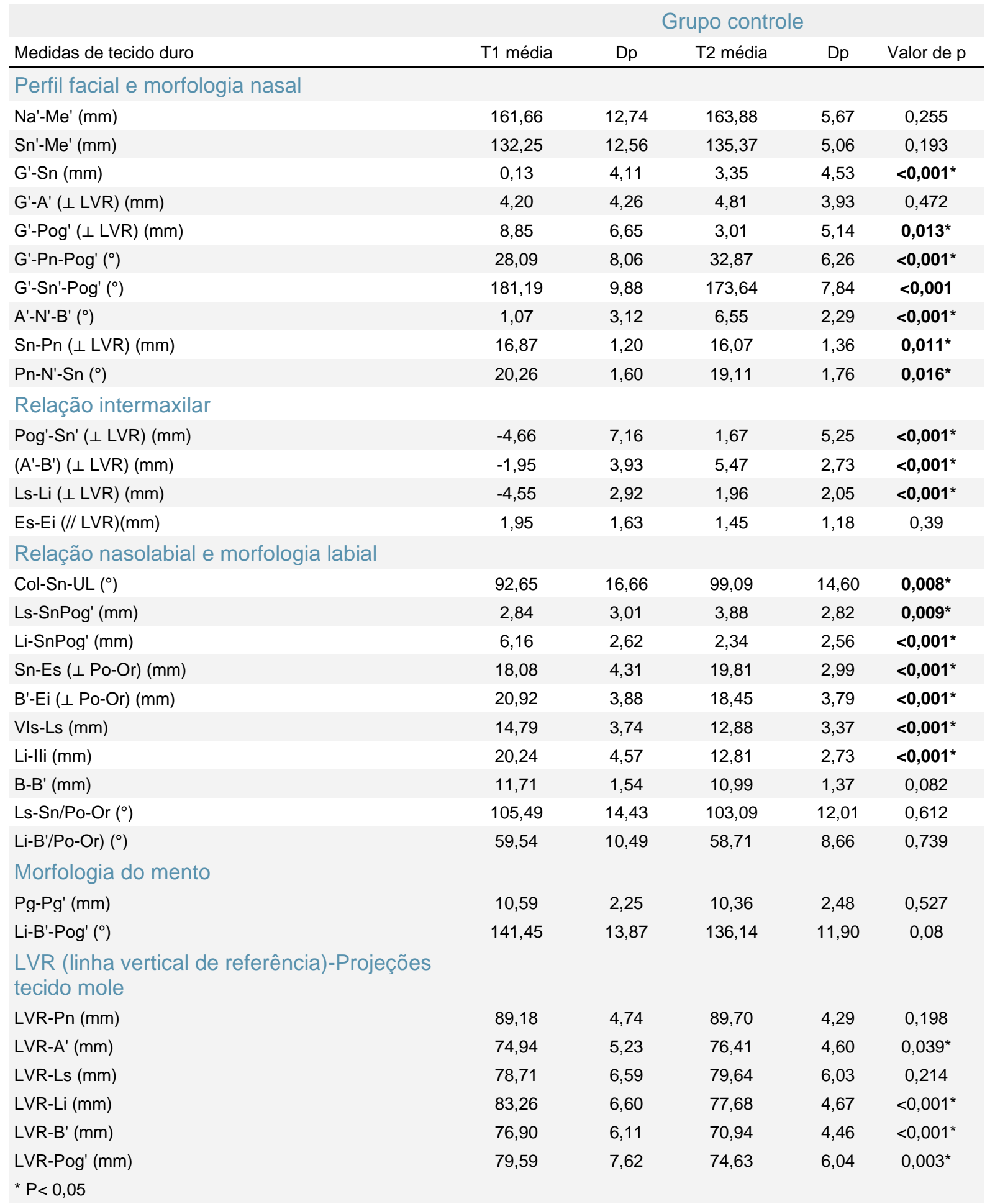


APÊNDICE F -Figura 16: Traçado médio do grupo experimental em T1:

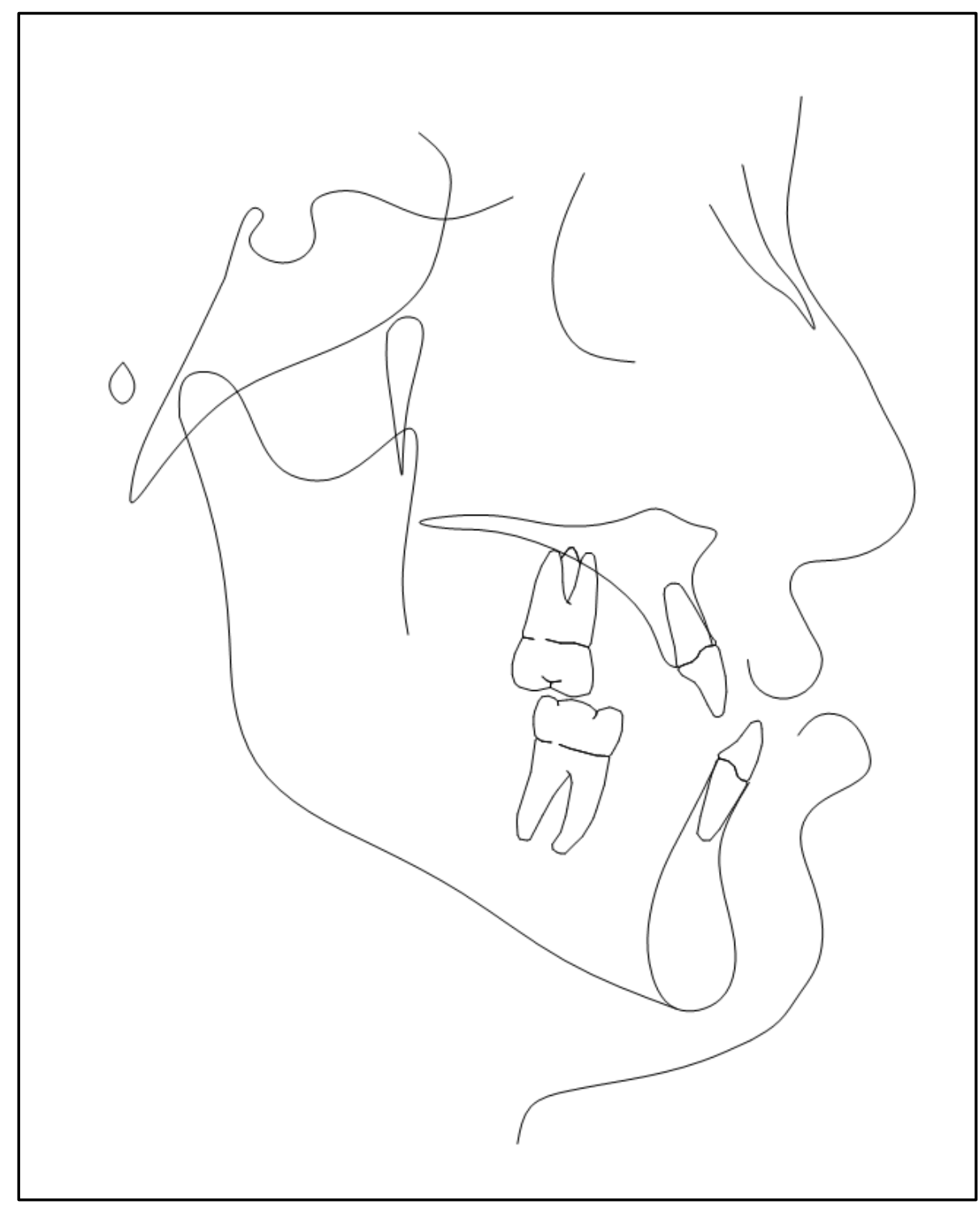


APÊNDICE G -Figura 17: Traçado médio do grupo experimental em T2:

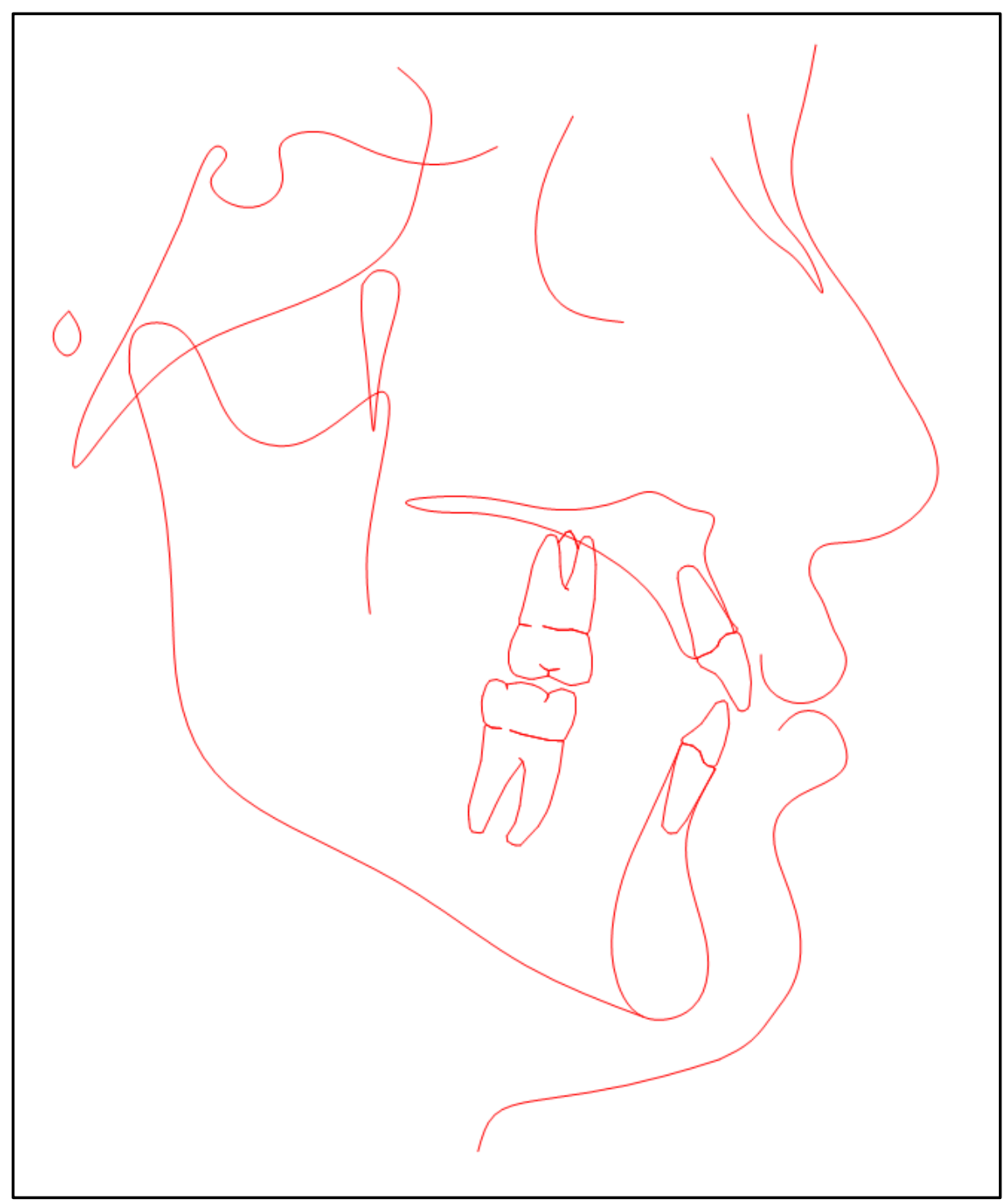


APÊNDICE H -Figura 18: Traçado médio do grupo controle em T1:

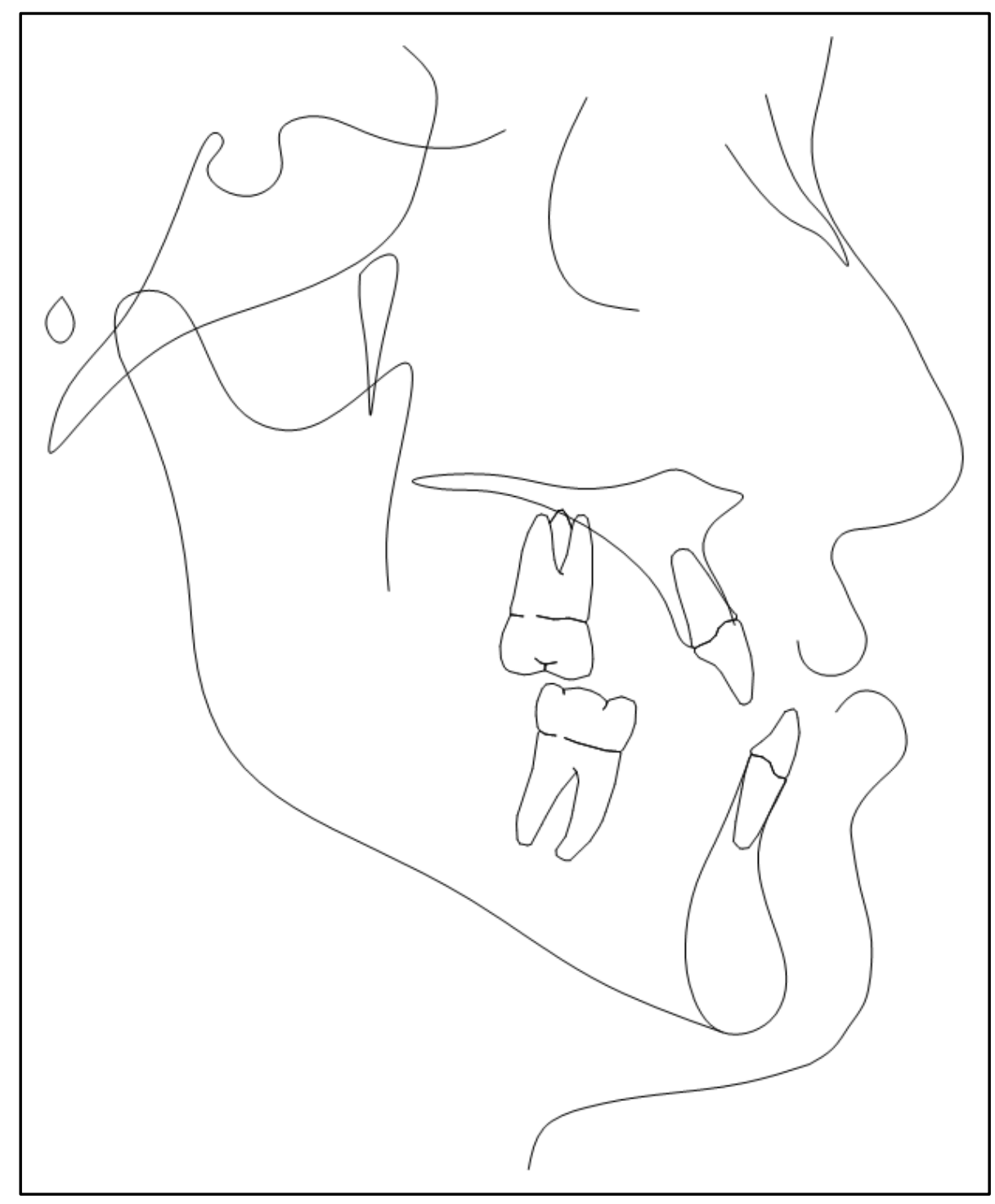


APÊNDICE I -Figura 19: Traçado médio do grupo controle em T2:

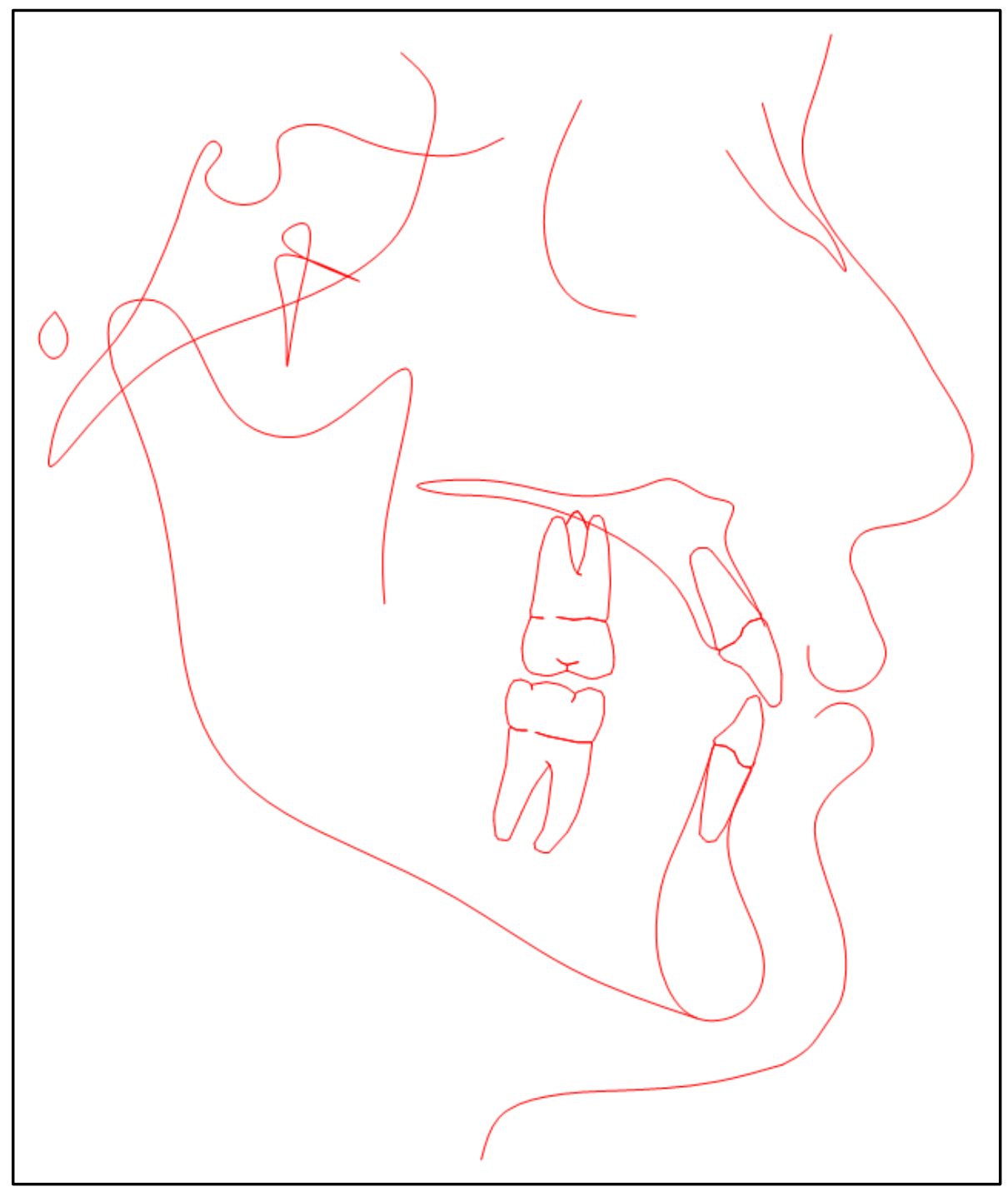


Anexo 

Anexo A: Aprovação do Comitê de Ética do Hospital de Reabilitação de Anomalias Craniofaciais-HRAC-USP

USP - HOSPITAL DE
REABILITAÇÃO DE
ANOMALIAS CRANIOFACIAIS
DA UNIVERSIDADE DE SÃO
PAULO -HRAC/USP

\section{PARECER CONSUBSTANCIADO DO CEP}

\section{DADOS DA EMENDA}

Título da Pesquisa: Comparação das alterações craniofaciais após a cirurgia ortognática bimaxilar em indivíduos classe III com fissura de lábio e palato unilateral e com fissura isolada de palato

Pesquisador: Tiago Turri de Castro Ribeiro

Área Temática:

Versão: 2

CAAE: 04255418.4 .0000 .5441

Instituição Proponente: Hospital de Reabilitação de Anomalias Craniofaciais da USP

Patrocinador Principal: Financiamento Próprio

\section{DADOS DO PARECER}

Número do Parecer: 4.057.576

Apresentação do Projeto:

Emenda de Projeto de Pesquisa de TESE para obtenção do título de DOUTOR em Ciências da Reabilitação do HRACUSP, aprovado em Dezembro de 2018. O objetivo deste estudo é comparar por meio de telerradiografias em norma lateral as alterações craniofaciais de pacientes com fissura de lábio e palato unilateral e pacientes com fissura isolada de palato submetidos a cirurgia ortognática de maxila e mandíbula para correção da $\mathrm{CI}$ III. A amostra do estudo será composta de telerradiografias em norma lateral de 45 pacientes selecionados retrospectivamente e aleatoriamente, divididos em 2 grupos: Grupo 1: 30 pacientes adultos com fissura de lábio e palato unilateral submetidos a cirurgia ortognática de maxila e mandíbula para correção da classe III. Grupo 2: 15 pacientes adultos com fissura isolada de palato submetidos a cirurgia ortognática de maxila e mandíbula para correção da classe III. Mensurações craniofaciais e de espessura de tecido mole serão realizadas nas telerradiografias em norma lateral, pré operatórias e de controle de 6 meses pós cirurgia. Os dados obtidos através da análise cefalométrica serão comparados estatisticamente utilizando o teste t de Student e a análise de regressão linear múltipla.

Objetivo da Pesquisa:

O Objetivo deste estudo é comparar as alterações craniofaciais promovidas pela cirurgia

Endereço: Rua Silvio Marchione, 3-20

Bairro: Vila Nova Cidade Universitária

UF: SP Municipio: BAURU

CEP: $17.012-900$

Telefone: (14)3235-8421

Fax: (14)3234-7818

E-mail: cephrac@usp.br 


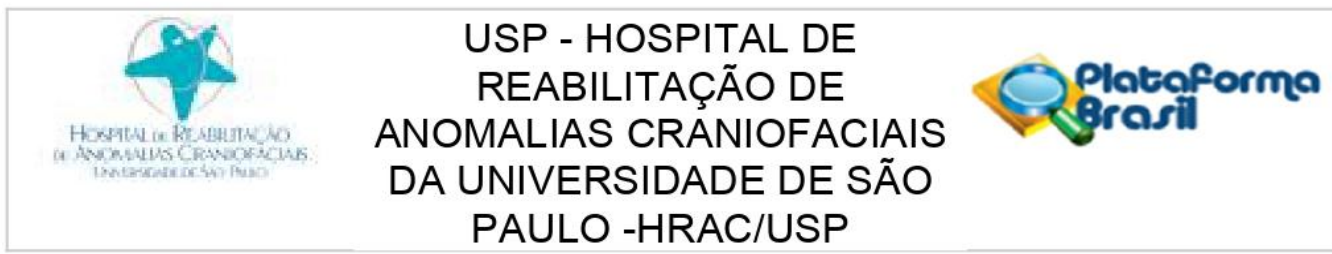

Continuação do Parecer: 4.057.576

ortognática de maxila e mandíbula em indivíduos com má oclusão de $\mathrm{Cl}$ III com fissura unilateral de lábio e palato e com fissura isolada de palato

Avaliação dos Riscos e Benefícios:

Segundo os autores:

"Riscos:

O possível risco aos pacientes envolvidos na seguinte pesquisa é a possibilidade de exposição com identificação das imagens radiográficas em questão. Esse risco será minimizado uma vez que o campo identificador das imagens radiográficas com os nomes dos pacientes será apagado no momento da análise das imagens pelo software a ser utilizado. No momento da publicação dos dados do trabalho em forma de artigo científico se houver necessidade de ilustrar o artigo com alguma radiografia específica, o paciente dono da imagem será contactado, esclarecido sobre a pesquisa e decidirá por ceder ou não a imagem para o fim necessário.

Benefícios:

Os benefícios possíveis da presente pesquisa não poderão retornar aos próprios participantes, já que todos já foram submetidos a cirurgia ortognática, a não ser que algum dos pacientes em questão necessite por algum motivo, ser submetido a uma nova cirurgia ortognática. Os maiores beneficiados serão os pacientes com fissura labiopalatina unilateral com indicação de reabilitação com cirurgia ortognática que poderão usufruir dos dados gerados pela pesquisa, além dos profissionais responsáveis diretamente pelo planejamento e execução do procedimento( ortodontistas e cirurgiões buco-maxilofaciais) que terão mais subsídios sobre os efeitos suscitados pelo tratamento ortodôntico-cirúrgico nestes pacientes."

Comentários e Considerações sobre a Pesquisa:

Pesquisa tem mérito e está bem delineada, já aprovada por esse CEP. Os autores comunicam vai emenda a alteração do tìtluo da pesquisa de "Análise comparativa dos efeitos sobre o tecido mole entre indivíduos com e sem fissura submetidos a cirurgia ortognática ", para "Comparação das alterações craniofaciais após a cirurgia ortognática bimaxilar em indivíduos classe III com fissura de lábio e palato unilateral e com fissura isolada de palato". Comunicam também a alteração do grupo controle (Grupo 2) de indivíduos sem fissura para indivíduos com fissura isolada de palato.

Os autores esperam com esse estudo determinar as diferenças existentes entre os 2 grupos de pacientes com relação as alterações craniofaciais após a realização da cirurgia ortognática de maxila e mandíbula. Com isso esperam obter parâmetros mais realistas para reabilitação com

Endereço: Rua Silvio Marchione, 3-20

Bairro: Vila Nova Cidade Universitária

UF: SP Municipio: BAURU

Telefone: (14)3235-8421

Fax: (14)3234-7818

CEP: $17.012-900$

E-mail: cephrac@usp.br 


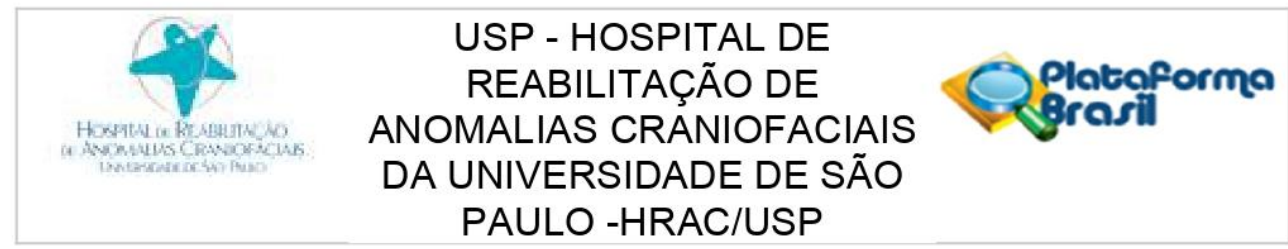

Continuação do Parecer: 4.057 .576

cirurgia ortognática de pacientes com esse tipo de fissura.

Descritores: : Má oclusão de Angle Classe III, Cirurgia Ortognática, Fissura labial e

Considerações sobre os Termos de apresentação obrigatória:

Foram todos apresentados em 2018.

Recomendações:

Não se aplica.

Conclusões ou Pendências e Lista de Inadequações:

Como as alterações propostas não ferem a ética, sugiro a aprovação das emendas por esse CEP.

Considerações Finais a critério do CEP:

O pesquisador deve atentar que o projeto de pesquisa aprovado por este CEP refere-se ao protocolo submetido para avaliação. Portanto, conforme a Resolução CNS 466/12, o pesquisador é responsável por "desenvolver o projeto conforme delineado", se caso houver alterações nesse projeto, este CEP deverá ser comunicado em emenda via Plataforma Brasil, para nova avaliação.

Cabe ao pesquisador notificar via Plataforma Brasil o relatório final para avaliação. Os Termos de Consentimento Livre e Esclarecidos e/ou outros Termos obrigatórios assinados pelos participantes da pesquisa deverão ser entregues ao CEP. Os relatórios semestrais devem ser notificados quando solicitados no parecer.

Este parecer foi elaborado baseado nos documentos abaixo relacionados:

\begin{tabular}{|c|c|c|c|c|}
\hline Tipo Documento & Arquivo & Postagem & Autor & Situação \\
\hline $\begin{array}{l}\text { Informações Básicas } \\
\text { do Projeto }\end{array}$ & $\begin{array}{l}\text { PB_INFORMAÇŌES_BÁSICAS_155620 } \\
7 \text { E1.pdf }\end{array}$ & $\begin{array}{c}18 / 05 / 2020 \\
20: 38: 57\end{array}$ & & Aceito \\
\hline $\begin{array}{l}\text { Projeto Detalhado / } \\
\text { Brochura } \\
\text { Investiqador }\end{array}$ & Projeto_emenda.pdf & $\begin{array}{c}18 / 05 / 2020 \\
20: 37: 27\end{array}$ & $\begin{array}{l}\text { Tiago Turri de Castro } \\
\text { Ribeiro }\end{array}$ & Aceito \\
\hline Outros & Emenda_Tiago.pdf & $\begin{array}{c}15 / 05 / 2020 \\
11: 23: 06 \\
\end{array}$ & $\begin{array}{l}\text { Tiago Turri de Castro } \\
\text { Ribeiro }\end{array}$ & Aceito \\
\hline Outros & Checklist_Prot_Pesq_103_2018.pdf & $\begin{array}{c}10 / 12 / 2018 \\
10: 12: 05\end{array}$ & $\begin{array}{l}\text { Rafael Mattos de } \\
\text { Deus }\end{array}$ & Aceito \\
\hline Outros & $\begin{array}{l}\text { Term_Comp_Tornar_Publico_Dest_Mat. } \\
\text { pdf }\end{array}$ & $\begin{array}{c}07 / 12 / 2018 \\
18: 17: 33 \\
\end{array}$ & $\begin{array}{l}\text { Tiago Turri de Castro } \\
\text { Ribeiro }\end{array}$ & Aceito \\
\hline Outros & Term_Comp_Pesq_Resp.pdf & $\begin{array}{c}07 / 12 / 2018 \\
18: 16: 27 \\
\end{array}$ & $\begin{array}{l}\text { Tiago Turri de Castro } \\
\text { Ribeiro }\end{array}$ & Aceito \\
\hline
\end{tabular}

Endereço: Rua Silvio Marchione, 3-20

Bairro: Vila Nova Cidade Universitária

UF: SP

Municipio: BAURU

CEP: $17.012-900$

Telefone: (14)3235-8421

Fax: (14)3234-7818

E-mail: cephrac@usp.br 


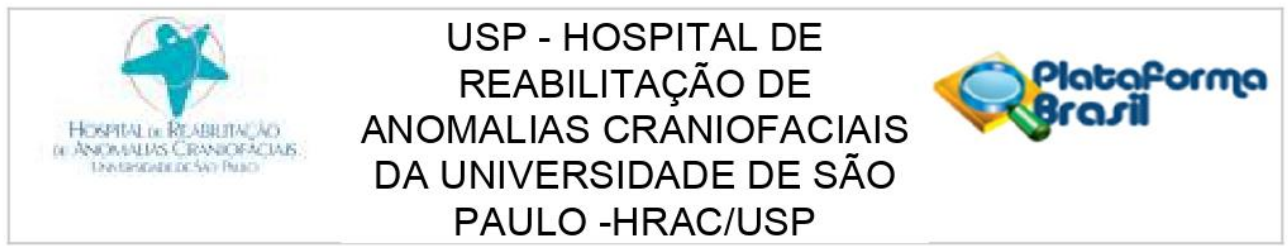

Continuação do Parecer: 4.057.576

\begin{tabular}{|l|l|c|l|c|}
\hline Outros & Term_Comp_Conf_Aut_Dados.pdf & $\begin{array}{c}07 / 12 / 2018 \\
18: 14: 18\end{array}$ & $\begin{array}{l}\text { Tiago Turri de Castro } \\
\text { Ribeiro }\end{array}$ & Aceito \\
\hline $\begin{array}{l}\text { TCLE / Termos de } \\
\text { Assentimento / } \\
\text { Justificativa de } \\
\text { Ausência }\end{array}$ & Justif_Dispensa_TCLE.pdf & $\begin{array}{c}07 / 12 / 2018 \\
18: 12: 54\end{array}$ & $\begin{array}{l}\text { Tiago Turri de Castro } \\
\text { Ribeiro }\end{array}$ & Aceito \\
\hline $\begin{array}{l}\text { Declaração de } \\
\text { Instituição e } \\
\text { Infraestrutura }\end{array}$ & Form_Cadastro_HRAC.pdf & $07 / 12 / 2018$ & $\begin{array}{l}\text { Tiago Turri de Castro } \\
\text { Ribeiro }\end{array}$ & Aceito \\
\hline Outros & & $18: 11: 46$ & $07 / 12 / 2018$ & $\begin{array}{l}\text { Tiago Turri de Castro } \\
\text { Ribeiro }\end{array}$ \\
\hline Folha de Rosto & Carta_Encaminham.pdf & $18: 11: 20$ & Aceito \\
& Folha_Rosto.pdf & $07 / 12 / 2018$ & $\begin{array}{l}\text { Tiago Turri de Castro } \\
\text { Ribeiro }\end{array}$ & Aceito \\
\hline
\end{tabular}

Situação do Parecer:

Aprovado

Necessita Apreciação da CONEP:

Não

BAURU, 29 de Maio de 2020

\section{Assinado por:}

Renata Paciello Yamashita

(Coordenador(a)) 